\title{
IRRADIATION TESTING OF INTERNALLY PRESSURIZED AND/OR GRAPHITE COATED ZIRCALOY-4 CLAD FUEL RODS IN THE NRX REACTOR
}

(AWBA Development Program)

NOVEMBER 1978

CONTRACT EY-76-C-11-0014

BETTIS ATOMIC POWER LABORATORY WEST MIFFLIN, PENNSYLVANIA 


\section{DISCLAIMER}

This report was prepared as an account of work sponsored by an agency of the United States Government. Neither the United States Government nor any agency Thereof, nor any of their employees, makes any warranty, express or implied, or assumes any legal liability or responsibility for the accuracy, completeness, or usefulness of any information, apparatus, product, or process disclosed, or represents that its use would not infringe privately owned rights. Reference herein to any specific commercial product, process, or service by trade name, trademark, manufacturer, or otherwise does not necessarily constitute or imply its endorsement, recommendation, or favoring by the United States Government or any agency thereof. The views and opinions of authors expressed herein do not necessarily state or reflect those of the United States Government or any agency thereof. 


\section{DISCLAIMER}

Portions of this document may be illegible in electronic image products. Images are produced from the best available original document. 
WAPD-TM-1376

Special External Distribution

IRRADIATION TESTING OF INTERNALLY PRESSURIZED AND/OR

GRAPHITE COATED ZIRCALOY-4 CLAD FUEL RODS IN THE NRX REACTOR

(AWBA Development Program)

R. C. Hoffman

J. Sherman

November 1978

$\mathrm{EY}-76-\mathrm{C}-11-0014$

Printed in the United States of America

Available from the

National Technical Information Service

U. S. Department of Commerce 5285 Port Royal Road

Springfield, Virginia. 22151

This notice

This report was prepared as an eccount of work sponsored by the United States Government. Neither United States nor the United States Department Energ. nor any of their employees, nor any of their contractors, subcontractors, or their employees, mak any warranty, express or implied, or assumes any les hathy or responsibility for the accuracy comple legal or usefulness of any information, apparatus, prodeness process disclosed, or represents that its use would or infringe privately owned rights.

\section{NOTE}

This document is an interim memorandum prepared primarily for internal reference and does not represent a final expression of the opinion of Westinghouse. When this memorandum is distributed externally, it is with the express understanding, that Westinghouse makes no representation as to completeness, accuracy, or usability of information contained therein.

BH"I"I'LS A'I'UMIC̈ FÜWER LABORATORY WEST. MIRTLIN, PENNSYLVANIA

Operated for the U. S. Department of Energy by WESTINCHOUSE ELECTRIC CORPORATTON 
This report was prepared as an account of work sponsored by the United States Government. Neither the United States nor the United States Department of Energy, nor any of their employees, nor any of their contractors, subcontractors, or their employees, makes any warranty, express or implied, or assumes any legal liability or responsibility for the accuracy, completeness or usefulness of any information, apparatus, product or process disclosed, or represents that its use would not infringe privately owned rights. 


\section{FOREWORD}

The Shippingport Atomic Power Station located in Shippingport, Pennsylvania was the first large-scale, central-station nuclear power plant in the United States and the first plant of such size in the world operated solely to produce electric power. This project was started in 1953 to confirm the practical application of nuclear power for largescale electric power generation. It has provided much of the technology being-used for design and operation of the commercial, central-station nuclear power plants now in use.

Subsequent to development and successful operation of the Pressurized Water Reactor in the DOE-owned reactor plant at the Shippingport Atomic Power Station, the Atomic Energy Commission in 1965 undertook a research and development program to design and build a Light Water Breeder Reactor core for operation in the Shippingport Station. In 1976, with fabrication of the Light Water Breeder Reactor (LWBR) nearing completion the Energy Research and Development Administration established the Advanced Water Breeder Applications program (AWBA) to develop and disseminate technical information which would assist U.S. industry in evaluating the LWBR-concept. All three of these reactor development projects have been administered by the Division of Naval Reactors with the goal of developing practical improvements in the utilization of nuclear fuel resources for generation of electrical energy using water-cooled nuclear reactors.

The objective of the Light Water Breeder Reactor project has been to develop a technology that would significantly improve the utilization of the nation's nuclear fuel resources employing the well-established water reactor technology. To achieve this objective, work has been directed toward analysis, design, component tests, and fabrication of a water-cooled, thorium oxide fuel cycle breeder reactor to install and operate at the Shippingport Station. Operation of the LWBR core in the Shippingport Station started in the Fall of 1977 and is expected to be completed in about 3 to 4 years. Then the fissionable fuel inventory of the core will be measured. This effort, when completed in about 2 to 3 years after completion of LWBR core operation, is expected to confirm that breeding actually took place.

The Advanced Water Breeder Applications (AWBA) project was initiated to develop and disseminate technical information that will assist U.S. industry in evaluating the LWBR concept for commercial-scale applications. The project will explore some of the problems that would be faced by industry in adapting technology confirmed in the LWBR program. Information to be developed includes concepts for commercialscale prebreeder cores which will produce uranium-233 for light water breeder cores while producing electric power, improvements for breeder cores based on the technology developed fo fabricate and operate the Shippingport LWBR core, and other information and technology to aid in evaluating commercial-scale application of the LWBR concept.

Technical information developed under the Shippingport, LWBR, and AWBA projects has been and will continue to be published in technical memoranda, one of which is this present report. 
II. SUMMARY AND CONCLUSIONS
A. Summary
B. Conclusions

III. TEST DESIGN

A. In-Pile Test Environment

B. Test Train Design

C. Fuel Rod Design

IV. TEST POWER AND TEMPERATURE CONDITIONS

A. Operating Power History

B. Fuel Rod Temperatures

V. EXAMINATION RESULTS

A. Overall Length Measurements

B. Incremental Length Measurements

C. Discussion of Length Changes

D. Diameter Measurement

\section{LIST OF FIGURES}

$\underline{\text { Figure }}$

Title

III-3 Assembly of Two Holders for NRX Blanket Test Fuel

III-5 Components of Teet Train $\Lambda$ esembly for NRX Blanket

III-6 Internal tayout and As-Built Lengths for Pressurized Rod 79-584 


\section{LIST OF FIGURES (Cont)}

$\underline{\text { Figure }}$

Title

$\underline{\text { Page }}$

III-7

Internal Layout and As-Built Lengths for Graphite

21 Coated Rod 79-706

III-8 Internal Layout and As-Built Lengths for Pressurized/ Graphite Coated Rod 79-707

IV-I

Heat Flux-Depletion History

28

IV-2

Pressurized Rod 79-584 HedL Flux-Depletion History

IV-3

Graphite Coated Rod 79-706 Heat Flux-Depletion

History

IV -4

Pressurized and Graphite Coated Rod 79-707 Heat FluxDeplellun Histury

IV-5 Unpressurized, Uncoated Rod 79-587 Heat Flux-

Depletion History

IV-6 . Intentionally Defected Rod 79-583D Heat FluxLlepletion History

Overall Length Changes

Rod Envelope Gage

Fiducial Mark Spacing Changes Rod 79-706

Fiducial Mark Spacing Changes Rod 79-587 


\section{LIST OF TABLES}

$\underline{\text { Table }}$

Title

Page

III-I

Physical and Chemical Properties of Zircaloy-4

III-2a

Tubing Used as Cladding for the Five Test Rods

III-2b Pellet-Cladding Gap and Pellet Parameters for $19-584$

III-3a

Rod Parameters for $79-706$.

III-3b

Pellet-Cladding Gap and Pellet Parameters for 7.9-706

22

III-4a

Rod Parameters for $79-707$

24

III-4b

Pellet-Cladding Gap and Pellet Parameters for 79-707

24

III-5

Comparison of the Five Test Rods

IV-1

Operating Conditions for Pre-Pressurized/Graphite Coated Rods

IV-2

Operating Conditions for Unpressurized, Uncoated

$\mathrm{V}-1$ Rods

$\mathrm{V}-2$

Rod Overall Length Changes for the Five Test Rods

Comparison of Average Cladding Axial Strains over the Fue

$\mathrm{V}-3$

Zircaloy Growth Contribution to Length Changes Rod 79-587 
Irradiation tests on 0.612 inch $0 . \mathrm{D}$. by 117 -inch long Zircaloy-4 clad fuel rods were performed to assess the effects on fuel rod performance of

(1) internal helium pre-pressurization to $500 \mathrm{psi}$ as fabricated, (2) the presence of a graphite barrier coating on the inside cladding surface, and (3) combined pre-pressurization and graphite coating. Periodic dimensional examinations were performed on the test rods, and the results were compared with data obtained from tro previously irradiated test rods - both unpressurized and uncoated and one intentionally defected. These comparisons indicate that both pre-pressurization and graphite coating can substantially improve fuel element performance capability.

\section{IRRADIATION TESTING OF INTERNALLY PRESSURIZED AND/OR GRAPHITE COATED ZIRCALOY-4 CLAD FUEL RODS IN THE NRX REACTOR}

(AWBA DEVELOPMENT PROGRAM)

R. C. Hof fman

J. Sherman

\section{INTRODUCTION}

The Light Water Breeder' Reactor (LWBR) Program is developing the technology to breed fissile material in a light.water reactor in order to use nuclear fuel more efficiently in light water thermal reactors. To achieve this objective, technology is being developed through the design and fabrication of a breeder reactor core that has been installed in the existing Department of Energy (DOE) owned pressurized water reactor plant at Shippingport, Pennsylvania. Design and fabrication of the reactor core were accomplished by the Bettis Atomic Power Laboratory under the technical direction of the Division of Naval Reactors, DOE. Operation of the LWBR core in the Shippingport Atomic Power Station is expected to confirm that breeding of fissile material can be achieved in a pressurized light water reactor using the thoria $\left(\mathrm{ThO}_{2}\right)$ and thoria/urania $\left(\mathrm{ThO}_{2}-\mathrm{UO}_{2}\right)$ binary fuel system.

In late 1974, the Bettis Laboratory began to examine areas in which advanced water breeder fuel rod technology could be developed in parallel with LWBR manufacture and early operation. The information to be developed was focused 
on fuel rod concepts for commercial scale prebreeder cores which would efficiently produce uranium-233 for light water breeder cores while producing electric power.

F'or the initial phase of this effort it was decided to fabricate a single rod pre-pressurized with helium to 500 psi. Although pre-pressurized rods are standard commercial practice, Bettis civilian power reactors, i.e., PWR and LWBR, did not utilize pre-pressurized rods. The advantages of rod prepressurization relate to the improved thermal conductivity with depletion of the gas mixture in the fuel-cladding gap. This is due to the increased number of atoms of high thermal conductivity helium as compared to the low thermal conductivity of the released fission gases. In addition, fuel-cladding interaction is delayed due to reduced pressure differentia. arrnss the oladding; and collapse into unsupported gaps is prevented. Delayed fuel-cladding interaction reduces cladding strain and the potential for the formation of fuel stack gaps. However, the increase in internal pressure can potentially degrade Loss-ofCoolant Accident (LOCA) performance with respect to an unpressurized rod, if the rod plenum volume is not increased proportionately.

Irradiation of the test rod was planned for the National Research Experimental Reactor (NRX) at Chalk River, Ontario, Canada. NRX is owned by Atomic Energy of Canada, Limited (AECL) and the ten foot active core length permits irradiation of full length test rods to evaluate axial effects. The pressurized rod was fabricated by pressurizing an existing spare LWBR irradiation test rod. This enabled irradiation of the pressurized rod in the same NRX facilities used for the LWBR test rods with the same test hardware, thereby facilitating performance comparison between the new and the original rods. Irradiation was started for the pressurized rod in May, 1975.

A second rod was fabricated from existing LWBR blanket irradiation test components and was also tested at NRX. This rod was not pre-pressurized but had a graphite barrier coating on the cladding inside surface. The presence of this lubricating coating, it was bclicved, would reduce the coefficient of friction between the cladding and the expanding fuel thereby reducing cladding strain and improving up-power transient behavior. It was also believed that graphite will protect the cladding from stress corrosion crasking by providing 
a barrier layer between the corrosive agent and the cladding. Graphite coating of cladding is not presently used in commercial reactors but development is in progress as described in Reference 1. Irradiation of the graphite-coated rod started at NRX in June, 1976.

The third and final rod in this series was a combined pre-pressurized (500 psi) and graphite-coated rod also fabricated from spare LWBR blanket irradiation test components." Irradiation of this rod started at NRX in February 1977.

This report describes the design and irradiation history of the three advanced LWBR blanket type test rods, and presents the results of non-destructive examination to determine changes in the cladding length and diameter. These examination results are compared to two previously irradiated LWBR blanket irradiation test rods - one unpressurized and uncoated and the other intentionally defected.

\section{SUMMARY AND CONCLUSIONS}

\section{A. Summary}

Alternate fuel rod design concepts were explored to improve performance capability for commercial scale light water pre-breeder cores to efficiently produce uranium-233 from thoria. The initial screening tests included 1) a rod pre-pressurized with helium to 500 psi at room temperature, 2) a rod with a graphite barrier coating on the cladding inside surface, and 3) a rod with combined pre-pressurization and graphite coating. The helium pressurization, which is standard commercial practice, prevents collapse into unsupported gaps, delays fuel-cladding interaction due to reduced cladding pressure differential and mitigates the reduction in thermal conductivity of the gas mixture in the fuel-cladding gap with depletion. The graphite coating provides lubrication of the fuel-cladding interface thereby reducing fuel-cladding interaction, and may provide a barrier to fission product stress corrosion attack of the cladding. The tests of pressurized rods were directed at investigation of fuel rod performance, and were not focussed on thermal-hydraulic considerations.

The three rods were assembled from spare components previously fabricated for an LWBR blanket irradiation test to provide a basis for comparison with two previously irradiated, uncoated, unpressurized rods, one of which was 
intentionally defected. The fuel was $\mathrm{ThO}_{2}-3.06 \mathrm{w} / \mathrm{O} \mathrm{UO}_{2}$ at a density of 95 to 98 percent TD. The fuel stack contained 84 inches of $\mathrm{ThO}_{2}-\mathrm{UO}_{2}$ pellets with thoria pellets above and below the $\mathrm{ThO}_{2}-\mathrm{UO}_{2}$ fuel stack. A lo-inch plenum incorporating an $\mathrm{Fe}-\mathrm{Ni}-\mathrm{Cr}$ alloy hold-down spring was present at the top of the stack.

The three test rods were irradiated, one rod at a time, in the NRX Reactor. The coolant was $2000 \mathrm{psi}$ water at an average temperature of $560^{\circ} \mathrm{F}$ with a pH of 10.1 to 10.3 maintained by $\mathrm{NH}_{4} \mathrm{OH}$. Flnw velocity was $19.6 \mathrm{ft} / \mathrm{sec}$.

tach rod was irradiated for approximately 100 full power days at peak linear power output of 13 to $14 \mathrm{Kw} / \mathrm{ft}$. Power was then increased by 30 percent to 17 to $18 \mathrm{Kw} / \mathrm{ft}$ to simulate the increased pnwer in an up-power mancuved. Thr power was maintained at the 30-percent higher level for about 40 full power days, and the rods reached a peak depletion of $1.5 \times 10^{20}$ fiss/cc (5800 MWD/MT) and a peak flast fluence (> 1 . Mev) of $1.9 \times 10^{20}$ neutrons $/ \mathrm{cm}^{2}$. The unpressur1zed, uncoated test rods experienced similar histories except that the intentionally defected rod did not experience the up-power maneuver. All rods were periodically removed from testing during reactor shutdowns and examined at Chalk River; these measurements included both rod length and diameter.

The greatest measured overall length increases were observed for the unpressurized, uncoated rod, and the smallest measured length increases were observed for the intentionally defected rod where the equalized pressure across the cladding minimizes fuel-cladding interaction. Measured overall length inrreases observed tor the rod with a combination of pre-pressurization and graphite coating wcrc also small and, unt1l the up-power maneuver, similar to the intentionally defected rod. These observations indicate a significant reduction in fuel-cladding interaction due to pre-pressurization and graphite soating. The increase in length observed for the pre-pressurized, graphite coated rod aubsequent to the up-power maneuver was still significantly less than that. for the unpressurized, uncoated rod.

The measured overall length changes of the pre-pressurized rod ond the graphite coated rod were essentially the same, and fell between the length changes observed for the unpressurized, uncoated rod and those observed for the pre-pressurized and graphite coated rod and the intentionally defected rod. 
Incremental length changes determined from fiducial marks showed that local axial cladding strains were proportional to power in the uncoated and unpressurized rod as well as in the graphite coated.rod. The peak local strains were essentially identical in both rods. In contrast, the pre-pressurized and graphite coated rod had a nearly uniform axial distribution of strain and significantly lower peak strains at all examinations.

Both the unpressurized, uncoated rod and the pre-pressurized, graphite coated rod had a $0.004-i n c h$ diametral fuel-cladding gap in the bottom half of the fuel stack and a 0.008-inch diametral gap in the top half. The greatest diameter decreases were measured in the 0.008-inch gap region of the unpressurized, uncoated rod, and the greatest diameter increases were measured in the 0.004 -inch gap region of the unpressurized, uncoated rod. In contrast, no significant diameter decreases were measured in the 0.008 -inch gap region of the pre-pressurized, graphite coated rod. Also, no significant diameter increases were measured in the 0.004 -inch gap region of the pre-pressurized, graphite coated rod except at the peak axial power location after the up-power maneuver.

Negligible diameter changes were measured on the intentionally defected rod which had an intermediate size 0.005 -inch diametral fuel-cladding gap throughout.

The pre-pressurized, uncoated rod had a 0.004-inch diametral fuel-cladding gap in the top half of the fuel stack and a 0.008 -inch gap in the bottom half of the fuel stack. This is the reverse of the arrangement in the unpressurized, uncoated and pre-pressurized, graphite coated rods. No significant diameter increases were measured in the 0.004-inch gap region. Diameter decreases were measured in the 0.008 -inch gap region, but not as great as those seen in the 0.008-inch gap region of the unpressurized, uncoated rod.

The graphite coated rod had fuel-cladding gaps in the range of 0.004 to 0.005 inches throughout, and diameter increases similar to the 0.004-inch gap region of the unpressurized, uncoated rod were observed on the graphite coated rod.

\section{B. Conclusions}

It is concluded from comparisons between the unpressurized, uncoated rod and the pre-pressurized and graphite coated rod that initial pre-pressurization with helium plus graphite coating the inside cladding surface have reduced both 
overall axial cladding strains and peak axial cladding strains. Diameter changes have also been significantly reduced. These reductions are attributed to reduced fuel-cladding interaction and possible enhanced fuel densification due to the relatively higher gas pressure on the fuel pellets. Either pre-pressurization or graphite coating by itself resulted in an intermediate level of improvement from the unpressurized, uncoated rod, but these comparisons are not as direct due to differences in fuel-cladding gap size.

III. TEST DESIGN

\section{A. In-Pile Test Environment}

The pressurized and/or graphite-coated rods were irradiated in the X-1 loop of the NRX Reactor. This is a natural uranium, heavy water-moderated reactor. with light water cooling of reactor fuel rod assemblifes. The $x-1$ tinn is nne of seven test loops presently operating in NRX. These loops provide pressure, flow, and heat removal systems independent of the reactor which provides the neutron environment. Figure III-l is a simplified diagram of an NRX loop showing the primary system components and the positioning of the rods relative to the NRX axial neutron flux profile.

The pressure tube assembly is shown schematically in Figure III-2. The fuel rod test assembly is inserted into a 1.125-inch 0.D. stainless steel in-pile tube which contains the pressurized water environment for the test and provides the inlet and outlet flow channels for the coolant. The in-pile tube is surrounded by an aluminum sheath which contains an argon filled insulating gap. The entire pressure tube assembly is inserted into the NRX core through an aluminum calandria tube which separates the pressure tube from the heavy water moderator. The gap between the pressure tube assembly and the calandria tube is filled with air.

The coolant is pressurized water maintained at a $\mathrm{pH}$ of 10.1 to 10.3 by * $\mathrm{NH}_{4} \mathrm{OH}$ additions. Coolant oxygen, hydrogen, and chlorine concentrations are maintained at < $0.14 \mathrm{ppm}, 40$ to $70 \mathrm{cc} / \mathrm{kg}$, and < $0.1 \mathrm{ppm}$ respectively by degassing and bypassing coolant through a purification system. Crud concentration in the coolant is maintained at less than $0.5 \mathrm{ppm}$ by use of the purification system. Coolant temperatures are controlled by heaters placed downstream of the pumps and by the bypass flow through the heat exchangers. The 2065-psi inlet pressure of the coolant is controlled by the pressurizer which is also used as the 


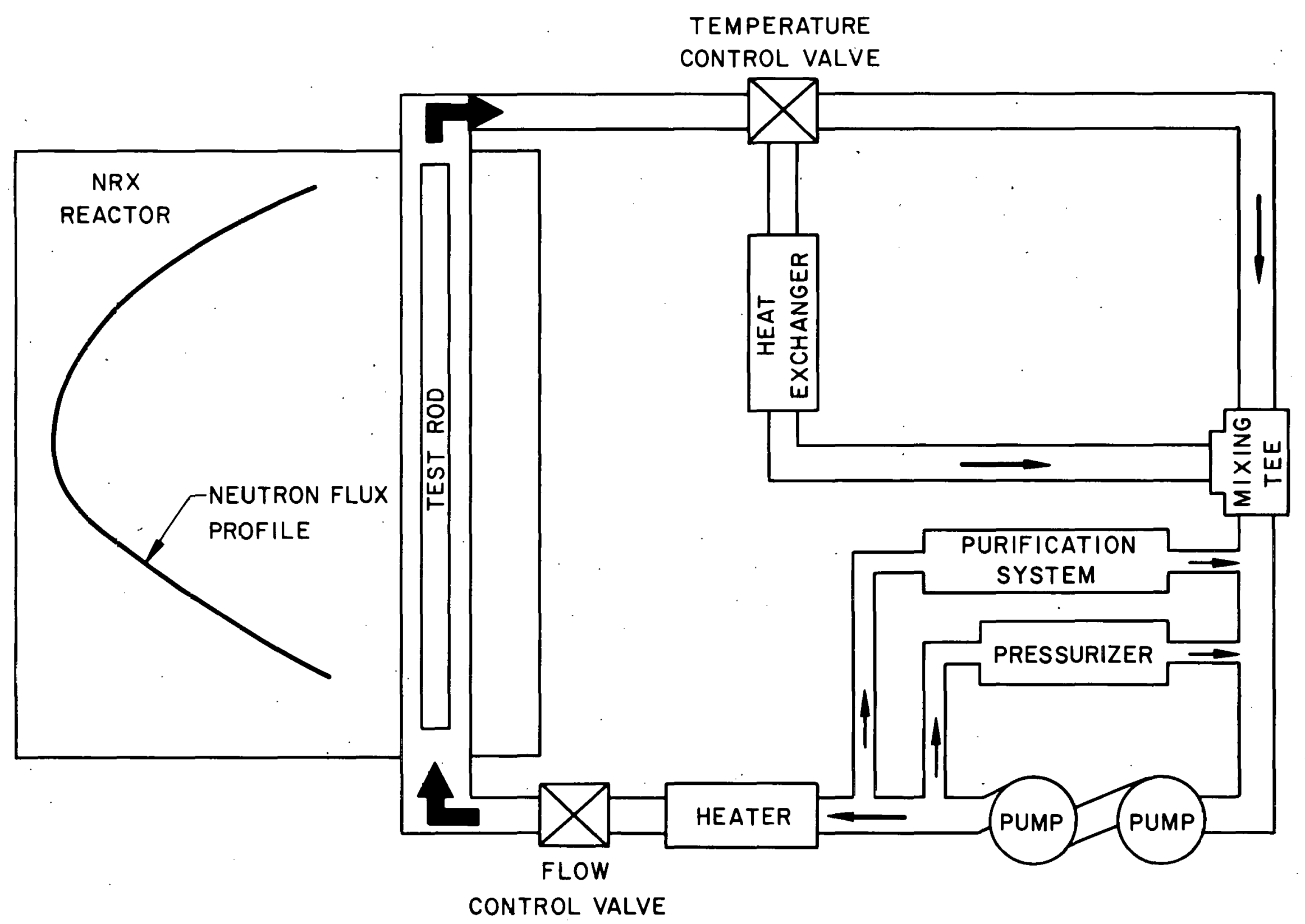




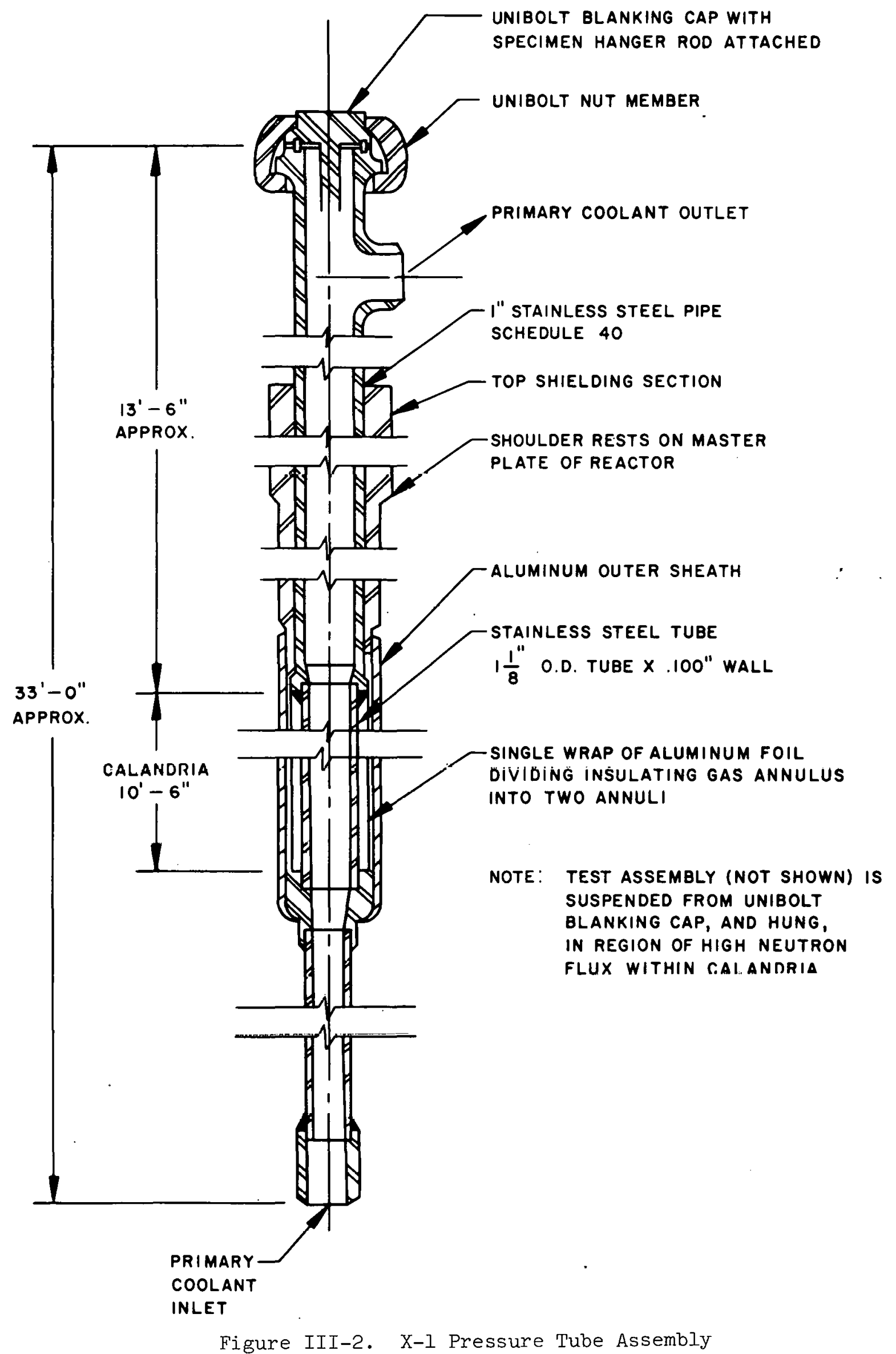

Figure III-2. X-I Pressure Tube Assembly 
degassing vessel for controlling chemistry. Coolant flow is maintained by two pumps with control of flow rates provided by a flow control valve located upstream of the in-pile tests. The nuclear evnironment of the fuel rods includes a fast neutron flux ( $>1 \mathrm{Mev}$ ) of approximately 0.1 to $0.2 \times 10^{14}$ neutrons $/ \mathrm{cm}^{2}-\mathrm{sec}$. The bulk coolant temperature at the inlet to the test is $530^{\circ} \mathrm{F}$, and the temperature rise along the rod is $55^{\circ} \mathrm{F}$. Variations of $\pm 10^{\circ} \mathrm{F}$ may exist in these temperatures from cycle to cycle. Flow in the test assembly is $11.5 \mathrm{gpm}$ which gives a coolant velocity of $19.6 \mathrm{ft} / \mathrm{sec}$. past the rod.

In-pile monitoring of test power is accomplished by calorimetry. Primary coolant temperatures are measured a.t. the inlet and outlet of the in-pile tube by platinum resistance temperature detectors (RTD's). Two RTD's are located on the inlet to the in-pile tube, one to measure inlet and one to measure differential temperature. The outlet line also has two RTD's for similar measurements. The differential temperature measurement has an uncertainty of \pm 2.5 percent including the recorder. The pressure drop across the venturi located at the in-pile tube coolant inlet and the venturi located at the in-pile tube coolant outlet are measured to an uncertainty of $\pm l$ percent by a transducer connected to a recorder.

The temperature rise of the coolant and the loop flow are used to calculate the power generated in the test loop including correction for heat loss from the in-pile tube to the reactor environment. This correction is determined by measuring the temperature loss across the in-pile tube with the loop at operating temperature and the reactor at zero power. Typically the loss is 2 to $3^{\circ} \mathrm{F}$.

The total power generated in the loop includes gamma heating in the loop structure and in the test holder hardware in addition to the fission power generated by the test rods. This gamma hcating cullrlbution to the measured power, calculated from the known structure weight and the gamma heating index (watts/ gram) as a function of reactor power, is subtracted from the total loop power measurement to give the fission power generated in the test rods.

The uncertainty in the test rod power is composed in part of the calorimetric measurements of temperature rise ( \pm 2.5 percent) and loop flow ( \pm I percent) deccribcd above. Gamma heating in the wall of the in-pile tube and the holder must be subtracted from this temperature rise. However, due to the low fast flux 
of the NRX, the uncertainty due to gamma heat is essentially negligible, \pm 0.5 percent. The uncertainty in calculation of the spatial power distribution in the NRX is composed of two factors, a radial uncertainty of \pm 5 percent and an axial uncertainty of \pm 3 percent.

The final allowances to be made for uncertainties are for intra- and inter-cycle time variation which occur because of neutron and gamma flux changes caused by variations in moderator level, fuel, and fission product inventory variations between NRX cores and over the lifetimc of a given core. Each of these effects (intra- and inter-cycle) has a \pm 5 percent uncertainty associated with it. Taking the RMS value of the six factors described above, an overall uncertainty of \pm 9.6 percent is obtained in the power of a given lest rod.

Normal operation of the lest is lefincd ac 25 to 7 , 5 percent, of the nominal test pnwer. Fixterlded uperation outcide of this range is avoided by increasing or decreasing the neutron flux to which the test is exposed, as required. This is done on a temporary basis by raising or lowering reactor power. A permanent adjustment is made during reactor shutdowns either by moving the lesl to another core location or by moving reactor t'uel elemenls in the vicinity of the test. In addition, an alarm setpoint is set on the in-pile tube $\Delta T$ corresponding to 110 percent of the nominal test power. If this limit is reached, reactor power is reduced to assure that. the test does not operate above 110 percent of the nominal test power. Alarm and reactor scram setpoints are also set to guard against low coolant f'low and low cuulant pressurc to ensure the thormal sarety ul lie test.

\section{B. Test Train Design}

The holders used to support the fuel rods during irradiation in the NRX $\mathrm{X}-1$ test loop are illustrated in F1gures III-3 and III 1. The holner assembIy is approximately 123 inches long and is composed of five segmented tubular sections (four, $25^{\circ}$ inches long and one, 23 inches long) incorporating two dual contilever spring rod support systems in each section resulting in a total of 10 levels of support. Each level of support incorporates twin cantilever springs facing free end to free end and two pair of opposed reaction dimples $60^{\circ}$ apart and 6.3 inches center-to-center axially.

All of the holders were manufactured from Zircaloy-4, and the springs and reaction dimples are an integral part of the holders. The springs were created 


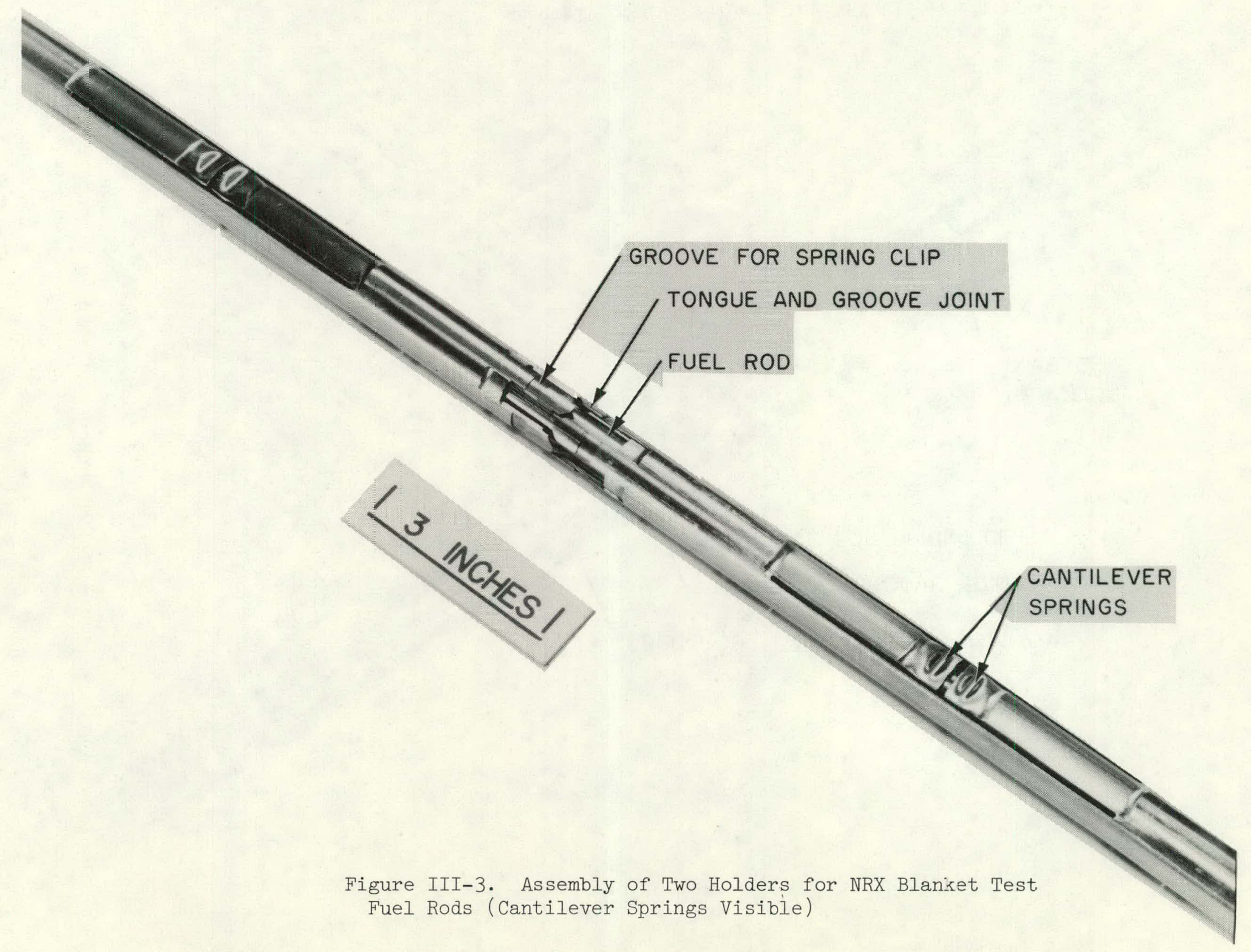




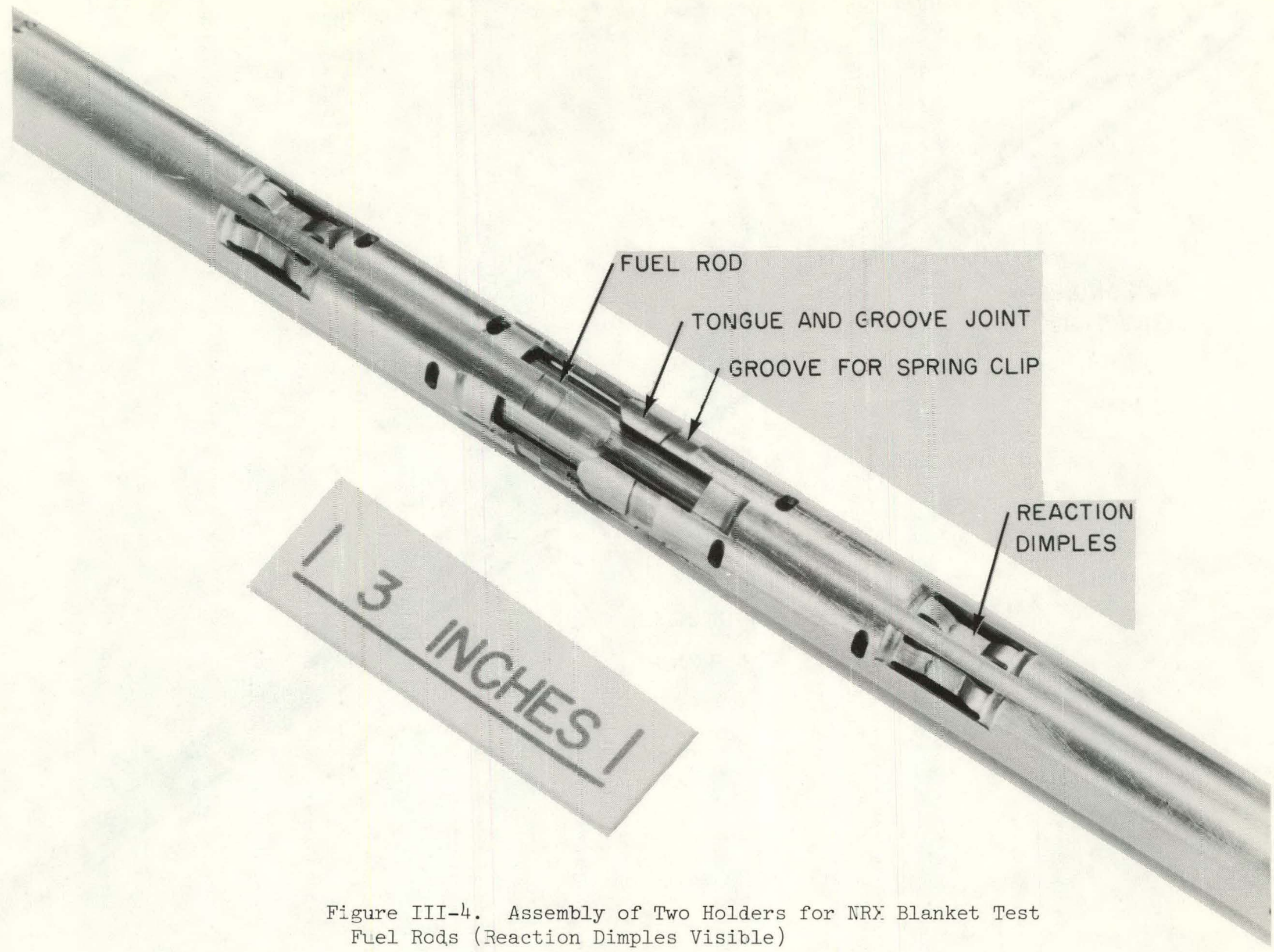


by cutting away the holder wall to identify and produce the cantilever spring, and the reaction dimples were cold formed into the holder wall. After fabrication, all holder segments were pickled, annealed, and corrosion tested.

The holder sections are connected to each other by means of a multiple tongue and groove joint with only sufficient clearance to permit ease of assembly. This limits the flexibility of the joint and prevents the tubular sections from contacting the fuel rod during extreme conditions. Axial motion is prevented by means of a groove through both portions of the joint and a spring clip closely fit into the groove.

The connection between the fuel rod and the holder assembly is made by means of a threaded stem on the top endclosure on the fuel rod and a nut with an integral crimping sleeve. The threaded stem fits through a hole in a 4.9-inch adapter, the nut is installed onto the threaded stem and tightened, then the sleeve is crimped onto flats on the endclosure. The circumferential orientation of the fuel rod is fixed with respect to the adapter by means of a flat in the rod top endclosure which permits the stem of the endclosure to fit through the hole in the adapter in only one orientation. The adapter itself mates with the top holder section by the same tongue and groove arrangement as the holder sections mate with each other.

When all holders are assembled on the fuel rod, all twenty cantilever springs are positioned along one line parallel to the axis of the fuel rod. This orientation is achieved by the keying of the top end of the fuel rod into the adapter described above coupled with indexing marks on adjacent holder segment tongues. This keying and indexing system was provided so that the springs and reaction dimples contact the rod in the same location after the test train is disassembled for fuel rod examination then reassembled for continued irradiation. Figure III-5 illustrates all of the components of the test train layed out for assembly.

A 1.8-inch long nose piece is installed over the bottom of the holder assembly by the tongue and groove system, and a hanger rod is attached to the adapter at the top of the test assembly. The hanger rod is attached to the top

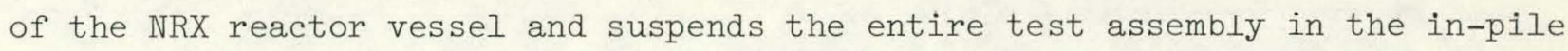
tube. The length of the hanger rod is such as to position the axial centerline of the fuel stack in the test rod at the same elevation as the axial centerline of the NRX reactor fuel elements. The thermal neutron flux of the NRX core 


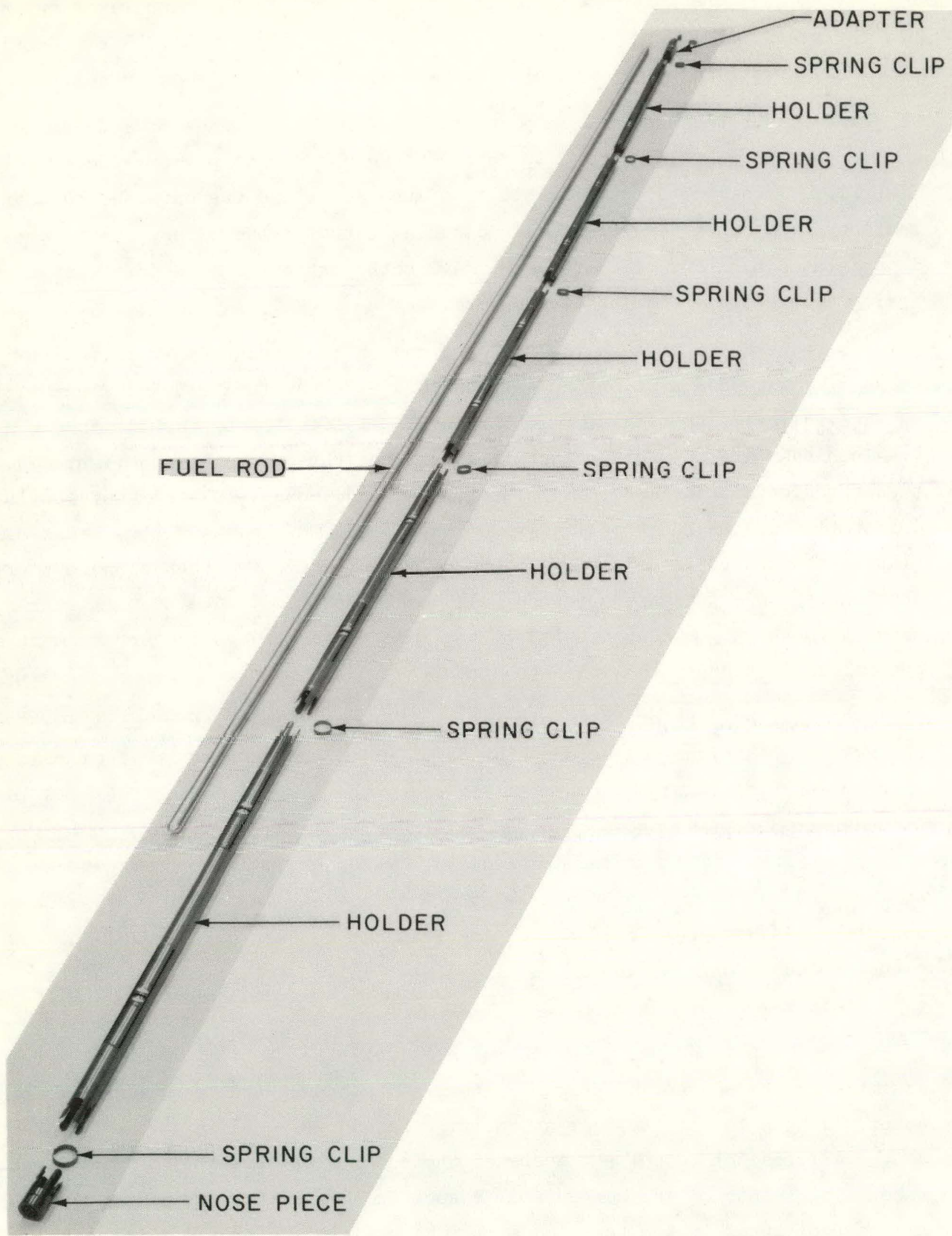

Figure III-5. Components of Test Train Assembly for NRX Blanket Test Fuel Rods 
varies axially over 120 inches in the shape of a cosine curve. The test rods described in this report varied in overall length from 105 to 1.17 inches and contained fuel stacks of 84 inches in length. When these fuel stacks are axially centered in the core, the neutron flux at the ends of the fuel stack is about 50 percent of the peak value.

The outside diameter of the test holders is 0.890 inches, and as was shown above, this test assembly is inserted into a stainless steel tube with an inside diameter of 0.925 inches. Because of the small gap between the test and the in-pile tube, there was insufficient room to provide for installing poisons such as hafnium-zirconium alloy shrouds around the test as a means to vary the test power. Therefore, adjustments in test power were made by moving the test to various locations in the NRX core where the available thermal neutron flux was such as to provide the required test power.

C. Fuel Rod Design

The design of the three modified fuel rods discussed in this report was similar to the design of two rods previously irradiated as part of the LWBR fuel element development program. The pressurized rod, 79-584, was a backup rod fabricated for the LWBR test, and the graphite coated rod, 79-706, and the pressurized/graphite coated rod, 79-707, were fabricated from spare components (fuel, tubing, plenum internals, etc.) originally manufactured for this test. Use of the LWBR test design and spare components permits direct comparisons between results obtained from the two unpressurized, uncoated test rods and the three new fuel rods.

\section{Unpressurized-Uncoated Fuel Rods}

These two test rods were fabricated in early 1969 to investigate features of the LWBR blanket fuel rod design. Test tubing to match final LWBR dimensions of 0.572 -inch $0 . D$. and 0.028 -inch wall was not available at that time. However, the core blanket design OD/t ratio of 20.4 was matched by setting the test tubing outside diameter at 0.612 with a wall thickness of 0.030 inches. The Zircaloy-4 tubing used for the rods was 74 percent cold worked with a $950^{\circ} \mathrm{F}, 4$ hours stress relief anneal. This is compared to the 70 percent cold work with a $950^{\circ} \mathrm{F}, 4$ hour stress relief anneal reference design tubing for the LWBR blanket. Chemical and physical properties of the tubing used for the five test rods are given in Table III-I. 
TABLE III-1. PHYSICAI AND CHEMICAL PROPERTIES OF ZIRCALOY-4 TUBING USED AS CLADDING FOR THE FIVE TEST RODS

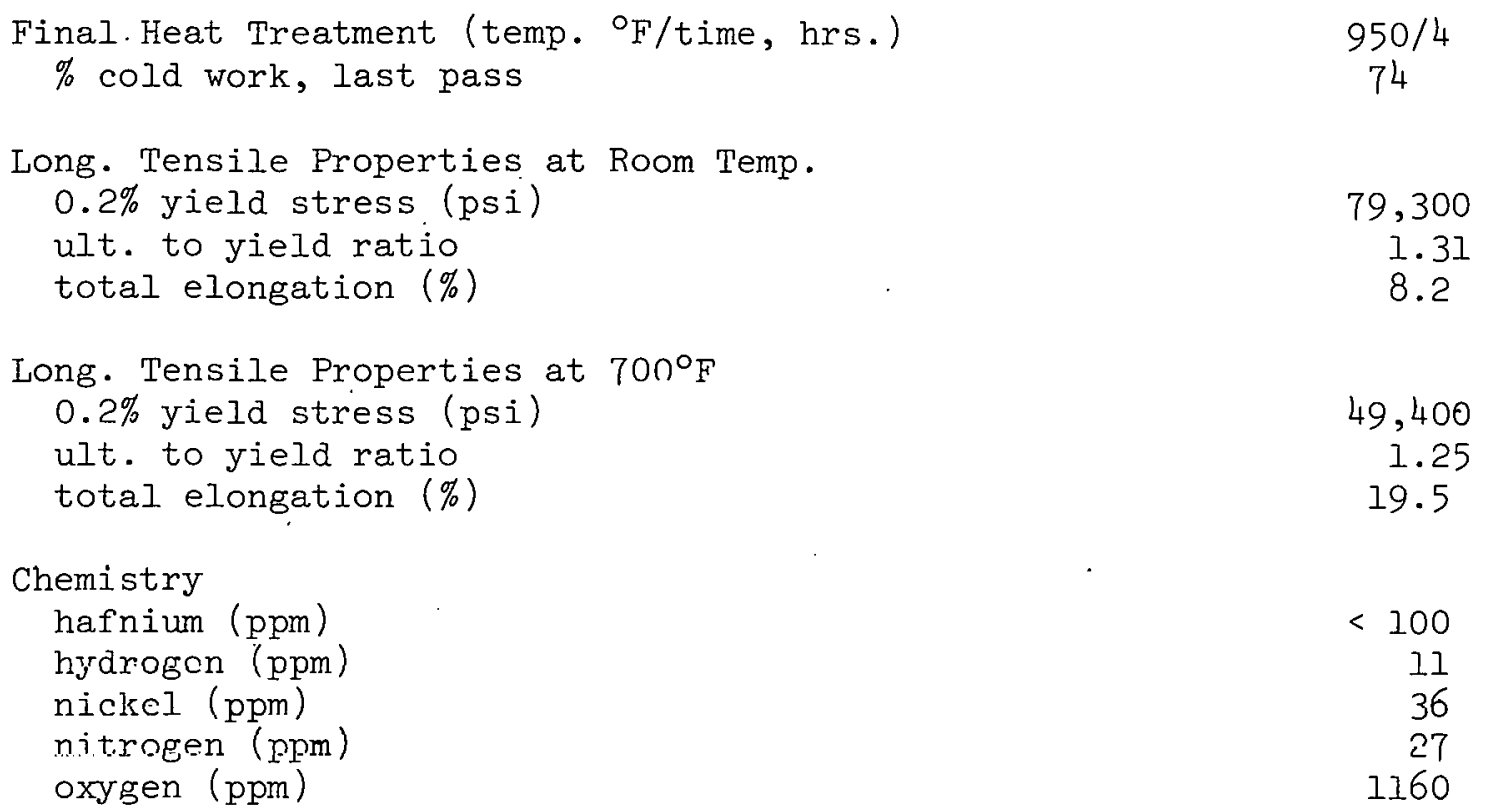

'l'he t'uel-cladding diametral gaps were specified as 0.004 and 0.007 inches to test in the range of the LWBR design. Binary ( $\mathrm{ThO}_{2}-\mathrm{UO}_{2}$ ) fuel pellet geometry was specified to match the LWBR design which incorporates a $0.014 \pm 0.004$ inch deep dish in the pellet ends with a $0.055 \pm 0.015$ inch wide end land shoulder. In addition, the pellet edges were tapered 0.100 to 0.200 inches long by 0.001 to 0.004 inches radially. The density of the $\mathrm{ThO}_{2}-\mathrm{UO}_{2}$ was between 96 and 99 percent of theoretical density (T.D.). The fissile material was $U^{235}$. Total fuel stack length of the test rods was set at 84 inches with a 9-inch stack of thoria. pellets above and below the active binary fuel stack for a total pellet stack length of 102 inches.

The plenum length was set at 10 inches. The plenum incorporates an $\mathrm{Ni}-\mathrm{Cr}-\mathrm{Fe}$ age hardenable alloy helical coiled spring. The spring free length is set such that a load of $54.7 \mathrm{lbs} \pm 5$ percent is applied to the pellet stack when the spring is compressed to the plenum length. This load prevents stack motion during handiing of the fuel rod. This spring load is approximately 6.5 times the weight of the pellet stack. Because the cladding with an oD/t ratio of 20.4 is non-f'ree standing under the 2000 psi external coolant pressure exerted durlng Irradiation, a stainless steel plenum support sleeve is incorporated to prevent cladding deformation in the plenum. This sleeve locks into the top 
endclosure, and fits into the space between the plenum spring and the inside cladding surface. Its length is such as to allow for differential thermal expansion of the fuel and cladding resulting in an axial distance of approximately 0.37 inches between the top of the pellet stack and the bottom of the plenum sleeve.

The top endclosure design was such as to permit installation in the rod holders and test train assembly. The bottom endclosure was basically a plug with rounded corners to streamline coolant flow past the end of the rod.

\section{Pre-Pressurized/Graphite Coated Test Rods}

a. Pressurized Rod 79-584

Rod 79-584 was fabricated as a backup specimen for the LWBR irradiation test program and incorporates the design features discussed above with two exceptions. First, the corners of the $\mathrm{ThO}_{2}-\mathrm{UO}_{2}$ fuel pellets were not tapered, but were maintained in a square configuration. This was done in the original LWBR test plan to provide data for comparison with the rods containing tapered pellets so that the effect of tapers could be evaluated. Second, the $\mathrm{ThO}_{2}-\mathrm{UO}_{2}$ pellet stack contains a simulated axial gap created by the inclusion of three reduced (0.49-inch). diameter $\mathrm{ZrO}_{2}-\mathrm{CaO}$ pellets in the fuel stack. This producès a 1.0-inch long region of relatively unsupported cladding (0.060-inch diametral gap) such as might oncur due to fuel densification combined with cladding elongation if a portion of the fuel stack became "locked" to the cladding.

Figure III-6 presents a schematic representation of the internal features of $79-584$ and also gives the as-built lengths of the various regions of the rod. Additional as-built data for 79-584 are given in Tables III-2a and III-2b. Note that the bottom half of the fuel stack has a 7.7-mil diametral fuel-cladding gap and the top half has a 3.8-mil diametral fuel-cladding gap.

Rod 79-584 was pressurized by drilling a 0.040-inch hole through the center of the bottom endclosure so that the interior of the fuel rod was exposed. The rod was subsequently installed in a specially built weld chamber. Then the chamber was evacuated to a pressure of 90 microns and backfilled with helium to $500 \pm 2$ psi. The drilled hole was then welded shut, and the chamber was depressurized. 


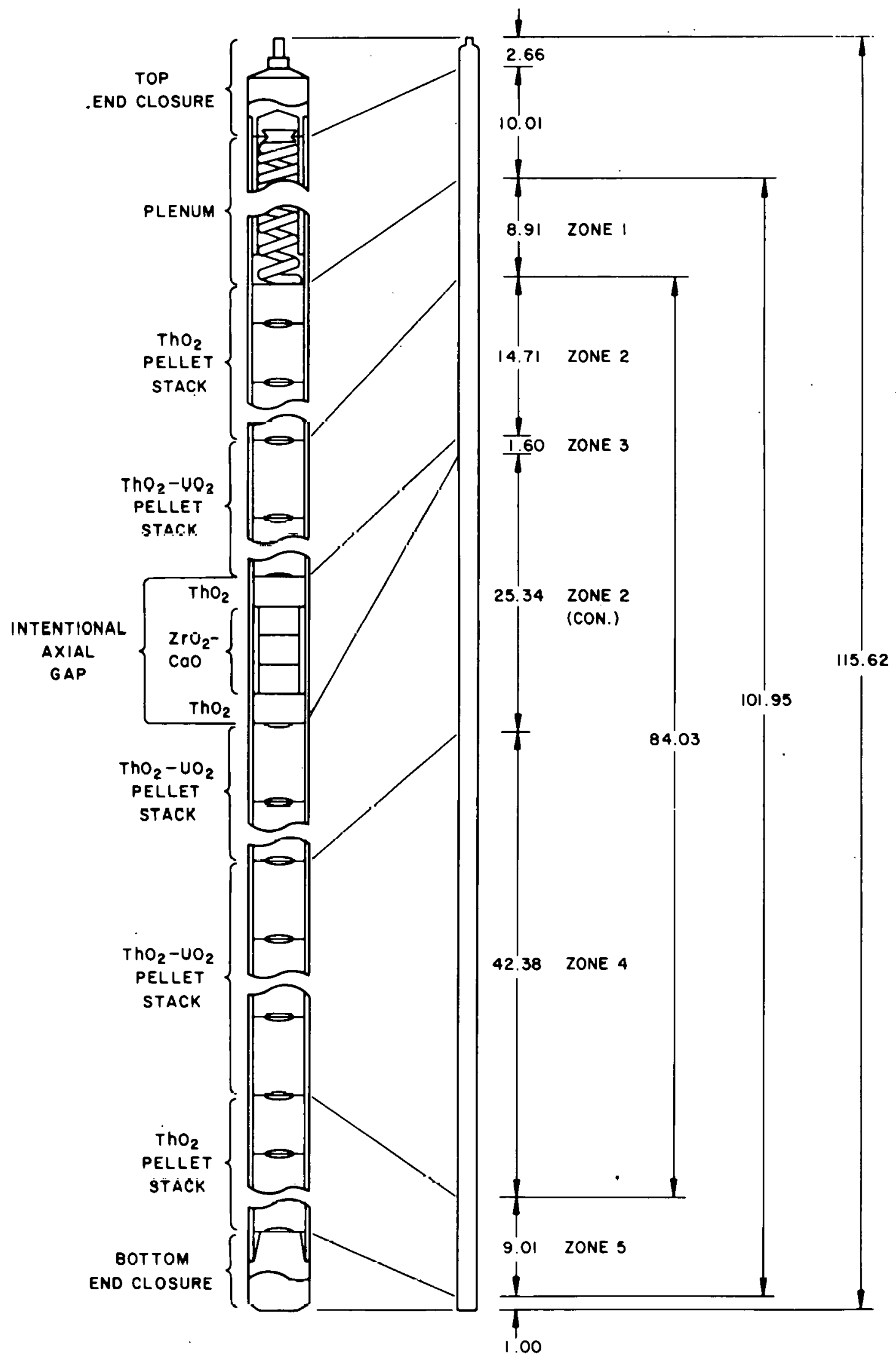

Figure III-6. Internal Layout and As-Built Lengths for Pressurized Rod 79-584 
TABLE III-2a. ROD PARAMETERS FOR 79-584

Cladding Outside Dlameter, inches Avg. 0.6129

Range $0.6072-0.6155$

Cladding Wall Thlckness, inches Avg. 0.0302

Range $0.0279-0.0319$

Outside Dram./Wall Thilk kness (OD/t) AvG. 20.3

TABLE III-2b. PELLET-CLADDING GAP AND PELLET PARAMETERS FOR 79-584

\begin{tabular}{|c|c|c|c|c|c|c|}
\hline & & Zone $1^{(1)}$ & Zone 2 & Zone $3(3)$ & Zone 4 & Zone 5 \\
\hline $\begin{array}{l}\text { Pellet-Cladding Diametral } \\
\text { Gap, Inches }\end{array}$ & $\begin{array}{l}\text { Avg. } \\
\text { Range }\end{array}$ & $\begin{array}{l}0.0038 \\
0.0036-0.0041\end{array}$ & $\begin{array}{l}0.0038 \\
0.0035-0.0040\end{array}$ & $\begin{array}{c}0.0599 \\
-\end{array}$ & $\begin{array}{l}0.0077 \\
0.0075-0.0079\end{array}$ & $\begin{array}{l}0.0077 \\
0.0075-0.0079\end{array}$ \\
\hline $\begin{array}{l}\text { Pellet Outside Diameter, } \\
\text { Inches }\end{array}$ & $\begin{array}{l}\text { Avg. } \\
\text { Range }\end{array}$ & $\begin{array}{l}0.5486 \\
0.5483-0.5488\end{array}$ & $\begin{array}{l}0.5486 \\
0.5484-0.5487\end{array}$ & $\begin{array}{l}0.4925 \\
0.4924-0.4926\end{array}$ & $\begin{array}{l}0.5448 \\
0.5445-0.5450\end{array}$ & $\begin{array}{l}0.6450 \\
0.5448-0.5451\end{array}$ \\
\hline Pellet Length, inches & $\begin{array}{l}\text { Avg. } \\
\text { Range }\end{array}$ & $\begin{array}{l}0.6022 \\
0.6007-0.6040\end{array}$ & $\begin{array}{l}0.8175 \\
0.8153-0.8200\end{array}$ & $\begin{array}{l}0.330 \\
0.242-0.374\end{array}$ & $\begin{array}{l}0.8149 \\
0.8134-0.8194\end{array}$ & $\begin{array}{l}0.6022 \\
0.6014-0.6040\end{array}$ \\
\hline $\begin{array}{l}\text { Pellet Length/Diameter (L/D) } \\
\text { Dish Dimensions (2) }\end{array}$ & Avg. & 1.10 & 1.49 & 0.67 & 1.50 & 1.10 \\
\hline Depth, inches & $\begin{array}{l}\text { Avg. } \\
\text { Range }\end{array}$ & $\begin{array}{l}0.0190 \\
0.0188-0.0197\end{array}$ & $\begin{array}{l}0.0195 \\
0.0180-0.0210\end{array}$ & None & $\begin{array}{l}0.0192 \\
0.0181-0.0204\end{array}$ & $\begin{array}{l}0.0190 \\
0.0188-0.0195\end{array}$ \\
\hline Shoulder, inches & $\begin{array}{l}\text { Avg. } \\
\text { Range }\end{array}$ & $\begin{array}{l}0.0505 \\
0.0500-0.0510\end{array}$ & $\begin{array}{l}0.0539 \\
0.0525-0.0550\end{array}$ & $N / A$ & $\begin{array}{l}0.0538 \\
0.0525-0.0550\end{array}$ & $\begin{array}{l}0.0486 \\
0.0475-Q_{0} .0495\end{array}$ \\
\hline Pellet Density, $\$$ TD & $\begin{array}{l}\text { Avg. } \\
\text { Range }\end{array}$ & $\begin{array}{l}98.67 \\
98.62-98.74\end{array}$ & $\begin{array}{l}96.18 \\
95.82-96.52\end{array}$ & $\begin{array}{l}89.95 \\
89.88-90.05\end{array}$ & $\begin{array}{l}97.06 \\
96.17-97.50\end{array}$ & $\begin{array}{l}98.67 \\
98.63-98.73\end{array}$ \\
\hline Pellet Composition & & $\mathrm{ThO}_{2}$ & $\begin{array}{l}\mathrm{ThO}_{2}-3.07 \text { w/o } \\
\mathrm{UE}_{2}\end{array}$ & $\mathrm{ZrO}_{2}-10 \mathrm{w} / \mathrm{OCaO}$ & $\begin{array}{l}\mathrm{ThO}_{2}-3.10 \mathrm{w} / 0 \\
\mathrm{UEO}_{2}\end{array}$ & $\mathrm{ThO}_{2}$ \\
\hline
\end{tabular}

(1) See Figure III-6 for definltion of pellet zones

(3) Data for $\mathrm{ZrC}_{2}-\mathrm{CaO}_{\mathrm{O}}$ pellets only

(2) Dish dimensions are as shown:

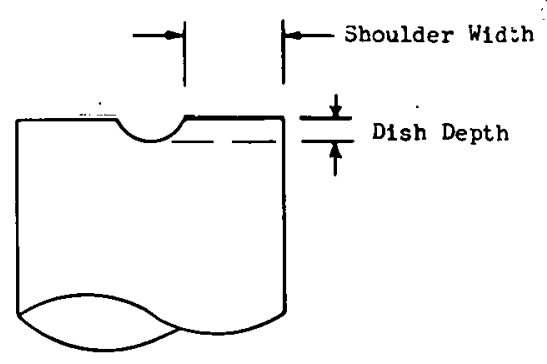




\section{b. Graphite Coated Rod 79-706}

Rod 79-706 was fabricated from LWBR test rod components and incorporates all of the basic test design features discussed above. After the bottom endclosure was welded to the tube, the inside cladding surface of 79-706 was graphite coated. The average film thickness was 0.3 mil with variations from 0.6 to $0.1 \mathrm{mil}$. The residual hydrogen content of the graphite coating was $46 \mathrm{cc}$ (STP).

Figure III-7 presents a schematic representation of the internal features of 79-706 and also gives as-built lengths of the various regions of the rod. Additional as-built data for 79-706 are given in Tables III-3a and III-3b. Fuel cladding gaps including the graphite coating vary from 4.0 to 4.9 mils.

\section{c. Pressurized/Graphite Coated Rod 79-70\%}

Rod 79-707 was also fabricated from compunents originally obtained for the LWBR irradiation test program and incorporates most of the basic test design features. However, the top half of the binary fuel stack rontains untapered pellets to provide additional data for comparison to rods containing tapered fuel.

Figure III-8 presents a schematic representation of the internal features of 79-707 and also gives as-built lengths of the various regions of the rod. Additional as-built data for 79-707 are given in Tables III-4a and III-4b. Note that due to the slightly shorter overali length of 79-707, the fuel stack is only 81 inches long and the upper and lower thoria stacks are 7.3 and 1.8 inches long respectively. The top half of the binary fuel stack has a 7.3-mil diametral fuel-cladding gap and the bottom half has a 4.1-mil diametral fuel-cladding gap.

As was done for 79-706, the inside surface of the cladding of 79-707 was coated with graphite after the bottom endclosure was welded into place. The average coating thickness achieved in 79-707 was 0.5 mil with variations in thickness from 1.4 to U.1 mils. 'I'he residual hydrogen content of the graphite coating was $80 \mathrm{cc}$ (STP). Rod 79-707 was also internally pressurized to 500 psi with helium by means of a pre-drilled hole in the bottom endclosure. The pressurization was accomplished as described above for 79-584. 


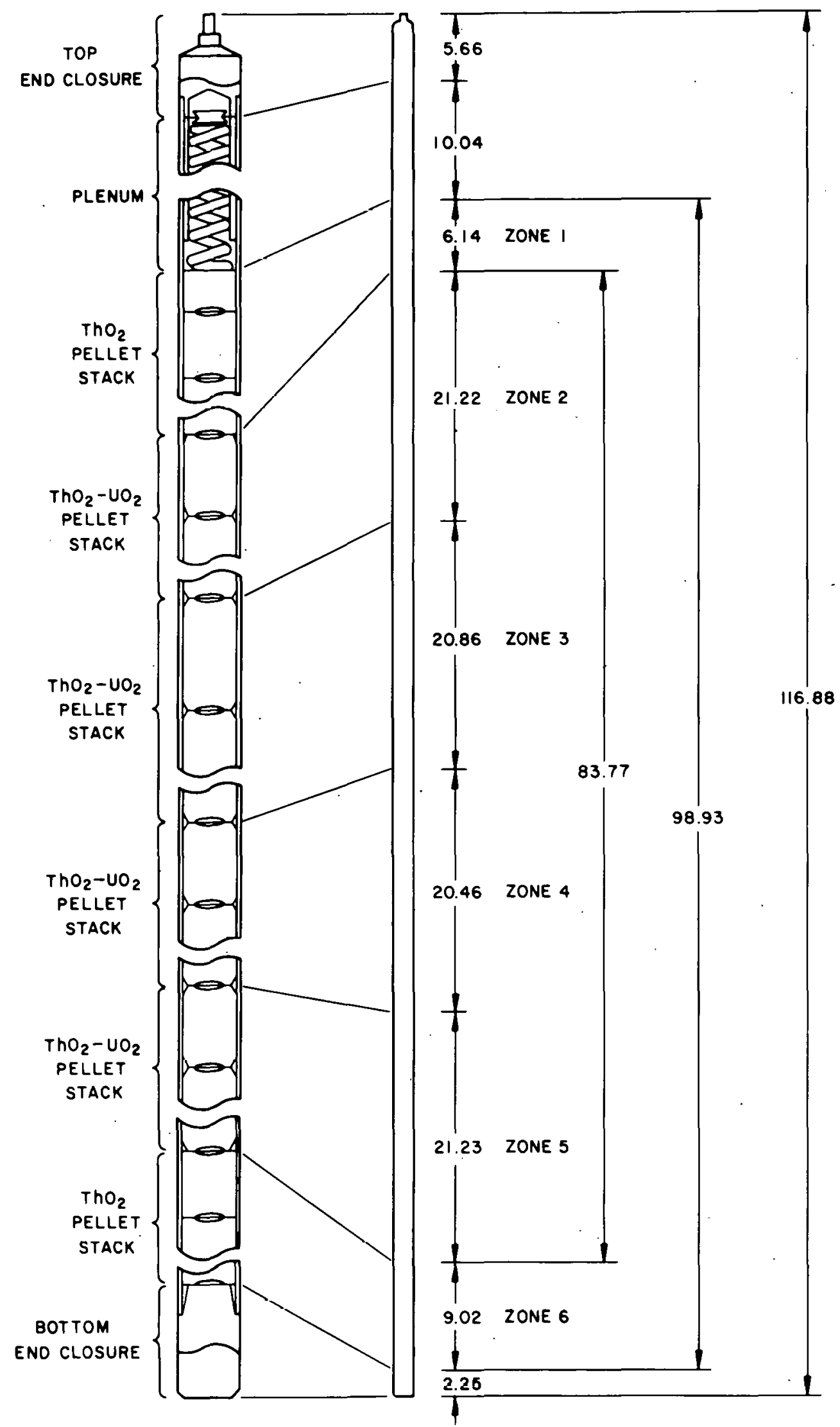

Figure III-7. Internal Layout and As-Built Lengths for Graphite Coated Rod 79-706 
TABLE III-3a. ROD PARAMETERS FOR 79-706

Cladding Outside Dameter

Avg. 0.6131

Range $0.6106-0.6150$

Cladding Wall Thickness

Avg. 0.0312

Range $0.0288-0.0318$

Outside Diam./Wall Thickness (OD/t) Avg. 19.7

TABLE III-3b. PELLET-CLADDING GAP AND PELLET PARAMETERS FOR 79-706

\begin{tabular}{|c|c|c|c|c|c|c|c|}
\hline & & Zone $I^{(1)}$ & Zone 2 & Zon: 3 & Zone 4 & Zone 5 & Zone $\underline{6}$ \\
\hline $\begin{array}{l}\text { Pellet-Cladding Diametral Gap, } \\
\text { Inches }\end{array}$ & $\begin{array}{l}\text { Avg. . } \\
\text { Range }\end{array}$ & $\begin{array}{l}0.0050 \\
0.0047-0.0054\end{array}$ & $\begin{array}{l}0.0048 \\
0.0044-0.0056\end{array}$ & $\begin{array}{l}0.0040 \\
0.0037-0.0043\end{array}$ & $\begin{array}{l}0.0043 \\
0.0041-0.0047\end{array}$ & $\begin{array}{l}0.0049 \\
0.0046-0.0052\end{array}$ & $\begin{array}{l}0.0056 \\
0.0053-0.0059\end{array}$ \\
\hline $\begin{array}{l}\text { Pellet Outside Diameter, } \\
\text { Inches }\end{array}$ & $\begin{array}{l}\text { Avg. } \\
\text { Range }\end{array}$ & $\begin{array}{l}0.5473 \\
0.5^{1}, 68-0.5^{4}, 75\end{array}$ & $\begin{array}{l}0.5474 \\
0.5^{1}+72-0.5^{1}+76\end{array}$ & $\begin{array}{l}0.548 \% \\
0.5430-0.5483\end{array}$ & $\begin{array}{l}0.5480 \\
0.5^{1} 78-0.5480\end{array}$ & $\begin{array}{l}0.5475 \\
0.5^{14} 73-0.5476\end{array}$ & $\begin{array}{l}0.5473 \\
0.5470-0.5475\end{array}$ \\
\hline Pellet Length, Inches & $\begin{array}{l}\text { Avg. } \\
\text { Range }\end{array}$ & $\begin{array}{l}0.6012 \\
0.6010-0.6020\end{array}$ & $\begin{array}{l}0.8166 \\
0.8151-0.8177\end{array}$ & $\begin{array}{l}1.0932 \\
1.0973-1.0997\end{array}$ & $\begin{array}{l}0.8186 \\
0.8175-0.8213\end{array}$ & $\begin{array}{l}0.8169 \\
0.8149-0.8178\end{array}$ & $\begin{array}{l}0.6012 \\
0.6008-0.6021\end{array}$ \\
\hline Pellet Length/Diameter ( $L / D)$ & Avg. & 1.10 & 1.49 & 2.00 & 1.49 & 1.49 & 1.10 \\
\hline \multicolumn{8}{|l|}{ Dish Dimensions ${ }^{(2)}$} \\
\hline Depth, Inches & $\begin{array}{l}\text { Avg. } \\
\text { Range }\end{array}$ & $\begin{array}{l}0.0196 \\
0.0190-0.0204\end{array}$ & $\begin{array}{l}0.0200 \\
0.0192-0.0208\end{array}$ & $\begin{array}{l}0.0196 \\
0.0190-0.0201\end{array}$ & $\begin{array}{l}0.0135 \\
0.0130-0.0138\end{array}$ & $\begin{array}{l}0.0191 \\
0.0185-0.0198\end{array}$ & $\begin{array}{l}0.0200 \\
0.0194-0.0205\end{array}$ \\
\hline Shoulder, Inches & $\begin{array}{l}\text { Avg. } \\
\text { Range }\end{array}$ & $\begin{array}{l}0.050 \\
0.048-0.051\end{array}$ & $\begin{array}{l}0.051 \\
0.050-0.052\end{array}$ & $\begin{array}{l}0.033 \\
0.032-0.034\end{array}$ & $\begin{array}{l}0.066 \\
0.064-0.069\end{array}$ & $\begin{array}{l}0.052 \\
0.051-0.052\end{array}$ & $\begin{array}{l}0.050 \\
0.050-0.051\end{array}$ \\
\hline Taper Dimensions (2) & & & & . & & & \\
\hline Length, Inches & $\begin{array}{l}\text { Avg. } \\
\text { Range }\end{array}$ & None & 0.132 & $\begin{array}{l}0.144 \\
0.116-0.162\end{array}$ & $\begin{array}{l}0.151 \\
0.122-0.182\end{array}$ & $\begin{array}{l}0.144 \\
0.131-0.159\end{array}$ & None \\
\hline Deptbr, Incheç & $\begin{array}{l}\text { Avg. } \\
\text { Ranqe }\end{array}$ & None & $\begin{array}{l}0.0026 \\
0.0022-0.0029\end{array}$ & $\begin{array}{l}0.0025 \\
0.00: 1-0.0029\end{array}$ & $\begin{array}{l}0.0038 \\
0.0031-0.0044\end{array}$ & $\begin{array}{l}0.0028 \\
0.0023-0.00312\end{array}$ & None \\
\hline Pellet Density, क TD & $\begin{array}{l}\text { Ave. } \\
\text { Range }\end{array}$ & $99.019-99.0$ & $\begin{array}{l}96.5 \\
95.9-96.9\end{array}$ & $\begin{array}{l}97.8 \\
97.6-98.0\end{array}$ & $\begin{array}{l}93.4 \\
98.2-98.5\end{array}$ & $\begin{array}{l}96.3 \\
95.9-96.3\end{array}$ & 99.0 \\
\hline Pellet Composition & & $\mathrm{ThO}_{2}$ & $\begin{array}{l}\mathrm{ThO}_{2}-3.10 \mathrm{w} / 0 \\
\mathrm{UEO}_{2}\end{array}$ & $\begin{array}{l}\mathrm{ThO}_{2}-3.02 \mathrm{w} / 0 \\
\mathrm{UE}_{2} \\
\mathrm{ThO}_{2}-3.09 \mathrm{w} / 0 \\
\mathrm{U}^{\mathrm{E} \mathrm{O}_{2}}\end{array}$ & $\begin{array}{l}\mathrm{ThO}_{2}-3.08 \mathrm{w} / 0 \\
\mathrm{U}^{\mathrm{E}} \mathrm{O}_{\mathrm{C}}\end{array}$ & $\begin{array}{l}\mathrm{ThO}_{2}-3.10 \mathrm{w} / 0 \\
\mathrm{UE}_{2}\end{array}$ & $\mathrm{ThO}_{2}$ \\
\hline
\end{tabular}

(i) See Figure III-7 for definition of pellet zones

(z) Digh and taper dimensions are as shown:

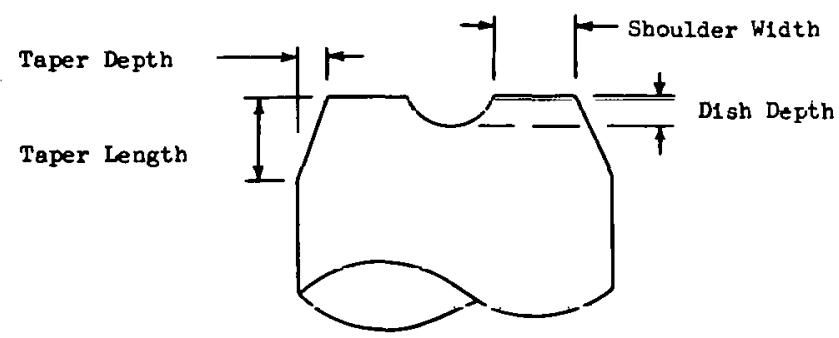




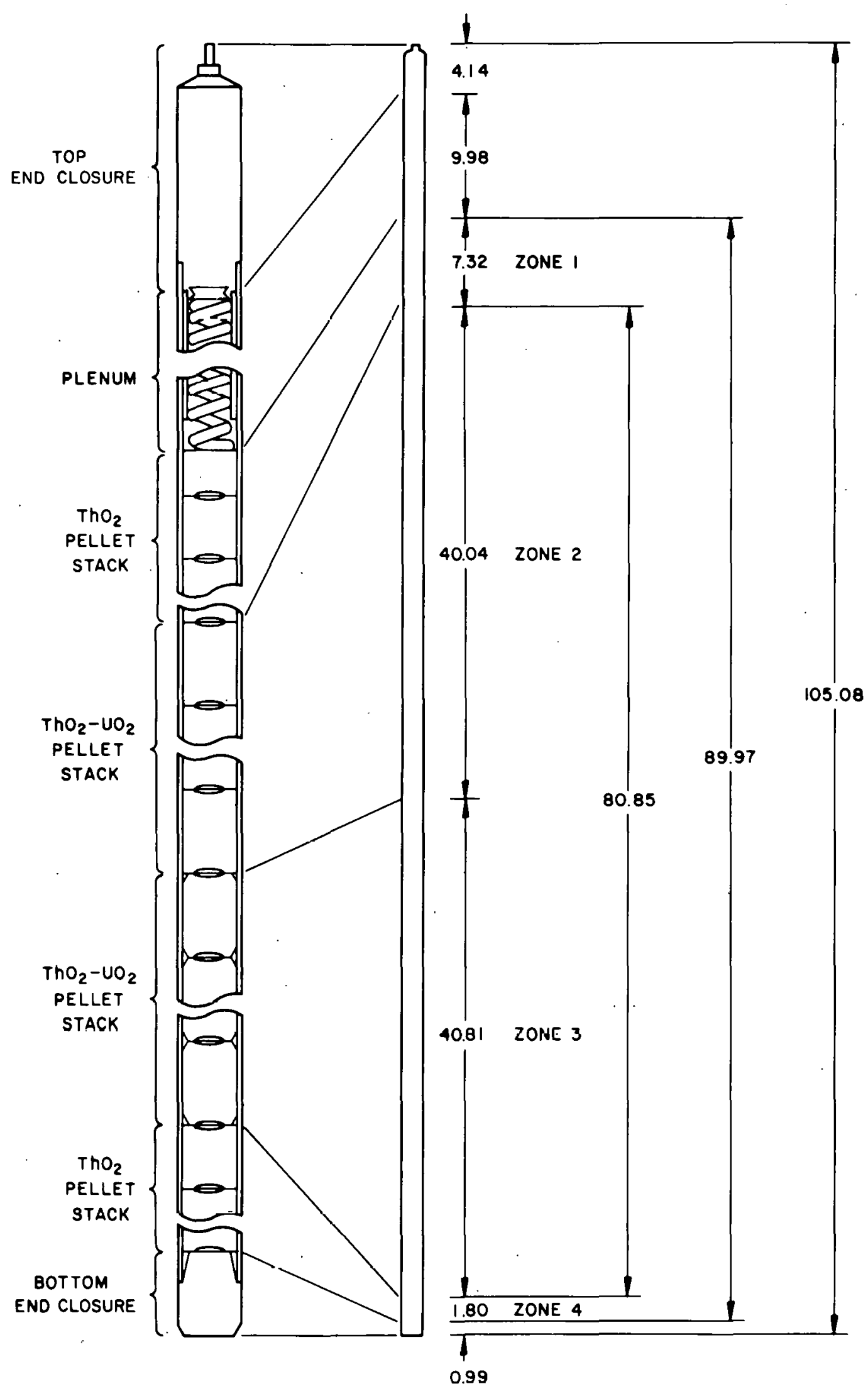

Figure III-8. Internal Layout and As-Built Lengths for Tressurized/Graphitc Coated Rod 79-707 


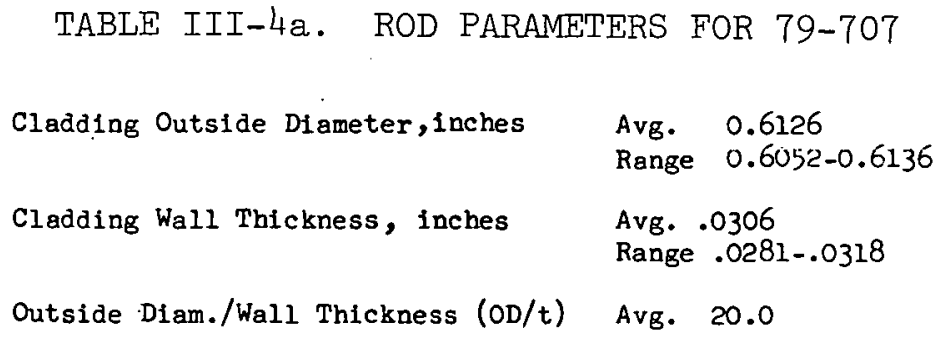

TABLE III-4b. PELLET-CLADDING GAP AND PELLET PARAMETERS FOR 79-707

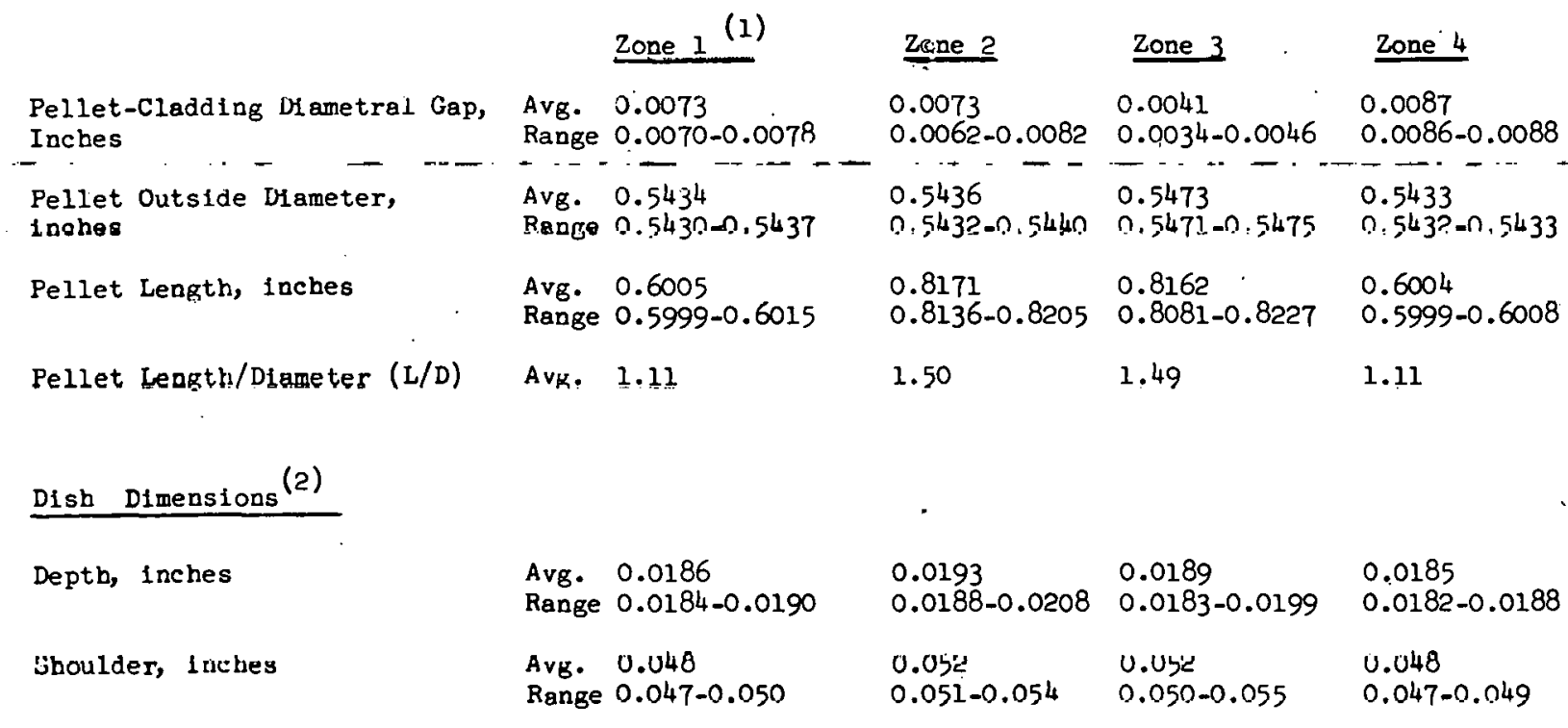

Taper D1mensions

(2)

Length, Inches

Depth, Inches

Pellet Density, क TD

Pellet Composition
Avg. None

Range

Avg. None Rạnge

Avg. 98.9 Range 98.9-99.0

$\mathrm{ThO}_{2}$

$\begin{array}{lll}\text { None } & 0.133 & \text { None } \\ & 0.108-0.153 & \\ \text { None } & 0.0025 & \text { None } \\ & 0.0019-0.0030 & \end{array}$

$96.4 \quad 96.4 \quad 98.9$

$95.5-97.5 \quad 95.4-97.0 \quad 98.9-99.0$

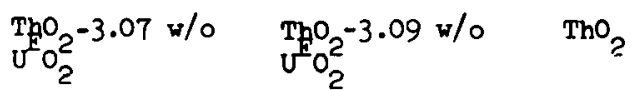

(1) See Figure III-8 for definition of pellet zones

(2) Dish and taper dimensions are as shown:

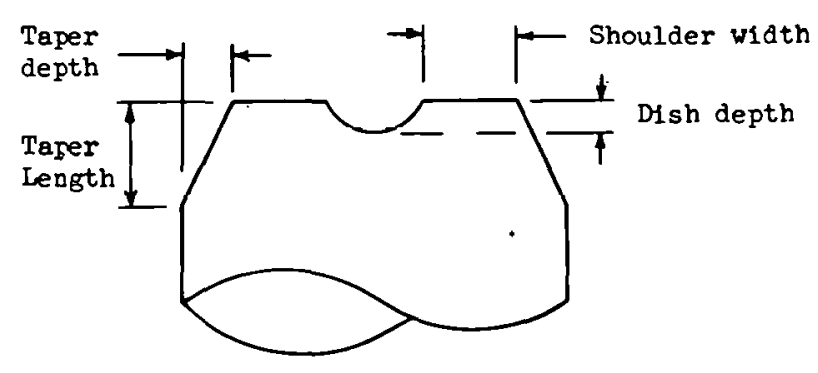




\section{Comparison of Pre-Pressurized, Coated and Unpressurized, Uncoated Rods}

Table III-5 presents a comparison of the principal physical characteristics of the five test rods which are discussed in sections IV and $V$ comparing irradiation histories and dimensional examination results. Other than prepressurization and graphite coating, the only other significant rod to rod variable is the fuel-cladding diametral gap with rods 79-706 and 79-583D having gaps in the range of 4 to 5 mils while the remaining rods have regions of $4-m i l$ and 7-to 8-mil gaps. Unpressurized, uncoated rod 79-587 and pre-pressurized, graphite coated rod 79-707 are the most directly comparable rods as both have the smaller fuel-cladding gap in the bottom half of the fuel stack and the larger fuel-cladding gap in the top half. 


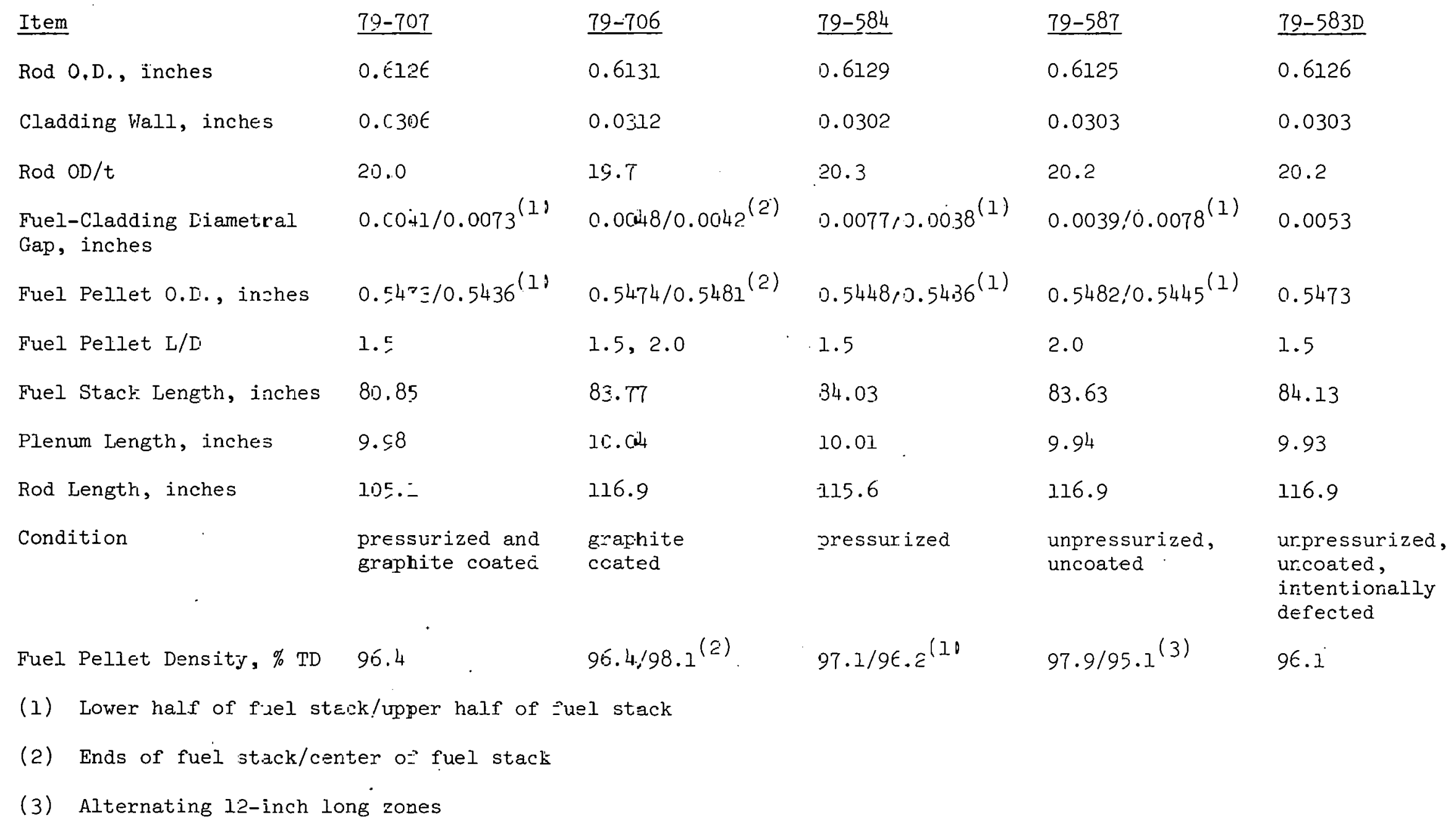


IV. TEST POWER AND TEMPERATURE CONDITIONS

\section{A. Operating Power History}

1. Basis

The test operation power versus depletion history for the test rods is based on a typical expected power history for LWBR except for the overpower transient and is shown in Figure $T V-1$. The sequence of testing was to irradiate

the fuel rod for about $100 \mathrm{full}$ power days to a depletion of about $1.1 \times 10^{20} \mathrm{f} / \mathrm{cc}$ and a fast fluence of about $1.4 \times 10^{20} \mathrm{n} / \mathrm{cm}^{2}$. Following this irradiation, the power was increased by approximately 30 percent to simulate the increased power in an overpower transient incident. The increased power was maintained for a full NRX cycle (about 40 days) to avoid the loss of irradiation time consumed in a reactor shutdown and startup.

Four of the five rods were subjected to the up-power maneuver; the intentionally defected rod 79-583D was not transient tested.

2. Uranium-235 Loading

Nuclear calculations were performed to determine the initial loading of $0.91 \mathrm{gm}$ of U-235 per inch of pellet length. The $\mathrm{UO}_{2}$ was highly enriched to $93.16 \mathrm{w} / \mathrm{O}-235$ in U-total. Based on the nominal density of 95 percent TD, the $\mathrm{UO}_{2}-\mathrm{ThO}_{2}$ pellets contain 3.06.w/o $\mathrm{UO}_{2}$ in thoria.

\section{Reactor Operation}

The actual power histories for the four rods that experienced the up-power maneuver are shown in Figures IV-2 through IV-5 and compared to the desired history. The pressurized rod, 79-584 (Figure IV-2) and the unpressurized, uncoated rod, 79-587 (Figure IV-5) had additional irradiation. It is noted that rod 79-587 did not match the desired history as well as the other three rods. This was due to operating constraints existing in the NRX reactor at that time.

The operation of the intentionally defected rod, 79-583D, that did not have an up-power maneuver is shown in Figure IV-6. Rod 79-583D was irradiated to a depletion of $1.9 \times 10^{20} \mathrm{f} / \mathrm{cc}$. 
$\stackrel{\infty}{\infty}$

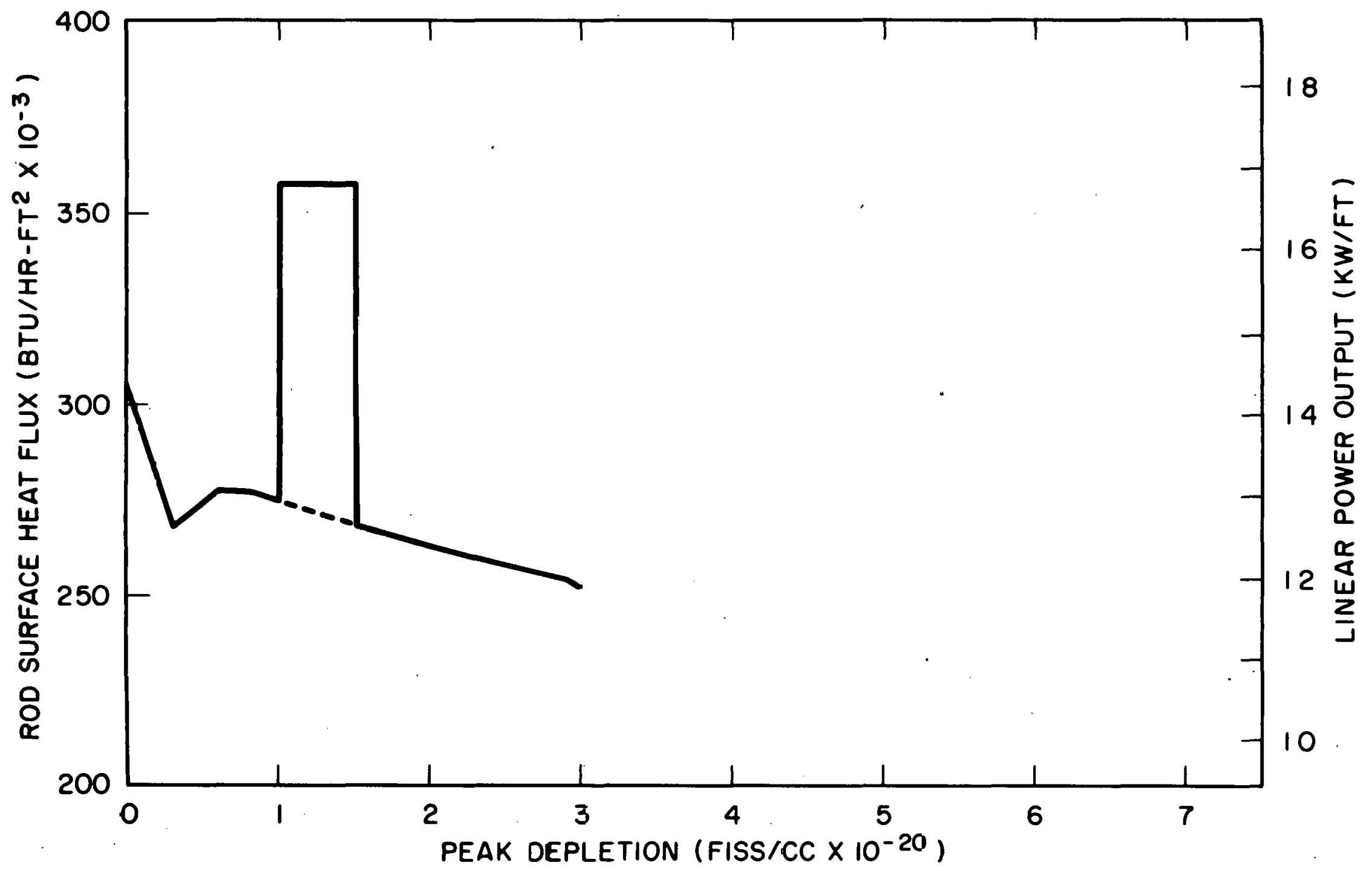

Figure IV-1. Heat Flux-Depletion History 


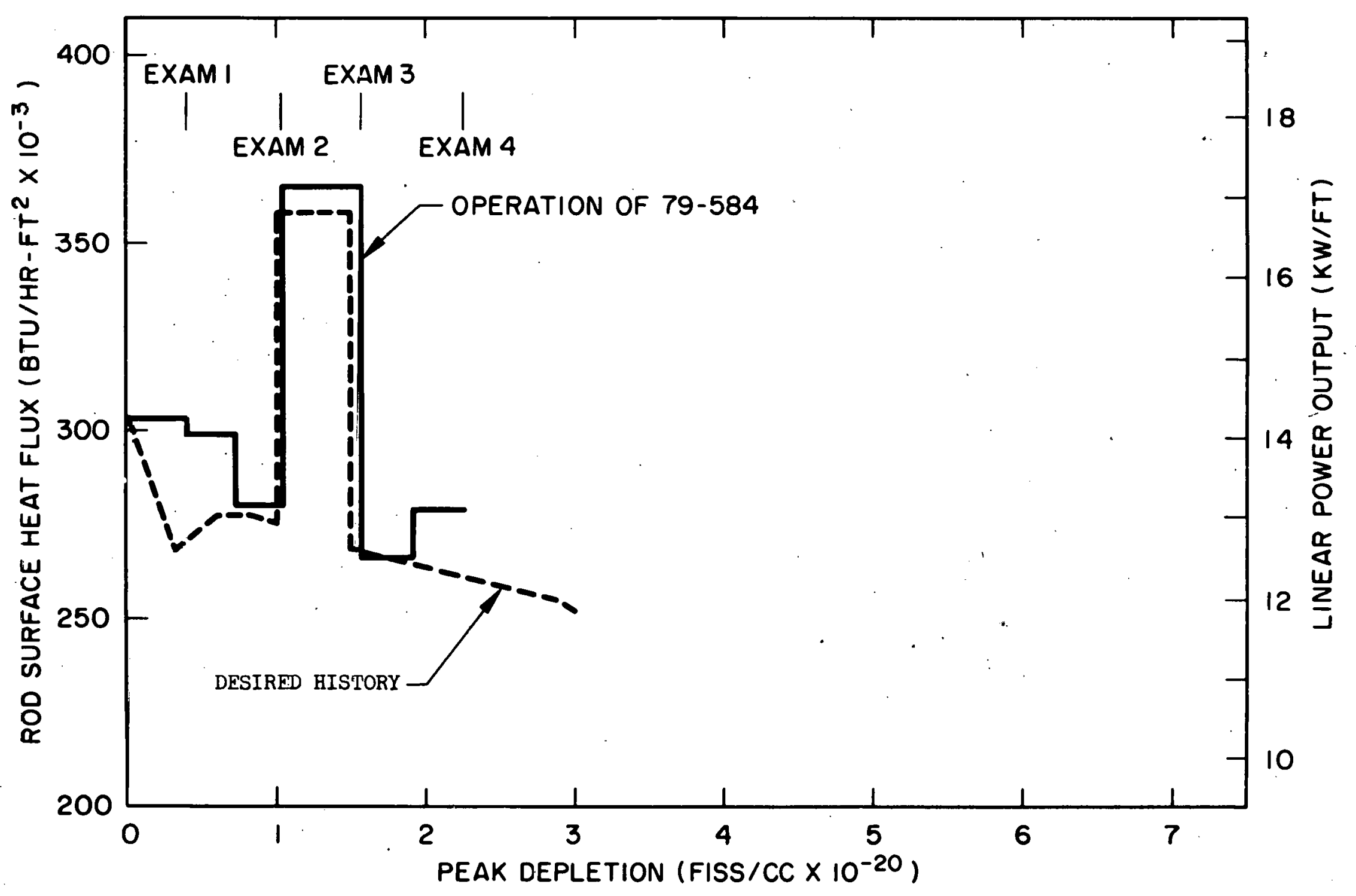




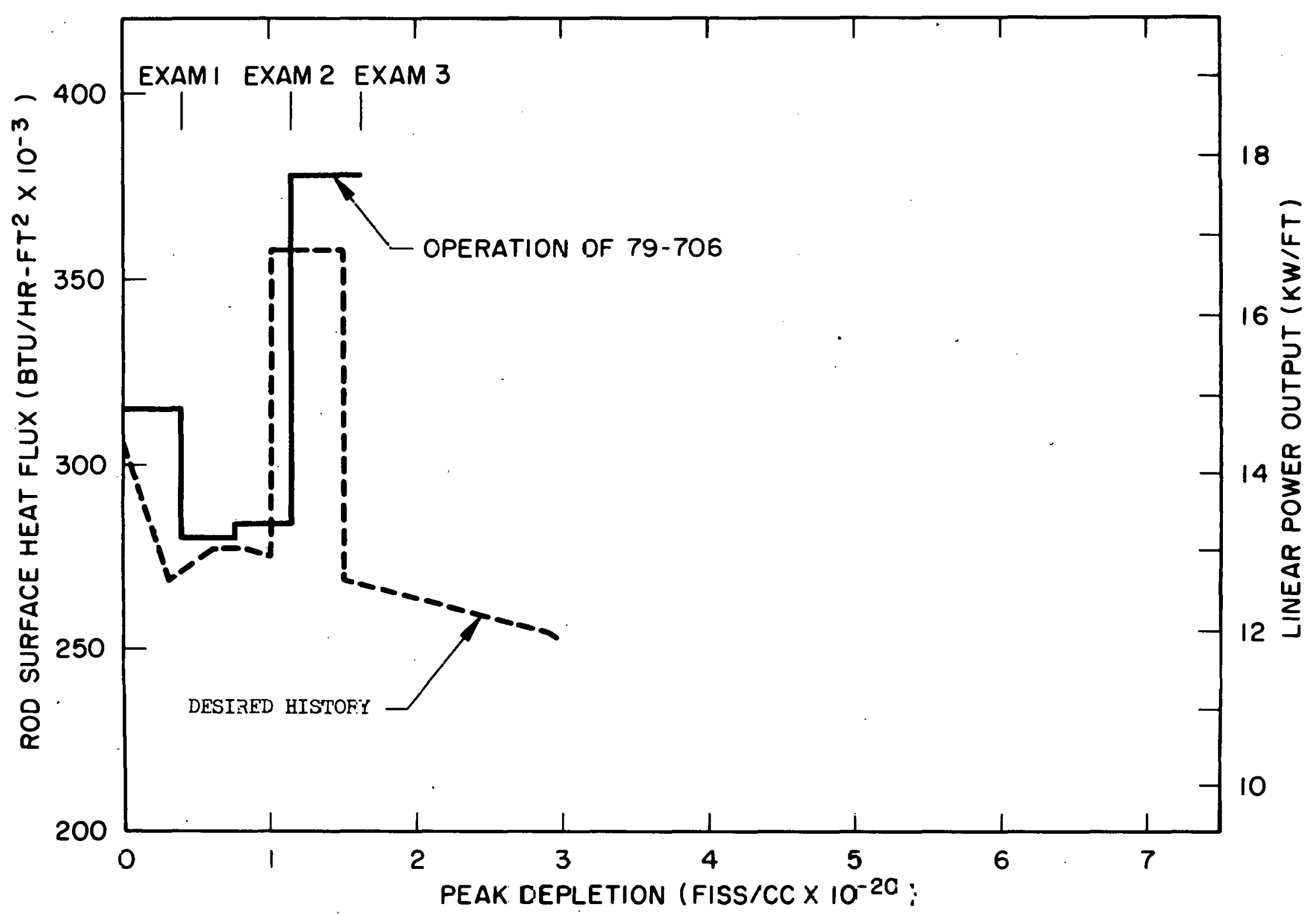

Figure IJ-3. Graphite Coated Rod 79-706 Heat Flux-Le:-letion History 


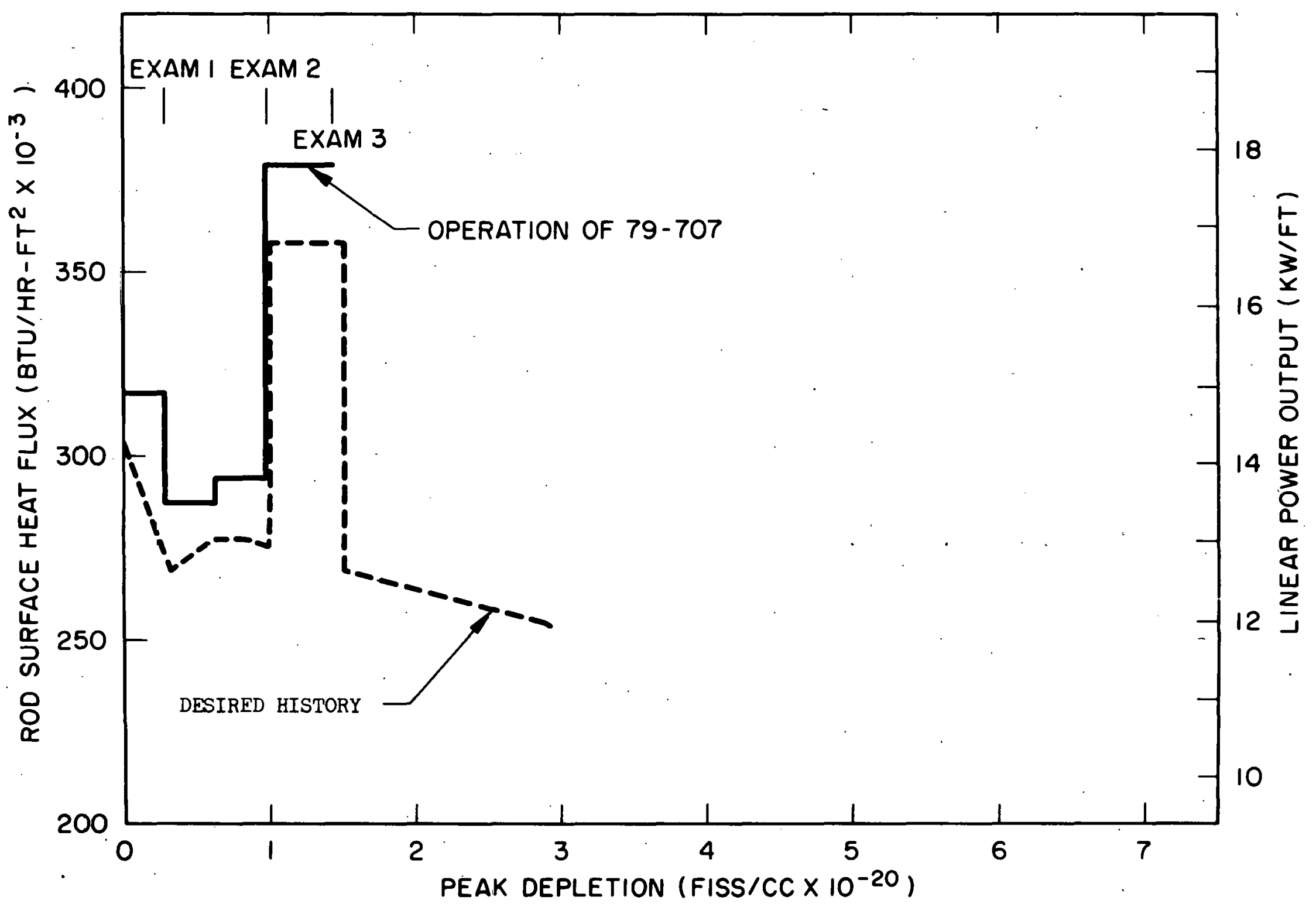


$\stackrel{w}{N}$

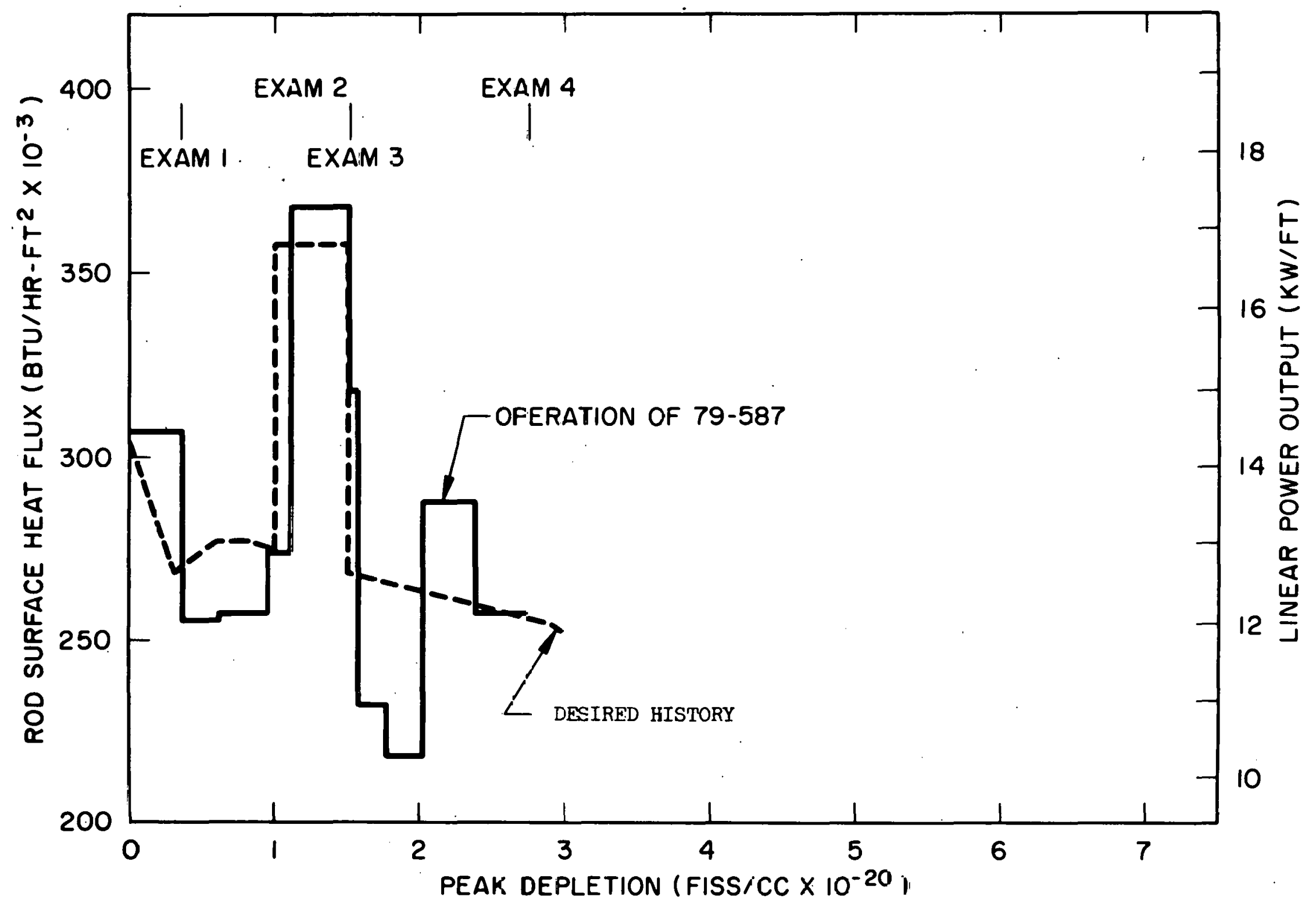

Figure IV-5. Unpressurized, Uncoated Rod 79-58- Həat Flux-Lepletion History 


\section{B. Fuel Rod Temperatures}

Temperature calculations were carried out with the CYGRO program, Reference 2. Modeling techniques and input parameters were, in general, those qualified for analysis of the LWBR Core Design.

The cycle average centerline temperature, depletion and fluence for the pre-pressurized, graphite coated rods shown in Figure IV-2, -3 , and -4 are given in Table IV-1. Similar information for the unpressurized, uncoated rods is given in Table IV- 2 . 


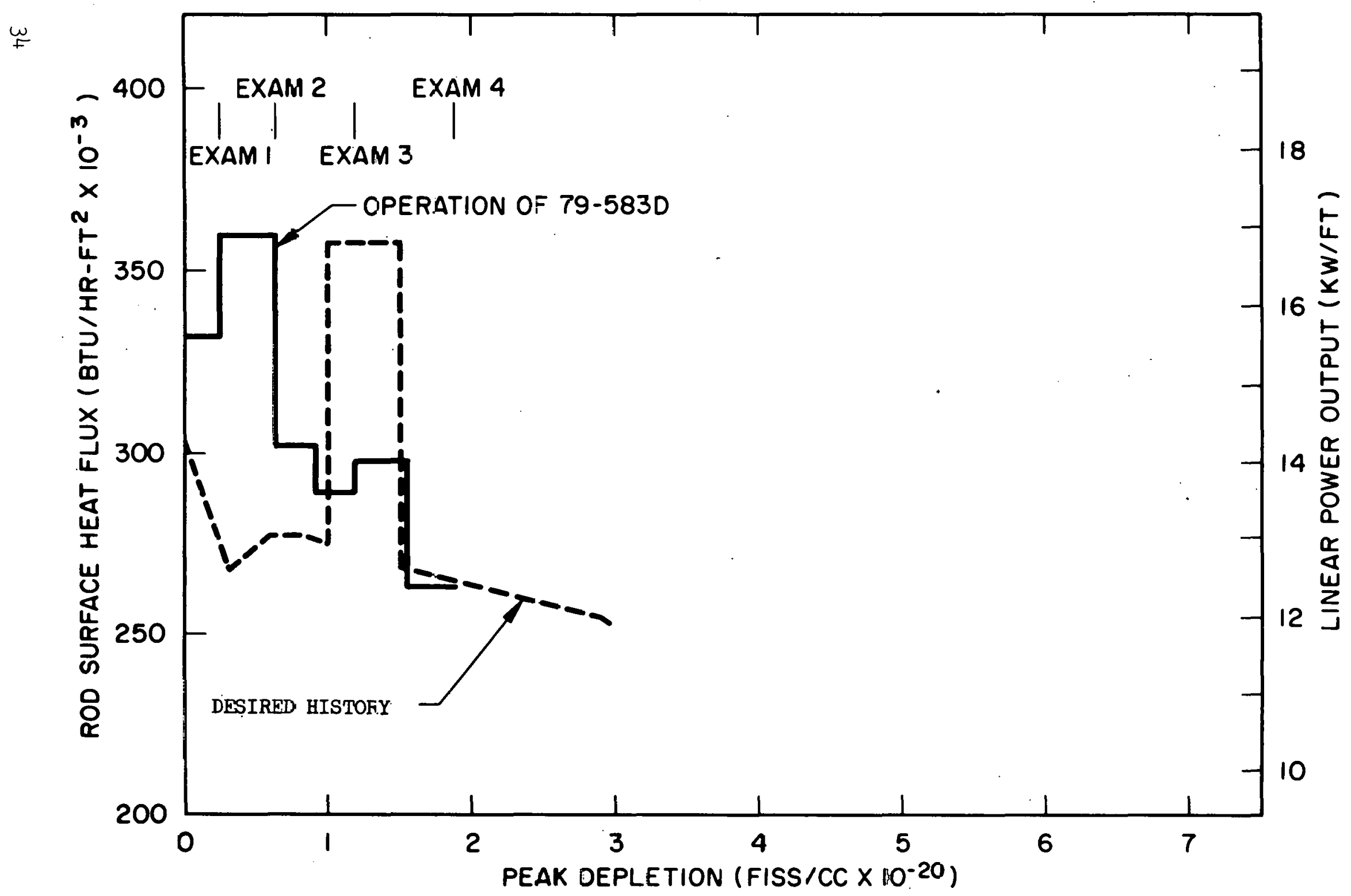

Figure. IV-Б́. Inten广ionally Defected Roc Tร-583D Heat Flux-Deplesion History 
TABLE IV-1. OPERATING CONDITIONS FOR PRE-PRESSURIZED, GRAPHITE COATED RODS

\begin{tabular}{|c|c|c|c|c|c|c|}
\hline Rod & Cycle & $\begin{array}{l}\text { Cumulative } \\
\text { Hours }\end{array}$ & $\begin{array}{l}\text { Heat Flux } \\
\mathrm{BTU} / \mathrm{hr}-\mathrm{ft}^{2} \times 10-3\end{array}$ & $\begin{array}{l}\text { Center } \\
\text { Temp. }{ }^{\circ} \text { F }\end{array}$ & $\begin{array}{l}\text { Depletion } \\
\text { f/cc } \times 10-20 \\
\end{array}$ & $\begin{array}{r}\text { Fluence } \\
\mathrm{n} / \mathrm{cm}^{2} \times 10^{-20}\end{array}$ \\
\hline $\begin{array}{l}79-584 \\
\text { (Pressurized) }\end{array}$ & $\begin{array}{l}1 \\
2 \\
3 \\
4 \\
5 \\
6\end{array}$ & $\begin{array}{l}1000 \\
1820 \\
2660 \\
3820 \\
4840 \\
5820\end{array}$ & $\begin{array}{l}303 \\
299 \\
280 \\
365 \\
266 \\
279\end{array}$ & $\begin{array}{l}2630 \\
2620 \\
2470 \\
3220 \\
2350 \\
2470\end{array}$ & $\begin{array}{l}0.39 \\
0.72 \\
1.03 \\
1.56 \\
1.91 \\
2.26\end{array}$ & $\begin{array}{l}0.49 \\
0.80 \\
1.28 \\
1.95 \\
2.40 \\
2.85\end{array}$ \\
\hline $\begin{array}{l}79-706 \\
\text { (G-aphite } \\
\text { coated) }\end{array}$ & $\begin{array}{l}1 \\
2 \\
3 \\
4\end{array}$ & $\begin{array}{r}950 \\
1980 \\
3050 \\
4040\end{array}$ & $\begin{array}{l}315 \\
280 \\
284 \\
378\end{array}$ & $\begin{array}{l}2720 \\
2440 \\
2480 \\
3260\end{array}$ & $\begin{array}{l}0.38 \\
0.75 \\
1.14 \\
1.62\end{array}$ & $\begin{array}{l}0.48 \\
0.95 \\
1.45 \\
2.04\end{array}$ \\
\hline $\begin{array}{l}79-707 \\
\text { (Pressurized, } \\
\text { graphite } \\
\text { coated) }\end{array}$ & $\begin{array}{l}1 \\
2 \\
3 \\
4\end{array}$ & $\begin{array}{r}680 \\
1600 \\
2530 \\
3460\end{array}$ & $\begin{array}{l}317 \\
287 \\
294 \\
379\end{array}$ & $\begin{array}{l}2790 \\
2530 \\
2600 \\
3400\end{array}$ & $\begin{array}{l}0.28 \\
0.62 \\
0.97 \\
1.43\end{array}$ & $\begin{array}{l}0.3 .5 \\
0.78\end{array}$ \\
\hline
\end{tabular}


TABLE IV-2. OPERATING CONDITIONS FOR UNPRESSURIZED, UNCOATED RODS

\begin{tabular}{|c|c|c|c|c|c|c|}
\hline$\underline{\text { Rod }}$ & Cycle & $\begin{array}{l}\text { Cumulative } \\
\text { Hours } \\
\end{array}$ & $\begin{array}{l}\text { Heat Flux } \\
\text { BTU/hr-ft } 2 \times 10-3\end{array}$ & $\begin{array}{l}\text { Center } \\
\text { Temp. }{ }^{\circ} \mathrm{F} \\
\end{array}$ & $\begin{array}{l}\text { Depletion } \\
\mathrm{f} / \mathrm{cc} \times 10^{-20} \\
\end{array}$ & $\begin{array}{l}\text { Fluence } \\
\mathrm{n} / \mathrm{cm}^{2} \times 10-20 \\
\end{array}$ \\
\hline $\begin{array}{l}\text { 79-583D } \\
\text { (Intention- } \\
\text { ally defected) }\end{array}$ & $\begin{array}{l}1 \\
2 \\
3 \\
4 \\
5 \\
6\end{array}$ & $\begin{array}{r}590 \\
1400 \\
2130 \\
2890 \\
3830 \\
4820\end{array}$ & $\begin{array}{l}332 \\
360 \\
302 \\
289 \\
298 \\
263\end{array}$ & $\begin{array}{l}3240 \\
3290 \\
3170 \\
3020 \\
3130 \\
2740\end{array}$ & $\begin{array}{l}0.25 \\
0.63 \\
0.91 \\
1.19 \\
1.55 \\
1.88\end{array}$ & $\begin{array}{l}0.31 \\
0.77 \\
1.13 \\
1.49 \\
1.95 \\
2.38\end{array}$ \\
\hline $\begin{array}{l}(9-587 \\
\text { (Uncoated, } \\
\text { unpressurized) }\end{array}$ & $\begin{array}{r}1 \\
2 \\
3 \\
4 \\
5 \\
6 \\
7 \\
8 \\
9 \\
10\end{array}$ & $\begin{array}{r}910 \\
1750 \\
2720 \\
3160 \\
3990 \\
4120 \\
4800 \\
5690 \\
6670 \\
7750\end{array}$ & $\begin{array}{l}307 \\
255 \\
257 \\
274 \\
368 \\
312 \\
232 \\
218 \\
288 \\
257\end{array}$ & $\begin{array}{l}2660 \\
2250 \\
2260 \\
2400 \\
3180 \\
2710 \\
2060 \\
1970 \\
2500 \\
2260\end{array}$ & $\begin{array}{l}0.36 \\
0.62 \\
0.95 \\
1.11 \\
1.52 \\
1.57 \\
1.77 \\
2.02 \\
2.38 \\
2.75\end{array}$ & $\begin{array}{l}0.45 \\
0.81 \\
1.23 \\
1.43 \\
1.91 \\
1.97 \\
2.21 \\
2.57 \\
3.03 \\
3.49\end{array}$ \\
\hline
\end{tabular}

\section{EXAMINATION RESULTS}

During irradiation testing, the rods were periodically removed from the reactor and examined at the Chalk River Nuclear Laboratory. These examinations included measurement of overall rod length; incremental rod length, and rod diameters. The rods were visually examined for. surface corrosion appearance and to detect any surface abnormalities. After irradiation, the five rods discussed in this report all exhibited the shiny, black, oxide appearance typical of corrosion tested Zircaloy, and no abnormalities were seen. Discussion of dimensional measurement techniques and results are given below.

\section{A. Overall Length Measurements}

\section{Measurement Technique}

Uverall rod length measurements are performed using a dial indiculor. to determine the difference in length between the fuel rod and a stainless steel standard rod. The dial indicator reads 0.100 inch per revolution and is graduated in 0.001 -inch increments. It is capable of measuring over a range of 0 to 2 inches. The standard length is 116.8755 inches at $76^{\circ} 3^{\circ} F^{\circ}$ compared to the pre-irradiation rod lengths ranging from 115.6 to 116.9 inches. A Zircaloy standard rod of shorter length ( 105.1671 inches at $69.5^{\circ} \mathrm{F}$ ) was used for rod 79-707 only, to match the shorter overall length. The standard lengths were 
measured in a controlled atmosphere gage laboratory at Bettis using a Pratt \& Whitney Measuring Machine accurate to \pm 0.0002 inches. This accuracy is maintained by yearly calibration using gage blocks which are themselves calibrated every two years by the National Bureau of Standards.

Two readings are taken on each fuel rod at specified orientations $90^{\circ}$ apart. This $90^{\circ}$ rotation reduces the effects of any non-perpendicularity of the rod end surfaces and the contacting surfaces. The ambient hot cell temperature and the rod surface temperature at the time of the length measurements are recorded to permit correction for temperature differences from the pre-irradiation measurements. The accuracy of these dial gage length measurements is \pm 0.003 inch which is twice the standard deviation (2a) determined from repeatability studies.

\section{Results}

Rod overall length changes were calculated by comparing the dial gage measurements obtained at the periodic examinations to pre-irradiation measurements also obtained at Chalk River. These length changes are presented in Table $V-1$, and a plot of the length changes normalized to the fuel stack length. $(\Delta \mathrm{L} / \mathrm{L}$ fuel stack, percent) versus peak depletion is given in Figure V-l. Based upon the \pm 0.003 -inch accuracy per measurement, the overall length changes are accurate to \pm 0.004 inch (RMS). This is less than 0.005 percent $\Delta \mathrm{L} / \mathrm{L}$ for the 84-inch long fuel stacks and is an acceptable level of accuracy for these data.

Due to variations in NRX cycle length and occasional unexpected reactor shutdowns, the examinations of the five rods did not occur at the same intervals of time or depletion. Direct examination-by-examination comparisons of the data do not take into account these differences in irradiation time between examinations. Thus, to assist in interpretation and comparison of the data, the individual data points of each rod plotted in Figure V-l have been joined by dashed lines. These lines do not necessarily represent the behavior of the rods between examinations, but serve to illustrate the trends in observed length increase with continuing irradiation for each rod.

As seen in Figure $\mathrm{V}-1$, based upon the results of the first examination the combination of pre-pressurization and graphite coating has reduced overall length increase as seen by the 0.04 percent $\Delta \mathrm{L} / \mathrm{L}$ measured for $79-707$ (similar 
TABLE V-l. ROD OVERALL LENGTH CHANGES FOR

THE FIVE TEST RODS

\begin{tabular}{|c|c|c|c|c|c|}
\hline$\underline{\operatorname{Rod}}$ & $\begin{array}{c}\text { Cumulative } \\
\text { Exposure } \\
\text { (EFPH) } \\
\end{array}$ & $\begin{array}{c}\text { Peak } \\
\text { Depletion } \\
\left(\mathrm{f} / \mathrm{cc} \times 10^{-20}\right) \\
\end{array}$ & $\begin{array}{c}\text { Peak } \\
\text { Fast Fluence } \\
\left(\mathrm{n} / \mathrm{cm}^{2} \times 10^{-20}\right) \\
\end{array}$ & $\frac{\text { Overall }}{\text { (mils) }}$ & $\frac{\text { Length Change }}{\left(\Delta \mathrm{L} / \mathrm{L}_{2} \%\right)}$ \\
\hline $79-584$ & $\begin{array}{l}1000 \\
2660 \\
3820 \\
5820\end{array}$ & $\begin{array}{l}0.39 \\
1.03 \\
1.56 \\
2.26\end{array}$ & $\begin{array}{l}0.49 \\
1.28 \\
1.95 \\
2.85\end{array}$ & $\begin{array}{r}56 \\
84 \\
118 \\
155\end{array}$ & $\begin{array}{l}0.07 \\
0.10 \\
0.14 \\
0.18\end{array}$ \\
\hline $79-706$ & $\begin{array}{r}950 \\
3050 \\
4040\end{array}$ & $\begin{array}{l}0.38 \\
1.14 \\
1.62\end{array}$ & $\begin{array}{l}0.48 \\
1.45 \\
2.04\end{array}$ & $\begin{array}{r}56 \\
88 \\
123\end{array}$ & $\begin{array}{l}0.07 \\
0.11 \\
0.15\end{array}$ \\
\hline $79-707$ & $\begin{array}{r}680 \\
2530 \\
3450\end{array}$ & $\begin{array}{l}0.28 \\
0.97 \\
1.43\end{array}$ & $\begin{array}{l}0.35 \\
1.23 \\
1.72\end{array}$ & $\begin{array}{r}36 \\
48 \\
89\end{array}$ & $\begin{array}{l}0.04 \\
0.06 \\
0.11\end{array}$ \\
\hline $79-58 \%$ & $\begin{array}{r}910 \\
3160 \\
3990 \\
7750\end{array}$ & $\begin{array}{l}0.36 \\
1.11 \\
1.52 \\
2.75\end{array}$ & $\begin{array}{l}0.45 \\
1.43 \\
1.91 \\
3.49\end{array}$ & $\begin{array}{r}61 \\
106 \\
171 \\
212\end{array}$ & $\begin{array}{l}0.07 \\
0.13 \\
0.20 \\
0.25\end{array}$ \\
\hline $79-583 D$ & $\begin{array}{r}590 \\
1400 \\
2890 \\
4820\end{array}$ & $\begin{array}{l}0.25 \\
0.63 \\
1.19 \\
1.88\end{array}$ & $\begin{array}{r}0.31 \\
0.77 \\
1.49 \\
2.38\end{array}$ & $\begin{array}{l}24 \\
46 \\
60 \\
87\end{array}$ & $\begin{array}{l}0.03 \\
0.05 \\
0.07 \\
0.10\end{array}$ \\
\hline
\end{tabular}

to the 0.03 percent $\Delta \mathrm{L} / \mathrm{L}$ measured for the intentionally defected rod) versus the 0.07 percent $\Delta \mathrm{L} / \mathrm{L}$ measured for 79-587. Rod 79-584 (pre-pressurized) and 79-706 (graphite coated) have the same measured length increase as the unpressurized, uncoated rod.

After the first examination the pre-pressurized and graphite coated rod shows continuing improvement over the unpressurized, uncoated rod. Between the first and second examinations rod 79-707 increased in length at an average rate of 0.04 percent $\Delta \mathrm{L} / \mathrm{L}$ per $10^{20}$ fiss/cc while rod $79-587$ increased at the greater rate of 0.08 percent $\Delta \mathrm{L} / \mathrm{L}$ per $10^{20}$ fiss/cc. The intentionally defected rod 79-583D also increased at a rate of 0.04 percent $\Delta \mathrm{L} / \mathrm{L}$ per $10^{20} \mathrm{t}^{\prime} \mathrm{iss} / \mathrm{cc}$, the same as 79-707, and rods 79-584 and 79-706 increased at a rate of 0.05 percent $\Delta \mathrm{L} / \mathrm{L}$ per $10^{20} \mathrm{fiss} / \mathrm{cc}$. Thus the pre-pressurized and the graphite coated rods no longer had length increases like the unpressurized, uncoated rod, but had a rate of length increase similar to the pre-pressurized and coated rod 79-707 and 


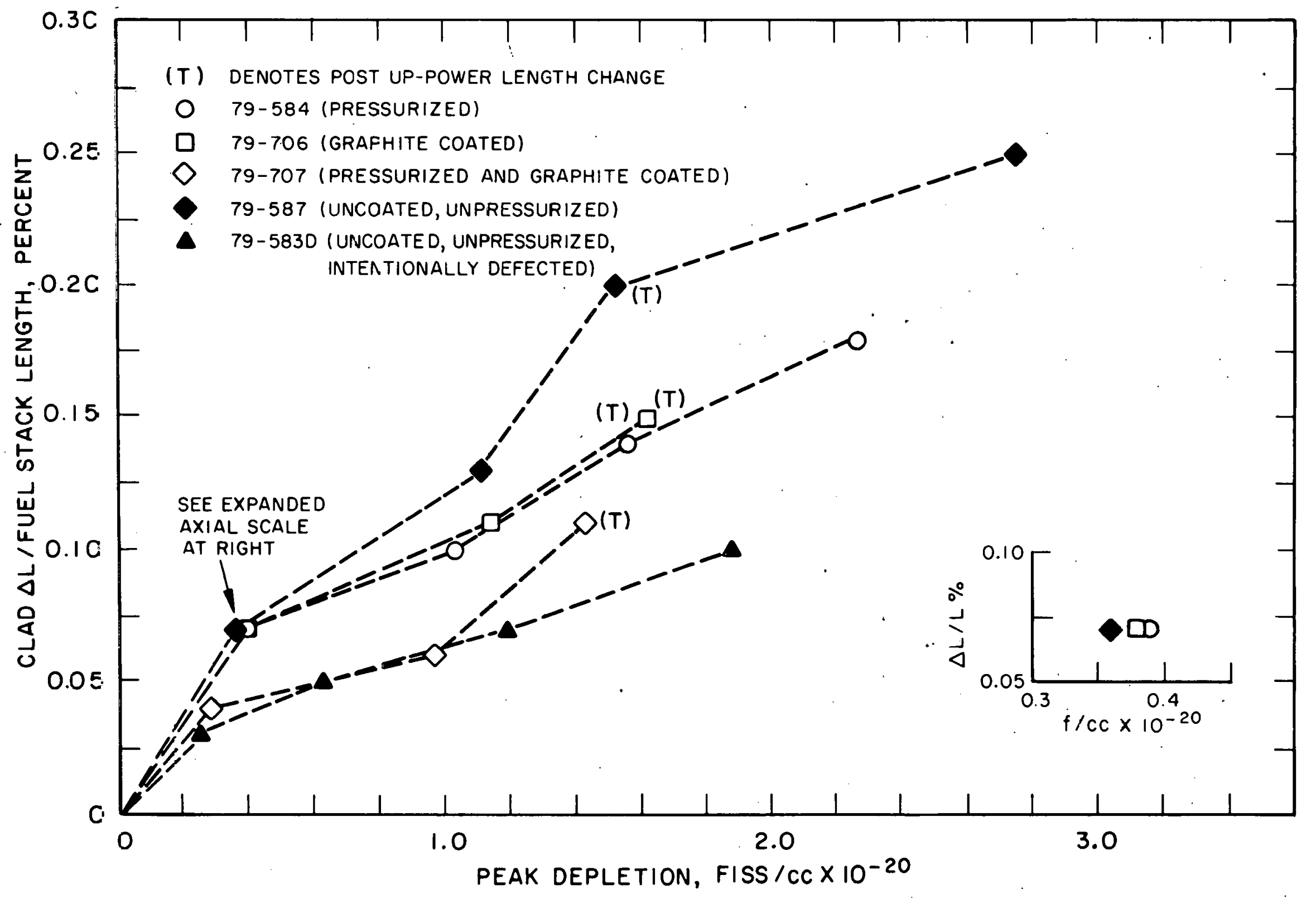


the intentionally defected rod 79-583D. Therefore, 79-706 and 79-584 continue to have greater total length increases than 79-583D and 79-707 primarily due to the differences at the first examination.

Following the up-power maneuver, rod 79-707 showed an increased slope ( 0.11 percent $\Delta \mathrm{L} / \mathrm{L}$ per $10^{20}$ fiss/ce) between its second and third examinations, while 79-583D continued unchanged in the absence of an up-power maneuver. The effect of the up-power maneuver was greater on unpressurized, uncoated rod $79-587$ as seen by the slope of 0.17 percent $\Delta \mathrm{L} / \mathrm{L}$ per $10^{20}$ fiss/cc between its second and third examinations. Neither 79-584 nor 79-706 experienced as great an effect of the up-power maneuver as 79-707, although both exhibited an increase in slope between the second and third (post up-power) examination from 0.05 to 0.08 percent $\Delta L / L$ per $10^{20}$ fiss/cc.

Following the up-power maneuver, both pre-pressurized rod 79-584 and unpressurized, uncoated rod 79-587 were operated at reduced power and experienced a reduced rate of length increase, 0.06 percent $\Delta \mathrm{L} / \mathrm{L}$ per $10^{20}$ fiss/cc for $79-534$ and 0.04 percent $\Delta \mathrm{L} / \mathrm{L}$ per $10^{20}$ fiss/cc for $79-587$.

\section{B. Incremental Length Measurements}

To measure incremental length changes over the fuel stack, fiducial marks were scribed on the cladding surface of rods 79-587, -706, and -707 at approximately 12-inch intervals over the power producing portion of the rod. These marks were 0.001 to 0.002 inch deep by 0.002 to 0.003 inch wide, $360^{\circ}$ around the rod. 'l'here were nine marks on rods $79-587$ and -707 and 10 marks on rod 79-706. Rods 79-583D and 79-584, the first two of the five rods to be fabricated, did not have these marks.

\section{Measurement Technique}

Fiducial mark spacing measurements were made at the Chalk River Nuclear laboratory using the Rod Envelope Gage (REG). This instrument, shown in Figure V-2 with a diameter measuring head in place, was designed and developed at Bettis for the dimensional inspection of fuel rods up to 10 feet in length. During fiducial mark measurements, the diameter measuring head is replaced with a television camera connected to an out of cell monitor. The camera is attached to a calibrated stainless steel lead screw and its axial location diun lie rod is determined by electronically counting revolutions of the lead screw. 


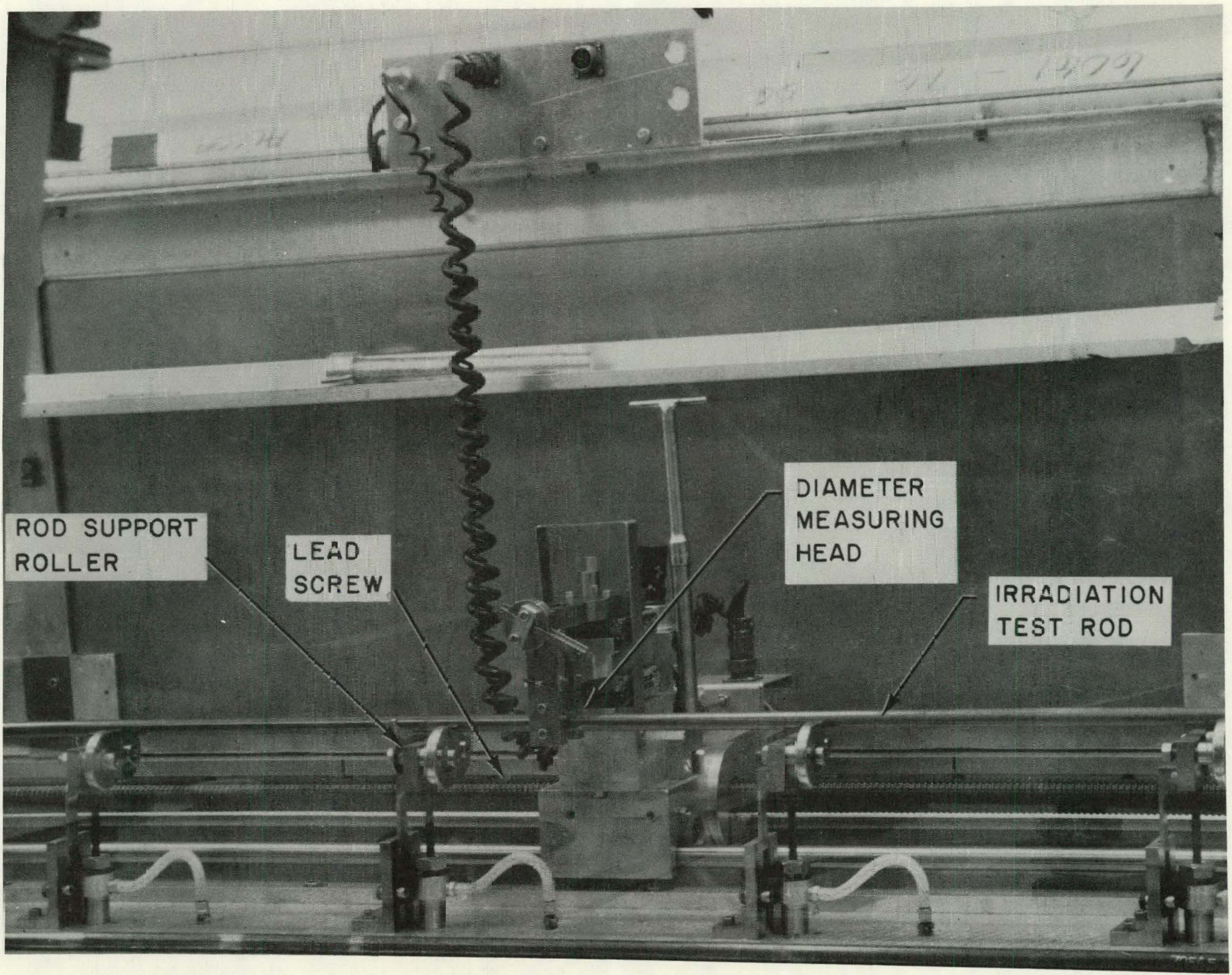

Figur $ə V-2$

Rod Envelope Gege 
When making fiducial mark measurements, the camera is focussed on the fiducial marks at a magnification of l70X. It is then centered on the mark nearest the bottom by means of a crosshair on the monitor screen and the axial position is recorded. This is repeated twice more to give a total of three readings. The camera is then moved up the rod to each succeeding mark and the process is repeated until all fiducial marks are measured. Rod surface temperature is also measured to permit correction to the pre-irradiation measurement temperature. Fiducial mark spacing changes are then calculated based upon preirradiation measurements also obtained at Chalk River using the REG. The

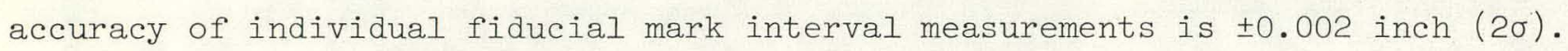
Therefore, spacing changes calculated from these measurements'are accurate to \pm 0.003 inch (RMS), and local strains calculated over 12-inch intervals are accurate to \pm 0.025 percent $\Delta \mathrm{L} / \mathrm{L}$.

\section{Axial Strain Distribution}

Figures V-3, -4 , and -5 present measured local cladding strain (expressed as percent $\Delta L / L)$ versus axial location on the fuel rod for rods $79-706,-587$, and -707 . The axial locations of the data points are at the centers of the intervals over which the strain has been calculated. Each figure includes the internal layout of the rod and the axial variation in power over the fuel stack. Data are presented for all examinations.

Comparing the behavior of prcssurized and coated rod 79-707 with that of unpressurized, uncoated rod 79-587, it is seen that 79-707 has an essentially uniform distribution of strain over the fuel stack while the local axia. cla.dding strains of 79-587 are proportional to the axial power shape with the highest strains measured in the region of power greater than 90 percent of peak. The behavior of graphite coated rod 79-706 is similar to 79-587. In both 79-587 and 79-706, the peak Local strains occur slightly above the 100 percent power location however, giving the strain distributions a slightly skewed appearance with respect to the symmetry of the axial power variation. These strain distributions are illustrated in Table V-2 which compares the average strain in the region of the fuel stack with power greater than 90 percent of peak (approximately the central 35 inches of the fuel stack) to the average strain over the rest of the fuel stack. 


\section{$\left|\mathrm{ThO}_{2}\right| \begin{gathered}\mathrm{ThO}_{2}-\mathrm{UO}_{2} \\ 4.8 \mathrm{MIL} \mathrm{GAP}\end{gathered}\left|\mathrm{ThO}_{2}-\mathrm{UO}_{2} 4.2 \mathrm{MIL} \mathrm{GAP}\right| \begin{gathered}\mathrm{ThO}_{2}-\mathrm{UO}_{2} \\ 4.8 \mathrm{MIL} \text { GAP }\end{gathered} \mid$ ThO 2 PLENUM|}
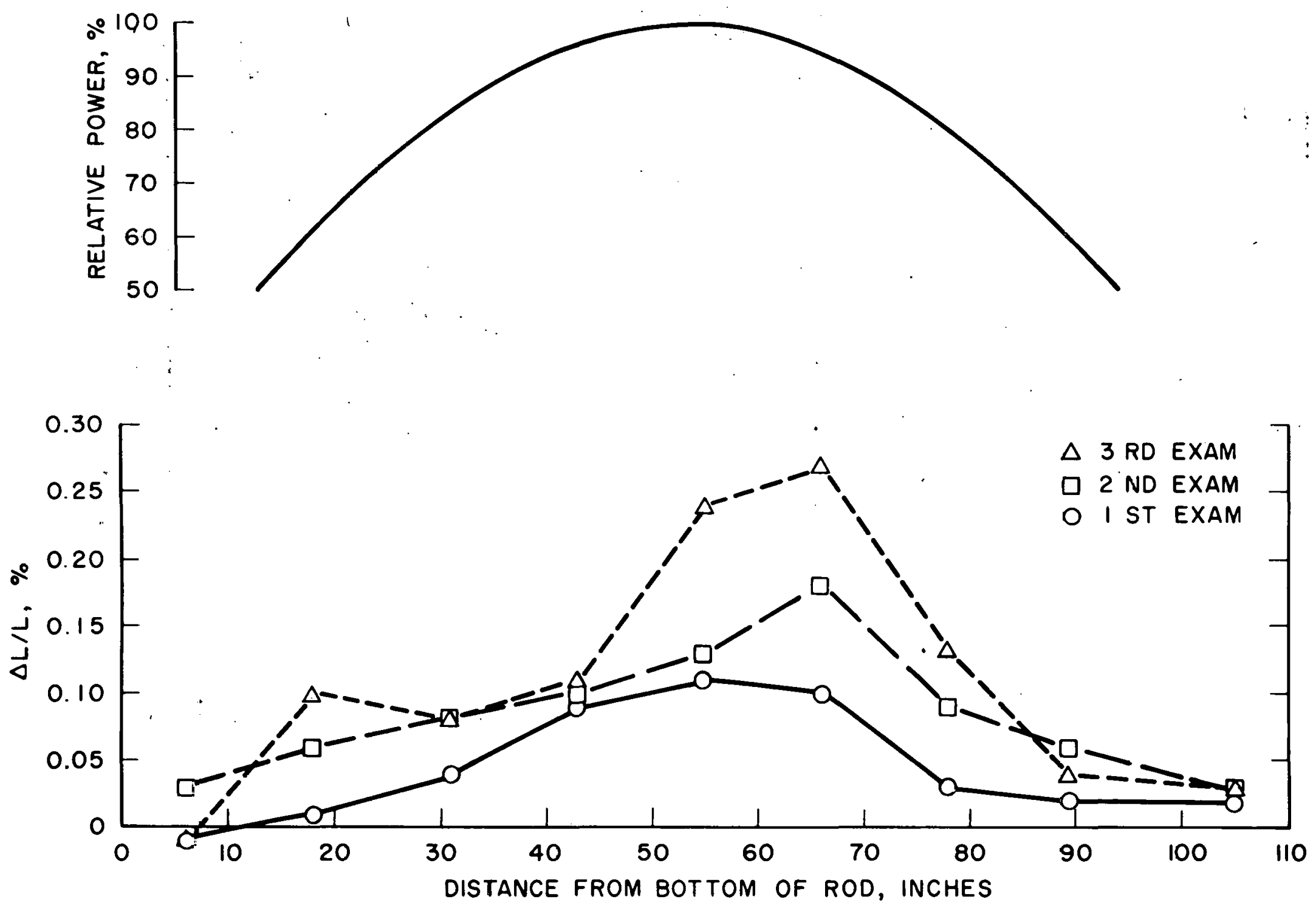

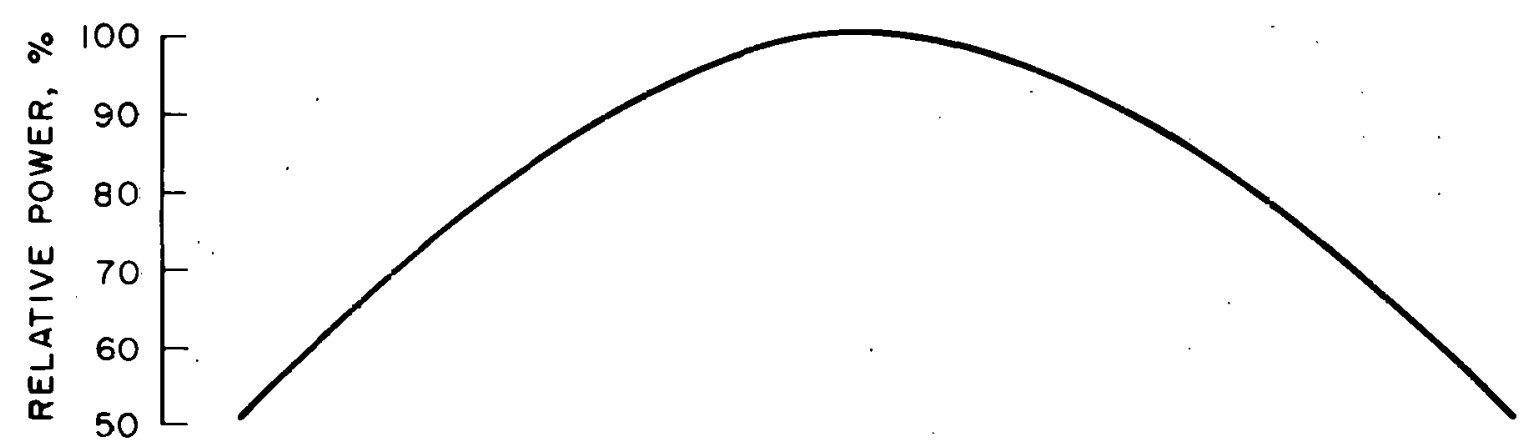

$-1$

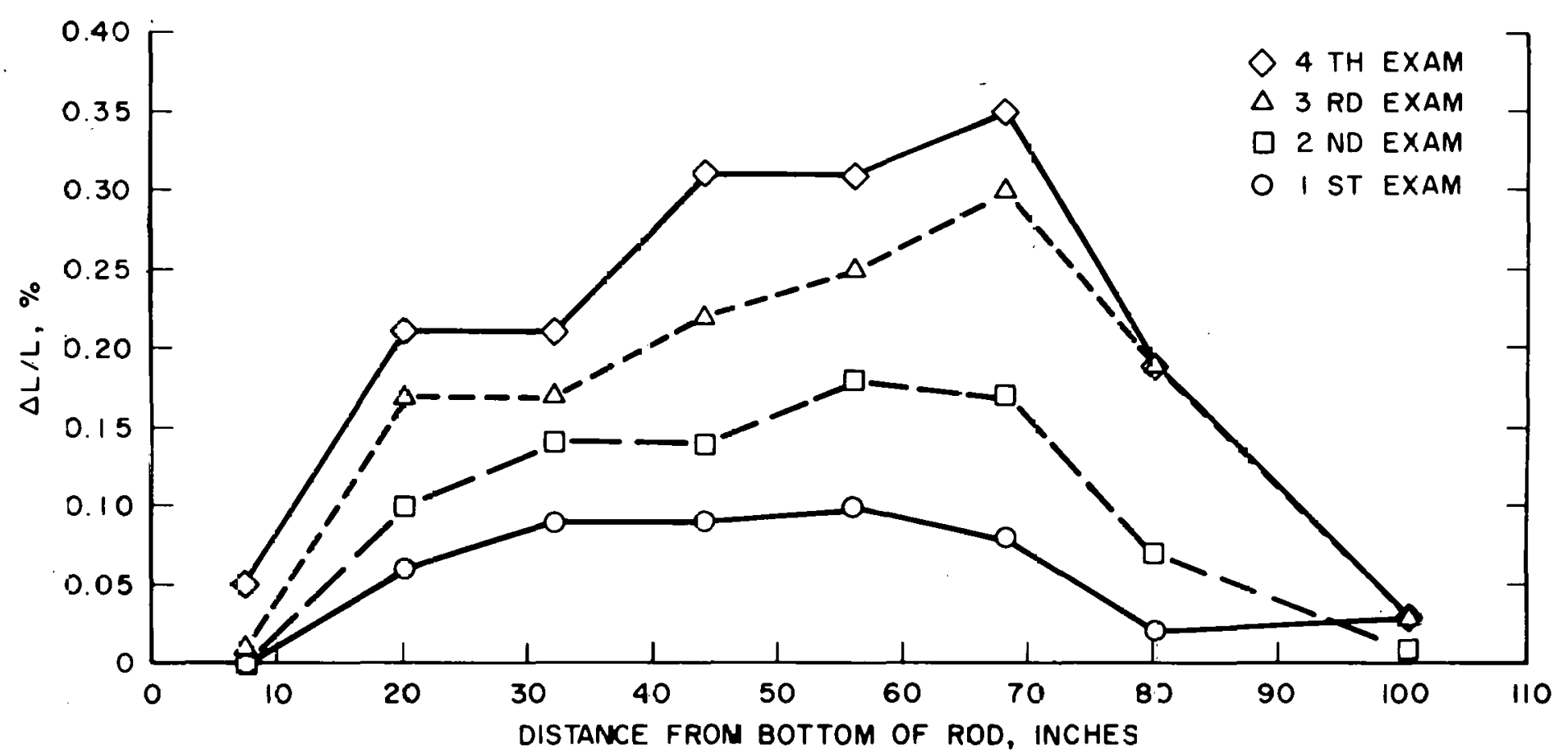

Figure V-L. Fidurial Mark Spacing, Changes Rod 79-587 


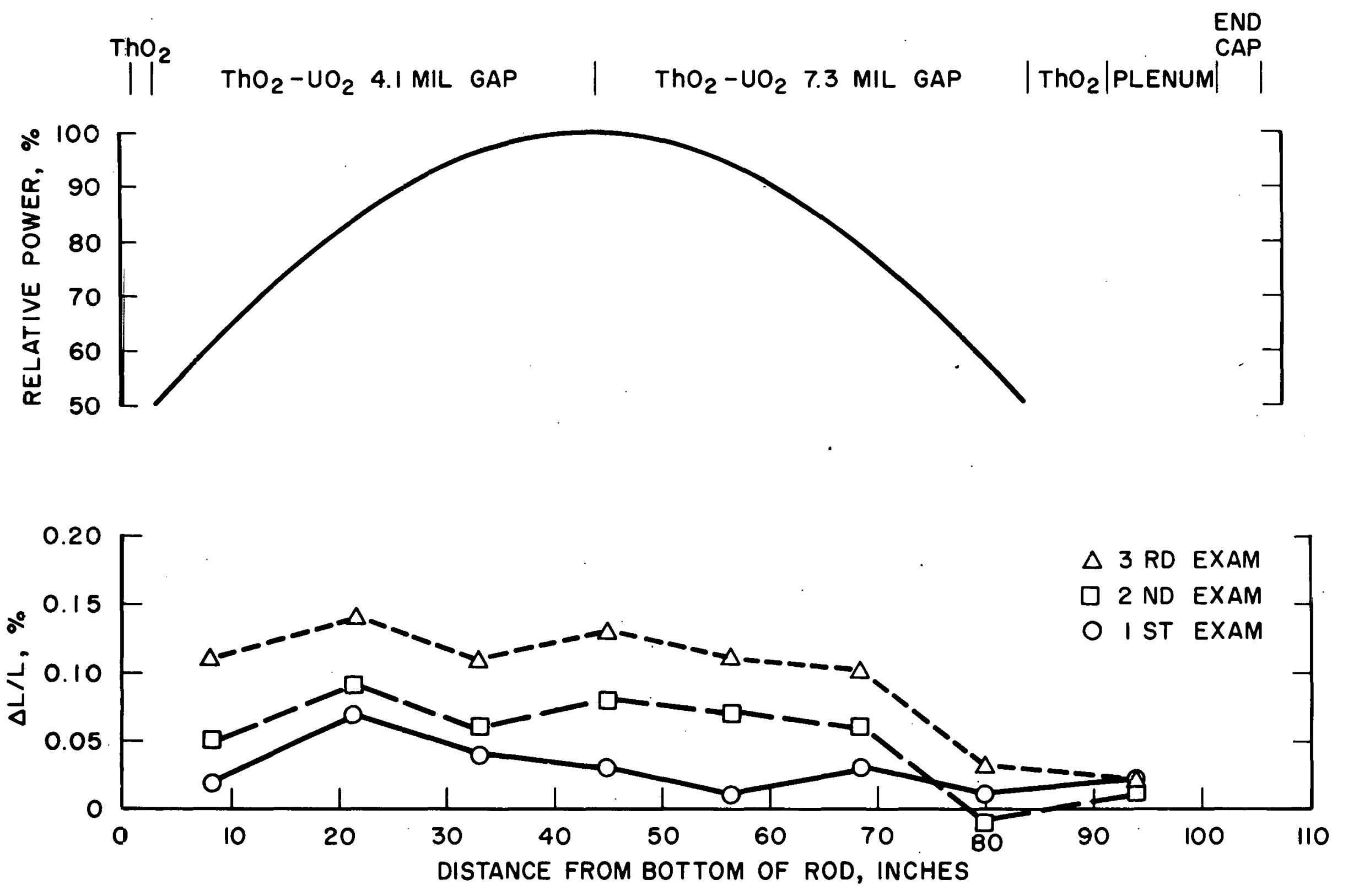


TABLE V-2. COMPARISON OF AVERAGE CLADDING AXIAL STRAINS OVER THE FUEL STACK AT POWERS ABOVE AND BELOW 90\% OF PEAK

\begin{tabular}{|c|c|c|c|}
\hline \multirow[b]{2}{*}{ Rod } & \multirow[b]{2}{*}{ Examination } & \multicolumn{2}{|c|}{ Average $\Delta \mathrm{L} / \mathrm{L}, \%$} \\
\hline & & Power >90\% & Power $<90 \%$ \\
\hline \multirow[t]{3}{*}{$79-706$} & 1 & 0.10 & 0.03 \\
\hline & 2 & 0.14 & 0.07 \\
\hline & 3 & 0.21 & 0.09 \\
\hline \multirow[t]{4}{*}{$79-587$} & 1 & 0.09 & 0.06 \\
\hline & 2 & 0.16 & 0.10 \\
\hline & 3 & 0.26 & 0.18 \\
\hline & !! & 0.33 & 0.22 \\
\hline \multirow[t]{3}{*}{$79-707$} & 1 & 0.03 & 0.04 \\
\hline & 2 & 0.07 & 0.05 \\
\hline & 3 & 0.12 & 0.10 \\
\hline
\end{tabular}

The data in Table V-2 show that for graphite coated rod 79-706 the peak power region strain is 0.07 percent $\Delta \mathrm{L} / \mathrm{L}$ greater than the rest of the fuel stack at the first two examinations and 0.12 percent $\Delta \mathrm{L} / \mathrm{L}$ greater at the third examination after the up-power maneuver. There is more uniform distribution of strain over the fuel stack of unpressurized, uncoated rod 79-587 at the first examination than $79-706$ as can be seen from the 0.03 percent $\Delta L / L$ difference between the high and low power regions although the peak region values were about the same. At subsequent examlnations, increasing $\perp$ greater axial strain is seen in the peak power region of 79-587 than in the rest of the fuel stack as seen by the differences of $0.06,0.08$, and 0.11 percent $\Delta \mathrm{L} / \mathrm{L}$.

The up-power maneuver caused an increase of 0.07 percent $\Delta \mathrm{L}_{\mathrm{d}} / \mathrm{L}(0.14$ to 0.21 percent) in the high power region of 79-706, but had little effect of the low power region where average strain increased only 0.02 percent $\Delta L / L(0.07$ to 0.09 percent). In rod 79-587 however, the up-power maneuver had almost the same effect over the entire fuel stack causing an increase of 0.10 percent $\Delta \mathrm{L} / \mathrm{L}$ ( 0.16 to 0.26 percent) in the high power region and an increase of 0.08 percent $\Delta \mathrm{L} / \mathrm{L}(0.10$ to 0.18 percent) in the rest of the fuel stack. This of course results in a greater overall strain in 79-587 as was seen in the overall length change data presented in Section V-A.

In contrast to both 79-706 and 79-587, there is an almost uniform distribution of strain over the fuel stack of pressurized, graphite coated rod 79-707 
at all examinations. As can be seen in Table V-2, the differences between high and low power are only 0.01 to 0.02 percent $\Delta \mathrm{L} / \mathrm{L}$ even after the up-power maneuver. This uniform axial strain distribution is desirable since, for a given overall axial strain, i.e., overall length increase, peak local strains are minimized.

\section{Peak Strains}

The peak axial strains are shown in Figure V-6 for rods $79-706,-587$, and -707 at each examination.

Comparing unpressurized, uncoated rod 79-587 to pre-pressurized and coated rod 79-707, significantly lower peak strains were measured for 79-707 at the three comparable examinations indicating that pre-pressurization and graphite coating has not only reduced total length increase as shown in Section V.A., but has also reduced peak axial strain. Graphite coated rod 79-706 had peak strains essentially identical to 79-587. This is in contrast to the effect seen in the overall length change data where, following initial irradiation, rod 79-706 had reduced overall length increases relative to uncoated, unpressurized rod 79-58\%.

\section{Discussion of Length Changes}

Length changes of Zircaloy clad, pelleted oxide fuel rods are believed to be the sum of three major components:

(1) Stress free, irradiation induced Zircaloy growth

(2) Elongation resulting from the diametral shrinkage and anisotropic mechanical properties of the tubing under the influence of system pressure

(3) Elongation induced by fuel-cladding interaction effects.

A model to describe stress free irradiation induced growth as a function of preferred orientation factor, temperature, fast flux, and fast fluence is incorporated into the CYGRO-4 model (Reference 2). Based on this model, length change due to Zircaloy growth is described by:

$$
\varepsilon_{z}=\varepsilon_{v z}+\varepsilon_{I z^{\prime}}+\varepsilon_{I z^{\prime \prime}}
$$




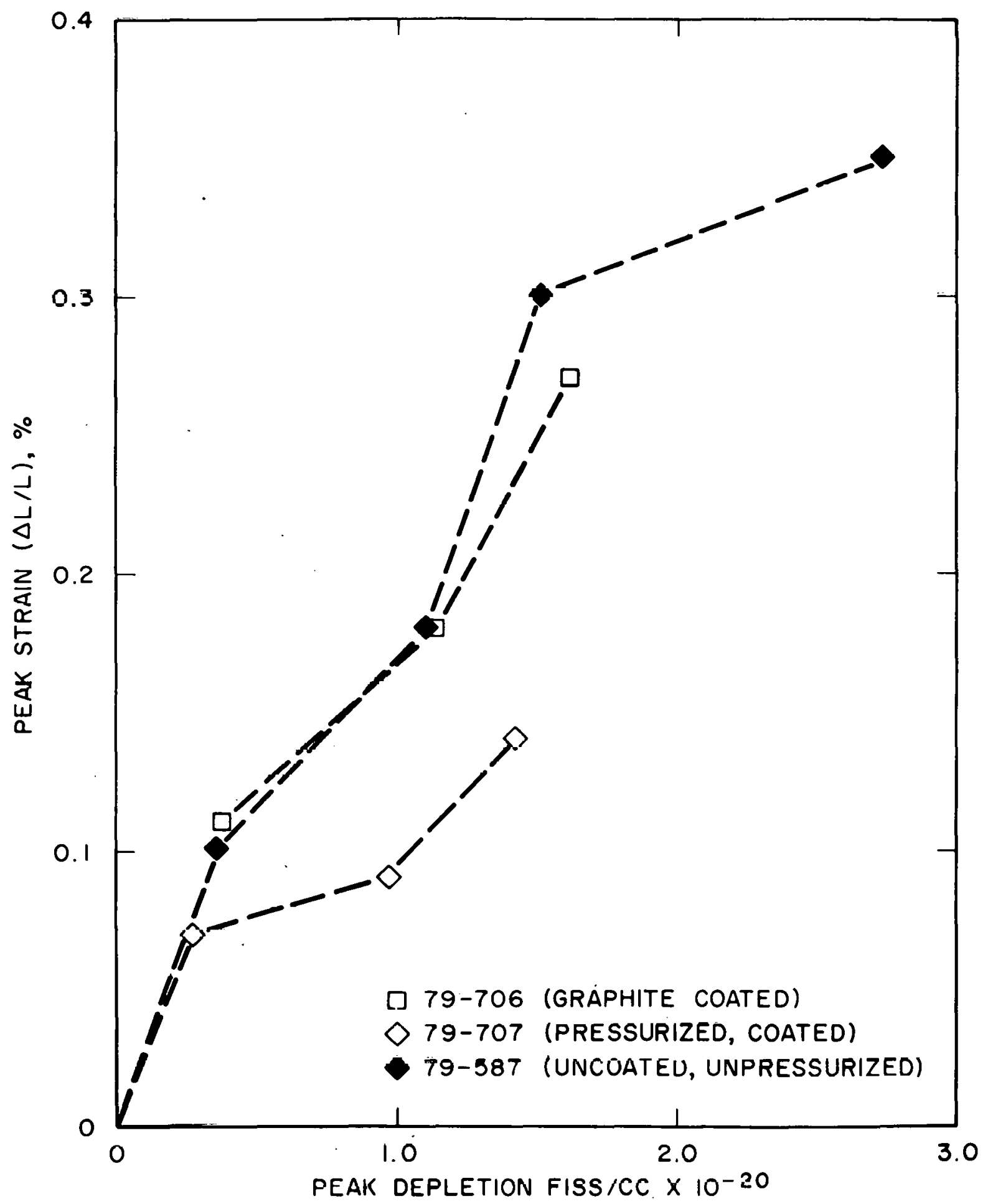

Figure V-6. Peak Local Strain from Fiducial Mark Measurements 
where:

$$
\begin{aligned}
& \varepsilon_{\mathrm{z}}=\text { growth strain in the length direction } \\
& \varepsilon_{\mathrm{vz}}=\text { strain associated with change in volume (assumed isotropic) } \\
& \varepsilon_{l_{\mathrm{z}}}{ }^{\prime}=\text { strain associated with nucleation of dislocations and transient } \\
& \text { dislocation loop growth } \\
& \text { For the five rods discussed in this report the appropriate equations are: } \\
& \begin{array}{l}
\varepsilon_{v z}=1.65 \times 10^{-4}\left(1-e^{-n v t / 10^{18}}\right) \\
\varepsilon_{I z^{\prime}}=5.25 \times 10^{-4}\left(1-e^{-n v t / 24 \times 10^{20}}\right) \\
\varepsilon_{I z^{\prime \prime}}=1.47 \times 10^{-24}(\text { nvt })
\end{array}
\end{aligned}
$$$$
\varepsilon_{l z "}=\text { strain associated with "quasi steady-state" dislocation loop growth. }
$$

where:

nvt $=$ fast fluence, neutrons $/ \mathrm{cm}^{2}(>1 \mathrm{Mev})$.

These equations were used to calculate the contribution of Zircaloy growth to length increase for all five rods at each examination. Results of calculations for 79-587, which had the highest fast fluence, are given in Table V-3 to illustrate the magnitude of the Zircaloy growth contribution.

Elongation resulting from diametral shrinkage and anisotropic mechanical

\begin{tabular}{|c|c|c|}
\hline Exam No. & $\begin{array}{l}\text { Rod Average Fast Fluence } \\
\left.\text { (neutrons } / \mathrm{cm}^{2} \times 10^{-20}\right) \\
\end{array}$ & $\begin{array}{l}\Delta \mathrm{L} / \mathrm{L} \\
(\%) \\
\end{array}$ \\
\hline 1 & 0.36 & 0.023 \\
\hline 2 & 1.16 & 0.037 \\
\hline 3 & 1.55 & $0.04 c$ \\
\hline 4 & 2.83 & 0.064 \\
\hline
\end{tabular}
properties of the cladding may be approximated under biaxial stress conditions appropriate to external pressure $\left(\sigma_{z}=\sigma_{\theta} / 2, \sigma_{r} \approx 0\right)$ according to the following formula which is based on Hill's anisotropic model, Reference 3.

$$
\% \frac{\Delta L}{L}=-\% \frac{\Delta D}{D} \times \frac{P(R-1)}{R(P+2)} \quad \text { assuming } R>1, P>1 \text {, and } \sigma_{z}=\frac{\sigma_{\Theta}}{2} \text {. }
$$

TABLE V-3. ZIRCALOY GROWTH CONTRIBUTION TO LENGTH CHANGES - ROD 79-587 
The " $R$ " value used in the calculation is obtained from tensile tests on unirradi-. ated tubing, and $P$ is taken to equal $R+I$ (Reference 4 ). The quantity $\Delta D$ is the measured diameter change. The effect of clad anisotropy given by the above equation applies only up to the time when fuel-clad interaction starts to occur and the assumed biaxial stress condition does not exist. Also, the resulting $\Delta L$ is somewhat overestimated in that the measured diameter change includes the effects of Zircaloy growth and fuel-clad interaction, in addition to system pressure.

For rod 79-707 the length change given by the above equation was less than 0.01 percent $\Delta \mathrm{L} / \mathrm{L}$ as compared to maximum length changes of 0.10 and 0.11 percent; for 79-706 the maximum was $U .02$ percent $\Delta \mathrm{L} / \mathrm{L}$ as compared to a maximum length change of 0.15 percent; for $79-584$ and $79=587$ the maximum was 0.03 peresnt $\Delta L / L$ ds compared to maximum length changes of 0.18 and 0.25 percent $\Delta L / L$. The equation does not apply to intentionally defected rod 79-583D as there was no net external prcssure on that rod.

Description of the mechanisms of clad elongation from fuel cladding interaction is complicated by the diverse conditions under which fuel and cladding can interact, but in all cases there must be some fuel-cladding contact to produce the cladding elongation. Zircaloy tubing with an OD/t of 20.1 , such as used on these rods, is non-freestanding under an external pressure of 2000 psi. Thus in the case of the unpressurized rods, the initial ovality present in the tubing is enhanced by the system pressure so that the cladding contacts the fucl ovcr some fraction of the circumference early during irradiation.

Both internal pre-pressurization and coating the inside cladding surface with graphite were expected to reduce the effect of fuel-cladding interaction on rod elongation. Pre-pressurization at room temperature to 500 psi results In an operating internal pressure of approximately $1000 \mathrm{psi}$, thus reducing the net external level on the cladding to 1000 psi. At this redured differential pressure, the OD/t of 20.1 tubing is expected to behave as freestanding, i.e., initial clddding ovality is not enhanced. Thus, fuel-cladding contact is delayed.

It should be noted that even in a rod with freestanding cladding; fuelcladding interaction can occur from the beginning of irradiation due to lucelized contact of the tuel with the cladding from such causes as fuel stack eccentricity (the pellets are stacked off-center from the cladding such that 
they contact the cladding at some point), non-perpendicularity of pellet ends (the pellets do not stack in a straight line, but become cocked in the rod touching the cladding at a pellet corner), pellet hourglassing (square cornered pellets assume an hourglass shape at power and can contact the cladding at the pellet ends resulting in the localized cladding deformation known as ridging), and pellet chips (small pellet fragments broken from the pellet corners which could become wedged in the fuel-cladding gap causing local contact).

Coating the inside cladding surface with graphite provides a lubricating film between the fuel and cladding during fuel-cladding contact which was expected to reduce the coefficient of friction between the fuel and cladding thus reducing axial cladding stresses developed due to differential thermal expansion between the fuel and the cladding.

To obtain an estimate of the effect of pressurization and graphite coating on reducing fuel-cladding interaction, the overall length change data given in Table V-I and Figure $\mathrm{V}-1$ are replotted in Figure V-7 with the calculated Zircaloy growth contribution to length increase subtracted. The remaining length increases represent an upper limit of fuel.cladding interaction since some effect of anisotropy (dịameter shrinkage under system pressure resulting in a length increase) may be present.

When the calculated.Zircaloy growth contribution is removed, the length changes of the five rods show the same relationships as seen in the as-measured data. This is as expected since the calculated Zircaloy growth contributions to length increase were almost identical for the five rods.

The greatest amount of fuel-cladding interaction is shown by the uncoated, unpressurized rod 79-587. At all but the first examination, greater length increases due to interaction are seen han for the other four rods. The smallest amount of fuel-cladding interaction is seen in intentionally defected rod 79-583D. Since there is no pressure differential across the cladding, fuelcladding contact would not be expected early in life. Thus the presence of some length increase attributable to fuel-cladding interaction in this rod indicates that the local gap reduction mechanisms such as fuel stack eccentricity, non-perpendicularity of pellet ends, etc. listed above may be responsible. The only exception is pellet hourglassing which would be reduced in 79-583D due to.tapering of the pellet ends. 


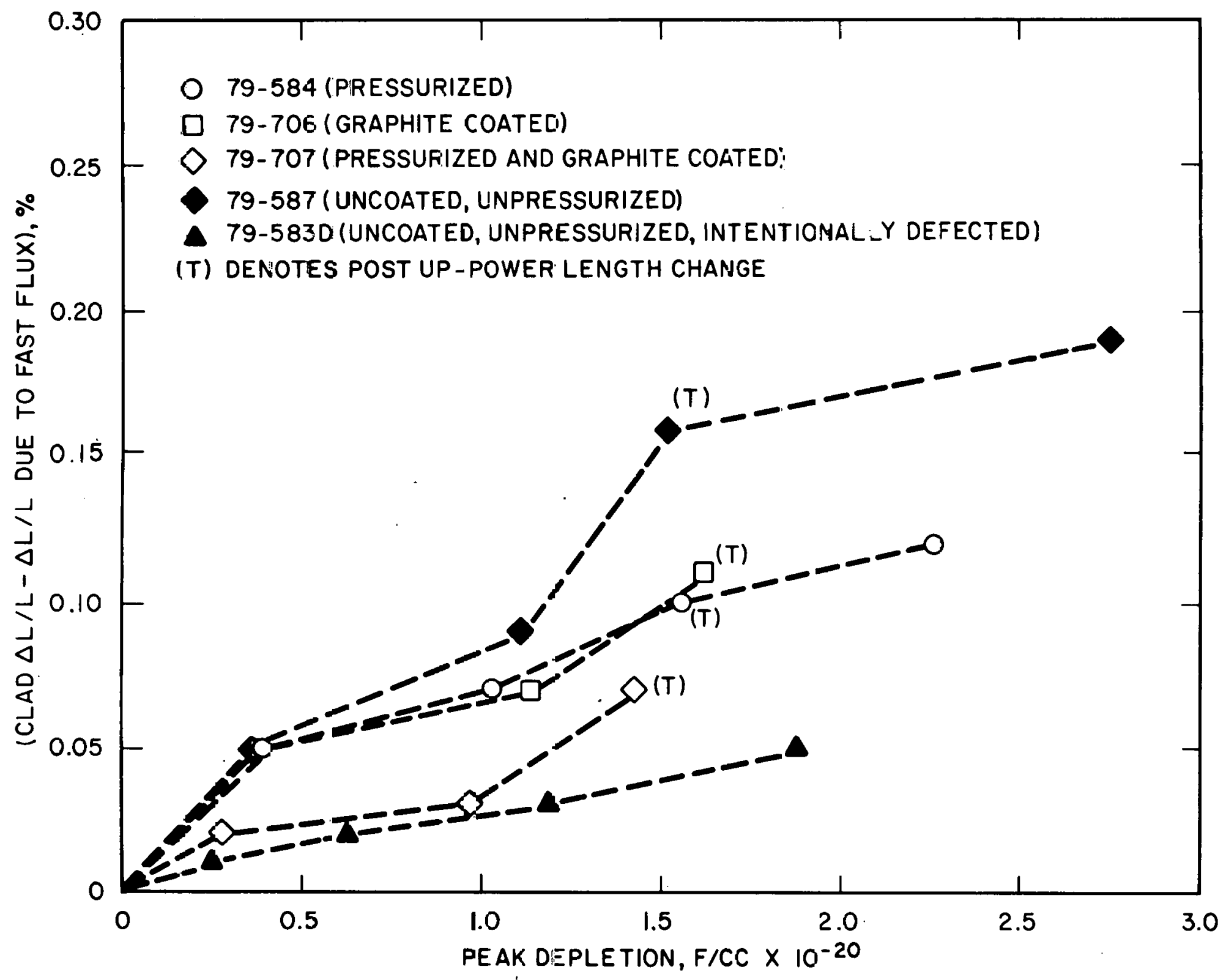

Figur $=J-7$. OveraiI Length Changes Less Zircaloy Grow,h 
The fuel-cladding interaction in pressurized, graphite coated rod 79-707 is almost identical to that of 79-583D until the up-power maneuver. This indicates that the pressurization has delayed fuel-cladding contact. Rod 79-707 contained untapered pellets in the 7.3-mil gap region which could have contributed to fuel-cladding interaction by. pellet hourglassing as was seen in pressurized rod 79-584 (see below), but there was no evidence of cladding ridging until after the up-power maneuver. This difference from 79-584 may be due to the presence of a graphite coating on 79-707. After the up-power maneuver fuel-cladding contact was.also seen in the high power 4.l-mil gap region (tapered pellets) as evidenced by diameter increases (see Section V.D). The effect of this fuel-cladding contact is seen in the increased fuel-claddiris interaction from that of $79-583 \mathrm{D}$ at the post up-power (third) examination.

An intermediate level of fuel-cladding interaction is seen for both pressurized rod 79-584 and graphite coated rod 79-706. Although it was expected that fuel-cladding contact would be reduced in 79-584 due to the reduction in net external pressure on the cladding, the presence of untapered pellets was expected to result in some fuel-cladding contact due to hourglassing. Cladding ridging was observed from the first examination (see Section V.D) indicating that contact has occurred at the pellet ends resulting in the cladding elongation seen in Figure V-7.

Due to the 2000 psi external pressure, the cladding of unpressurized, graphite coated rod 79-706 was expected to contact the fuel over some portion of the circumference from the start of irradiation as described above. However, the presence of a graphite coating on the inside cladding surface appears to have reduced friction between fuel and cladding when in contact resulting in lower length increases than uncoated, unpressurized rod 79-58\%, particularly during the up-power maneuver.

D. Diameter Measurement

1. Measurement Technique

Rod diameter measurements were obtained at Chalk River with the Rod Fnvelope Gage (REG). This instrument is shown in Figure V-2 with the diameter measuring head installed and a rod in place. 
Diameter measurements are obtained with a caliper-type measurement head which may be translated axially along the length of the rod by means of a precision lead screw. As shown schematically in Figure V-8, the diameter head contains two diametrically opposed cylindrical probes of 0.125 inch diameter which contact the surface of the fuel rod. The sensing portion of the device is a linear variable differential transformer (LVDT) which delivers an output voltage proportional to the opening between the probes. The caliper jaws are spring loaded so that they follow the fuel rod diameter at all times. Thus, the output of the LVDT is proportional to the rod diameter. This output may be obtained either in analog form as a continuous trace on an X-Y plotter or as a digital readout of: rod diameter at any given axial position. Both types of measurement output were obtained during the dimensional examination of the fíel 1 uls

The continuous axial traces are of particular use in detecting such pellet end effects as cladding ridging or grooving, while the digital readouts provide direct quantitative data for calculation of chanees in diameter from pre-irradiation. Both ridging and grooving can result from mechanical interaction between the cladding and the ends of the fuel pellets while at power. If the pellets are right circular cylinders, then circumferential ridges occur giving the rod a bamboo-type appearance. Ridging occurs because a right circular cylinder pellet assumes an "hourglass" shape on going to power. On the other hand, if the pellet ends are tapered and if the tapers are sufficiently deep, clrcumierential grooves may appear. Tapering locally decreases pellet diameters, and grooves appear as the clad shrinks onto the fuel as a result of creep.

'l'he axial location of the diameter hean nn the rod is detormincd by electronically counting revolutions of the lead screw. The digital readout gives the diameter to four decimal places $(0.0001$ inch). Prior to rod measurements, the REG diameter head is calibrated using a standard of the same nominal. diameter as the fuel rod being. measured. The maximum allowablo deviationo from the standard are $\pm 0.2 \mathrm{mil}$. However, experience with repeat measurements on irradiated fuel rods indicates that the accuracy of the diameter measurements is $\pm 0.5 \mathrm{mil}$ ( $2 \sigma$ value). 
SCHEMATIC REPRESENTATION OF REG DIAMETER MEASUREMENT

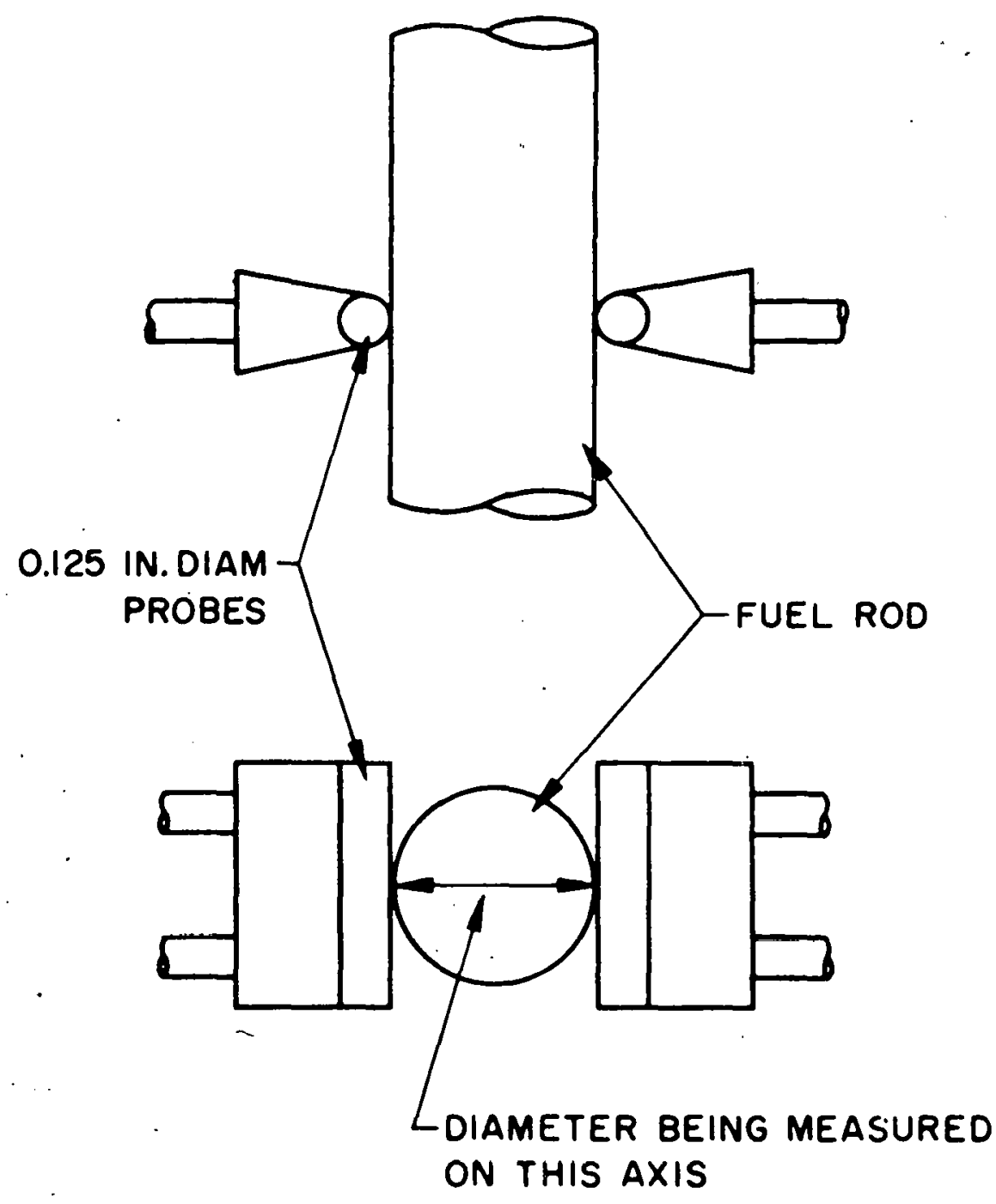

Figure V-8. Schematic Representation of REG Diameter Measurement 
For rods 79-583D, 584, and 587, diameters were measured along two axes oriented at $90^{\circ}$, and for rods $79-706$ and 707 diameters were measured along four axes oriented at $45^{\circ}$. The measurement axes were referenced to the rod identification numbers to ensure that pre- and post-irradiation measurements were made with the rod in the same orientation to within $\pm 5^{\circ}$. Continuous traces and digital readings at pre-selected stations typically at 1.0-inch intervals along the length of the rod were obtained. Changes in diameter from preirradiation were calculated by comparing the digital readouts to corresponding pre-irradiation values.

\section{Results}

Results of the cladding diameter measurements for rods 79-533D, 587, 707, 584, and 706 are presented in Figures V-9 through V̈-13. Cladding diameter changes in Zircaloy clad fuel rods are made up of five components:

(1) Diameter shrinkage under external coolant pressure, which includes two components: (a) initial deformation of non-free standing cladding by the coolant pressure, and (b) fast neutron flux enhanced creep of the cladding.

(2) Diameter shrinkage due to axidl elongation caused by fuel-clad interaction.

(3) Diameter increase resulting from creep due to differential thermal expansion of the fuel and clad while at power.

(4) Diameter increase due to fuel peliet fission induced swelling.

(5) Slress-free, istadialivilinduced airealoy growth; which io a function of the fast neutron fluence: depending on the cladding texture, Zircaloy growth may result in either clad diameter increase or decrease.

At the depletions of the rods discussed in this report, fission product swelling of the fuel is not large enough to cause by itself the observable diameter changes through gap closure and outward cladding deformation. For instance, application of one third of 0.7 percent $\Delta V / V$ per $10^{2 \mathrm{U}} \mathrm{f} / \mathrm{cc}$ fuel swelling rate, reported in Reference 5 to fuel pellet diameter increases at a depletion of $2 \times 10^{20} \mathrm{f} / \mathrm{cc}$, typical of the peak depletions of the rods in this report, 
yields an increase of $2.6 \mathrm{mils}$ in pellet diameter. Thus, even in the small 4-mil gap regions at peak depletion, fuel swelling alone does not close the fuel-cladding gap, but does contribute to closing the gap at power particularly later in life.

Using the technique discussed in Reference 4, the length changes calculated in Section V.C from the Zircaloy growth model may be related to diametex changes by the equation:

$$
\frac{\% \Delta D / D}{\% \Delta L / L}=\frac{1-3 f_{C}}{1-3 f_{z}}
$$

where $f_{z}$ and $f_{c}$. are the texture factors for the axial and circumferential directions respectively. For $f_{z}$, a value of 0.06 has been determined for the tubing used in this test program. In addition it has been found empirically that:

$$
R \simeq \frac{f_{r}}{f_{c}}
$$

where $f_{r}$ is the radial texture factor and $R$ is the ratio of circumferential to radial strain determined.from axial tensile tests of the cladding (Reference 3). For the tubing used in this test program, $R$.was found to be 1.6. Since $f_{x}+f_{c}+f_{z}=1$, it is possible to calculate $f_{c}$ knowing $f_{z}$ and $R$. A value of 0.36 is determined and then:

$$
\frac{\% \Delta \mathrm{D} / \mathrm{D}}{\% \Delta \mathrm{L} / \mathrm{L}}=\frac{1-3(0.36)}{1-3(0.06)}=-0.098
$$

Applying this factor to the value of 0.075 percent $\Delta \mathrm{L} / \mathrm{L}$ calculated for the peak fast fluence of $3.5 \times 10^{20} \mathrm{n} / \mathrm{cm}^{2}$ seen in this test yields a maximum of -0.007 percent $\triangle D / D$, which is a diameter decrease of 0.04 mil. Thus it is seen that the Zircaloy growth contribution to diameter change is negligible and may be ignored in the discussion of diameter. changes below.

\section{a) Intentionally Defected Rod 79-583D}

Figure V-9.is a plot of the diameter changes from pre-irradiation measured on rod 79-583D at the first three examinations. The data for each examination are the numerical average of diameter changes calculated every 0.5 inch along the length rod on two axes $90^{\circ}$ apart. Internal rod features and the relative power shape over the fuel stack are included. 


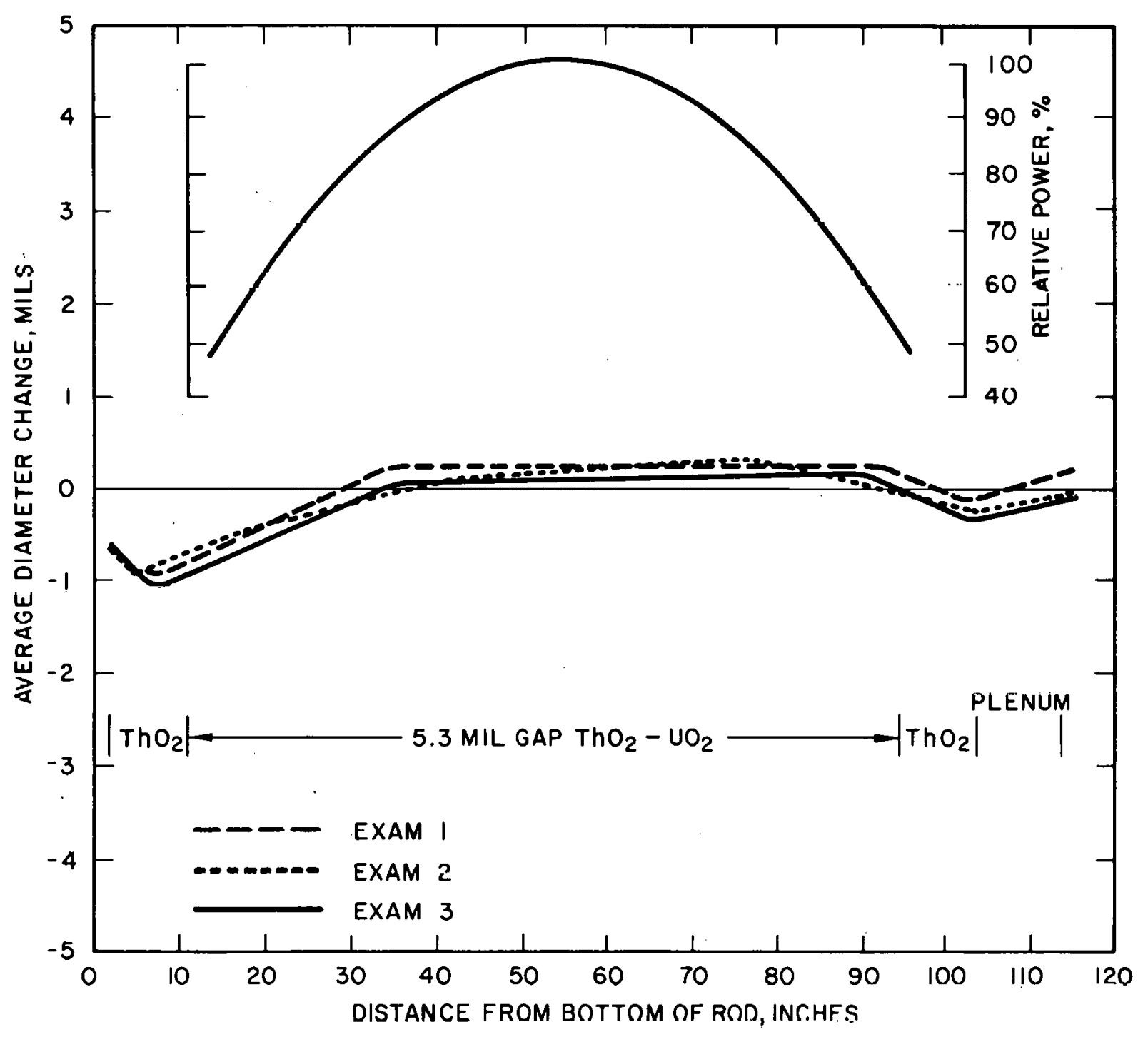

Figure V-9. Rod 79-583D, Intentionally Defected 
The pattern of diameter changes on $79-583 \mathrm{D}$ is the same at all three examinations with no significant changes in diameter over most of the fuel stack and decreases of up to $1.0 \mathrm{mil}$ at the bottom of the fuel and lower thoria pellet stack region. The axial diameter traces at all three examinations show no signs of fuel-cladding contact, i.e., clad grooving, which could result from contact with the tapered fuel pellets present in 79-583D.

Since 79-583D is intentionally defected, there is no net external pressure on the cladding from the coolant which could cause diameter shrinkage. The decreases seen at the bottom of the rod are inconsistent with the behavior of the rest of the rod. These changes may not be real, and could have resulted from errors in the pre-irradiation measurements. The absence of diameter increases indicates that the 5.3-mil gap in 79-583D is sufficient to accommodate differential thermal expansion and fuel swelling without closing.

b) Uncoated, Unpressurized Rod 79-587

Figure V-10 is a plot of diameter changes seen on rod 79-587 at all four examinations versus location on the rod. The curve for each examination was constructed from diameter changes calculated every 0.5 inch along the length of the rod on two axes $90^{\circ}$ apart.

The most striking feature is the abrupt change in behavior seen at the transition between the 3.9-mil and 7.8-mil gap regions of the fuel stack. Diameter increases resulting from differential fuel-cladding thermal expansion are seen in the highest powered portion of the 3.9-mil gap region at all but the second examination with the greatest increases at the third examination following the up-power maneuver when the highest fuel temperatures were seen. At lower power axial locations, diameter decreases are seen where a sufficient fuel-cladding gap 'remained during irradiation for the cladding to shrink under system pressure. The reduced shrinkage at the lowest power end of the 3.9-mil gap region is considered to be due to lower fast neutron flux enhanced creep at the end of the fuel stack.

- In the 7.8-mil gap region, diametral shrinkage is seen throughout with the greatest shrinkage at the highest rod power indicating a dependence of the shrinkage on fast neutron flux. Shrinkage continues to increase from examination to examination until the up-power maneuver. The fourth examination results show that little further shrinkage has occurred except at the highest power location. 


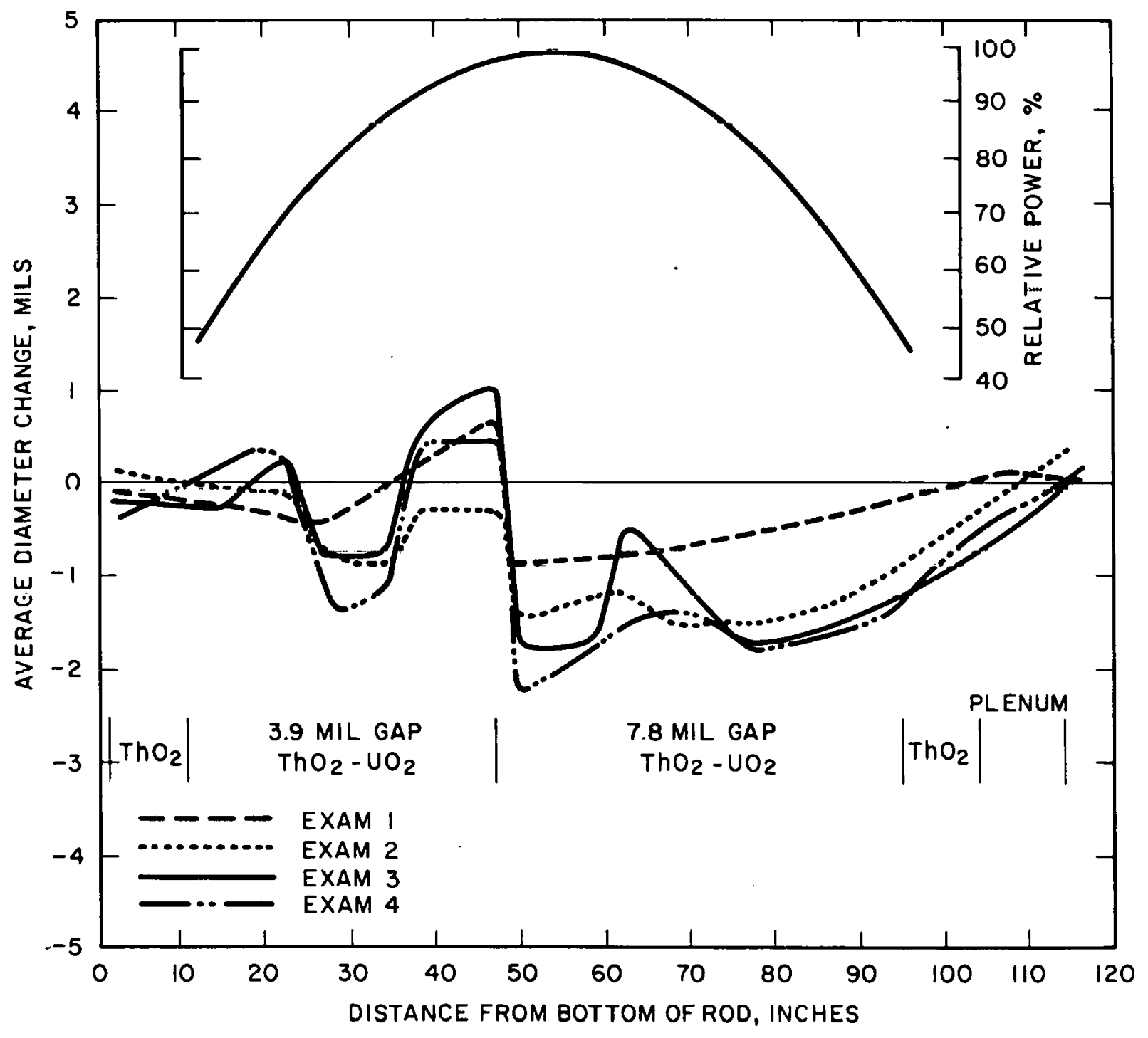

Figure V-10. Rod 79-587, Unpressurized and Uncoated 
The increase in diameter from the second to the third examination seen between 60 and 70 inches may have resulted from local fuel-cladding contact during the up-power maneuver due to the presence of fuel pellet chips in the fuel-cladding gap. Pre-irradiation X-radiography of 79-587 detected 8 loose chips in the fuel-cladding gap and 3 in-place chips (broken fragments at pellet corners) in the region from 62 to 68 inches from the bottom of the rod.

\section{c) Pressurized/Graphite Coated Rod 79-707}

Figure V-Il is a plot of the diameter changes seen on rod 79-707 at all three examinations versus location on the rod. The curve at each examination was constructed from diametcr changes calculated every 1.0 inch along the length of the rod on four axes $45^{\circ}$ apart. Rod 79-707 contains a 4.1-mil gap and a 7.8-mil gap region in the same arrangement as the 3.9- and 7.8-mil gap regions of rod 79-587.

In the 4.1-mil gap region little change in diameter is seen prior to the up-power maneuver. This is similar to pressurized rod 79-584 where negligible diameter changes were measured in the small gap region. After the up-power maneuver, diameter increases up to $0.8 \mathrm{mil}$ were seen.in the highest powered part of the 4.l-mil gap region indicating a slight effect of fuelcladding differential expansion. It may be that the approximately 1000 psi internal pressure seen at power by the fuel pellets in 79-707 has enhanced fuel densification over that in an unpressurized rod such as 79-587. Because of the resulting decrease in pellet diameter, differential thermal expansion is no longer large enough to cause significant diameter increases in the small gap region of $79-707$.

Negligible dianleter changes are seen throughout the 7.8-mil gap region both before and after the up-power maneuver. Internal pressurization would be expected to reduce creep shrinkage, from that seen in the 7.8-mil gap region of unpressurized rod $79-587$ by reducing the net load on the cladding from the coolant pressure. Also the graphite coating may have reduced the effect of fuel cladding interaction which, as discussed below, is thought to be in part responsible for the diameter decreases in the 7.7-mil gap region of $79-584$ by reducing the friction between fuel and cladding. 


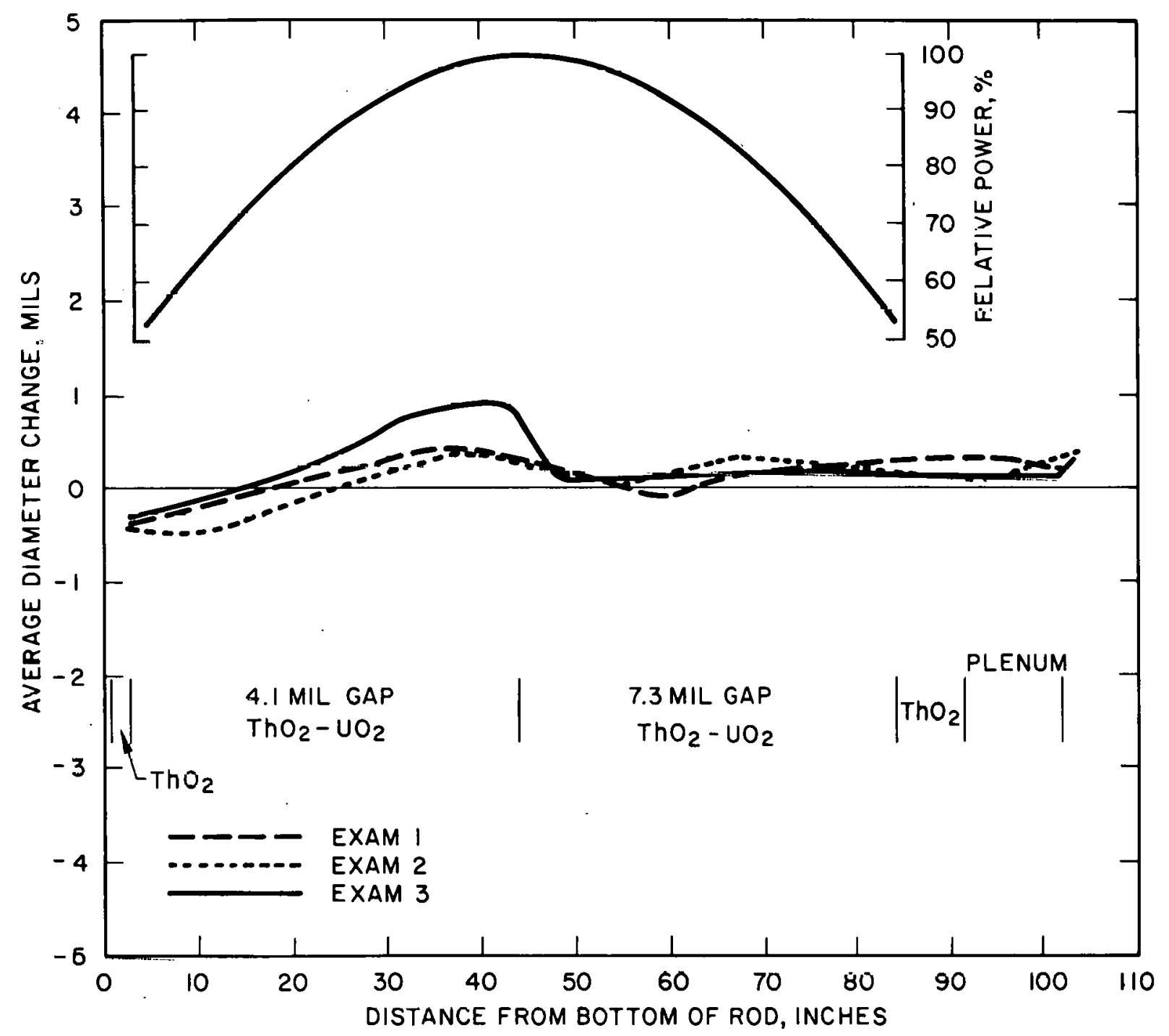

Figure V-11. Rod 79-707, Pressurized and Graphite Coated 


\section{d) Pressurized Rod 79-584}

Figure V-12 is a plot of the diameter changes from pre-irradiation seen on rod 79-584 at all four examinations versus location on the rod. The curve for each examination was corishructed from diameter changes calculated every 0.5 inch along the length of the rod on two axes $90^{\circ}$ apart.

Rod 79-584 is similar to 79-587 in that its fuel stack is divided into two regions of different gap size, but in the case of 79-584 the large gap region is on the bottom, where with 79-587 it is on the top. A consistent pattern of behavior is seen at all four examinations of 79-584 with diameter decreases in the 7.7 -mi.l. gap region and little or no change in diameter in the 3.8-mil gap region. This behavior is in contrast to $79-587$ in that there is no sharp transition between the two regions, and in the 7.7-mil gap region the largest shrinkage does not occur at the highest power. No diameter increases are seen in the high power 3.8-mil gap region, although increases due to differential thermal expansion might have been expected on the basis of the increases seen. in 79-587 which operated at the same power as 79-584.

As discussed above for 79-707, it may be that the approximately 1000 psi internal pressure seen at power by the fuel pellets in $79-584$ has enlianced fuel densification, resulting in a decrease in pellet diameter. Thus differential thermal expansion is no longer large enough to cause diameter increases in the small gap region of 79-584. The diameter shrinkage seen in the 7.7-mil gap.section of 79-584 may not be due entirely to creep shrinkage, which would be expected to be 'reduced due to the internal pressurization of 79-584; but may also result from fuel-cladding interaction in which local cladding elongation takes place, resulting in diameter decrease. The diameter traces of 79-584 showed cladding ridging at all examinations throughout the 7.7-mil gap region and in the high powered (> 80\%) 3.8-mil gap region, indicating that fuel-cladding contact had taken place at pellet ends. The ridge heights averaged $0.9 \mathrm{mil}$ in the 7.7 -mil gap region before the up-power maneuver and 1.6 mils after the up-power maneuver. In the high power, 3.8 mil gap region they averaged $0.6 \mathrm{mil}$ before and $0.9 \mathrm{mil}$ after the up-power maneuver. 


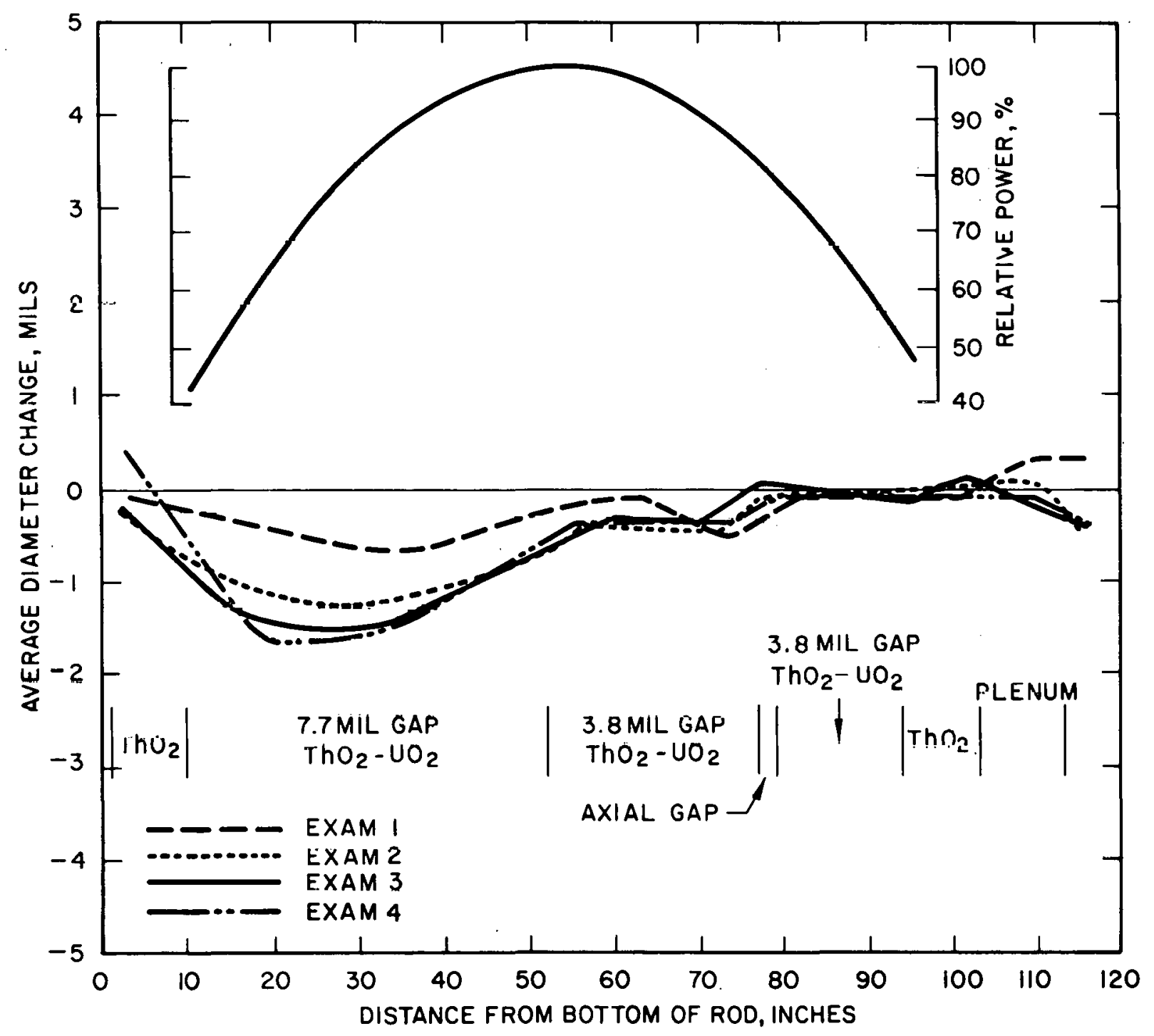

Figure V-12. Rod 79-584, Pressurized 
e) Graphite Coated Rod 79-706

Figure V-13 is a plot of the diameter changes seen on rod 79-706. at all three examinations versus location of the rod. The curve at each examination was constructed from diameter changes calculated every 1.0 inch along the length of the rod on four axes $45^{\circ}$ apart. At the first examination, data was not obtained above 70 inches due to malfunction of the REG.

Unlike rods 79-587, 79-707, and 79-584 which have both 4- and 8-mil gap regions in the fuel stack, rod 79-706 has a 4.2-mil gap at the peak power region with 4.8-mil gap in regions above and below the peak. Thus the overall behavior of 79-706 can be compared to the small gap regions of 79-587, $\div 707$, and -584 . Like 79-587, rod 706 showed diameter increases in the high power region attributed to differential thermal expansion of fuel and cladding with the greatest increases seen following the up-power maneuver. Diameter decreases are seen at lower power where the combination of reduced temperatures and a slightly larger cold gap result in a fuel-cladding gap remaining at power into which the cladding shrinks under system pressure. This behavior is unlike pressurized rod 79-584 and pressurized and coated rod 79-707 where negligible diameter change was measured in the small gap region, indicating that, as discussed above, pressurization may contribute to reduced diameter increases in the high power, small gap region by enhancing fuel densification.

The continuous diameter traces obtained from 79-706 gave further evidence of fuel-cladding contact in the 4.2-mil gap region in that cladding grooves were seen with an average depth of 0.3 mil at the first examination and - $0.6 \mathrm{mil}$ at the second and third examinations. Development of grooves requires that fuel and cladding be in contact over the length of the pellel since they do not form until the cladding is supported by the pellet at all but the tapered pellet ends. Negligible grooving was seen in the 4.8-mil gap regions, indicating no contact. 


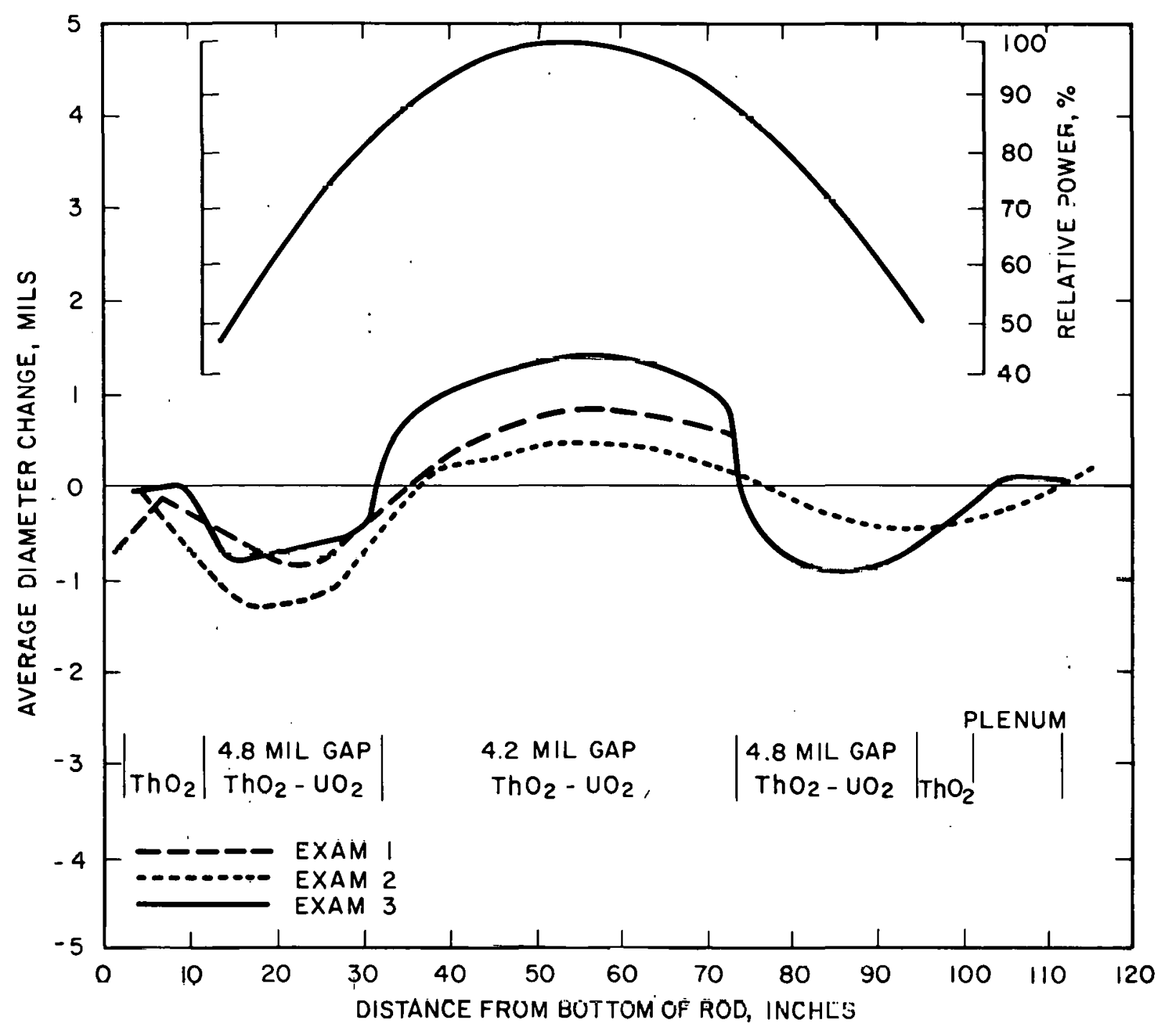

Figure V-13. Rod 79-706, Graphite Coated. 
The irradiation tests described herein were carried out under the direction of the Power Reactor Fuel Irradiation group at Bettis. The authors wish to recognize the engineers, who, in addition to the authors, were members of this group: Mr. J. T. Engel, Mr. L. R. Lynam, Mr. D. A. Mertz, Mr. C. D. Sphar, and Dr. L. A. Waldman. Numerous informal technical discussions with these individuals contributed to the development of the irradiation test program discussed in this document.

The authors wish to acknowledge the following persons whose efforts contributed to the successful fabrication, irradiation, examination, and reporting of the results of the tests of graphite coated and pre-pressurized rods reported herein.

Mr. D. A. Mertz for overall cognizance of the manufacture of the graphite coated and the graphite coated and pressurized rods.

Mr. F. O. Bingman for assistance in the manufacture of the graphite coated and the graphite coated and pressurized rods.

Dr. W. J. Danley. Jr. and Dr. S. S. Strunk for development and application of the welding technique for internally pressurizing the fuel rods.

Mr. J. M. Ranish for development and application of the technique for graphite coating the cladding inside surfaces.

Mr. L. E. Sandy for nuclear and thermal/hydraulic calculations, operational follow of the irradiation tests, and liaison with Atomic Energy of Canada, Ltd.

Mr. C. E. Ferris and Mr. V. O. McBride of the AECL Chalk River Nuclear Laboratory under whose guidance the test handling, irradiation, and examinations were condurtien.

Mr. G. F. Giovengo for assistance in performing fast neutron filux growth calculations.

Mr. E. M. Filowat for data reduction and calculational assistance.

Ms. S. T. Bently for typing the document.

Mr. T. H. Alff, Mr. J. J. Brennan, Dr. E. Duncombe, Mr. I. Goldberg, and Dr. H. R. Warner for their careful technical review and helpful comments during the plepualallull of this document.

Mr. J. T. Fong, Manager - Materials Technology, for his assistance and guidance. 
VII. REFERENCES

1. AECL-4589, "Effect of Surface Films on the Initiation of Stress Corrosion Cracking of Zr-2," Presented at Annual CIC Meeting, Montreal, Canada, June 4, 1973.

2. J. B. Newman, J. F. Giovengo, and L. P. Comden, "The CYGRO-4 Fuel Rod Analysis Computer Program," WAPD-TM-1300, July 1977.

3. C. R. Woods, Ed., "Properties of Zircaloy-4 Tubing," WAPD-TM-585, December 1966 .

4. R. C. Daniel, "In-Pile Dimensional Changes of Zircaloy-4 Tubing Having Low Hoop Stresses (LWBR Development Program)," Nuclear Technology,

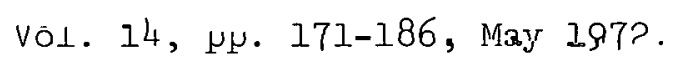

5. R. C. Danicl, M. L. Rleiherg, H. D. Meieran, and W. Yeniscavich, "Iffccts of High Burnup on Zircaloy Cläd, Bulk $\mathrm{UO}_{2}$, Plate Fuel Element Samples," WAPD-263, September 1.962. 